Andrews University

Digital Commons @ Andrews University

Master's Theses

Graduate Research

1972

\title{
The Effect of Kindergarten Attendance on Later School Experiences
}

Janice Louise Trevan

Andrews University

Follow this and additional works at: https://digitalcommons.andrews.edu/theses

Part of the Early Childhood Education Commons

\section{Recommended Citation}

Trevan, Janice Louise, "The Effect of Kindergarten Attendance on Later School Experiences" (1972). Master's Theses. 148.

https://dx.doi.org/10.32597/theses/148

https://digitalcommons.andrews.edu/theses/148

This Thesis is brought to you for free and open access by the Graduate Research at Digital Commons @ Andrews University. It has been accepted for inclusion in Master's Theses by an authorized administrator of Digital Commons@Andrews University. For more information, please contact repository@andrews.edu. 


\title{
ABSTRACT OF GRADUATE STUDENT RESEARCH
}

Thesis

\author{
Andrews University
}

Department of Education

Tit1e: THE EFFECT OF KINDERGARTEN ATTENDANCE ON LATER SCHOOL EXPERIENCES Name of researcher: Janice Louise Trevan

Name of faculty adviser: Dr. Millie Youngberg, Ed.D.

Date completed: May 1972

\section{Problem}

It is estimated that about one-half of our nation's six-year-olds receive their initial formal education when entering first grade. Many authorities in the field of education feel that an early childhood educational experience may be a causative factor in a child's later academic and social adjustment in school.

The purpose of this study was to: (1) compare the academic achievement and social adjustment of first-grade children who have had kindergarten experience and first grade children who have not had kindergarten experience; and (2) compare the academic achievement and social adjustment of fourth grade children who have had kindergarten experience and fourth grade children who have not had kindergarten experience to find if there is a significant difference which has an effect as late as fourth grade. 


\section{Method}

One-hundred-seventy-two children from public schools were used for this study: ninety-three from the Osceola School and seventy-nine from the Moran School. Each child was given the SRA Primary Mental Abilities Test and the California Test of Personality. Each first grade child was given the Metropolitan Readiness Test. All of the children in both first and fourth grade participated in the composition of a sociogram for their individual rooms. Each student in both the first grade and the fourth grade was given a character trait rating and also a rating for achievement academically in the areas of reading, writing and mathematics. These ratings were teacher opinion ratings.

\section{Results}

It was found in this study that there is a significant difference in the readiness of children entering first grade, the difference being in the favor of the child who has had kindergarten experience. There was varied evidence for the comparison of mental abilities of children entering first grade. However, all comparisons of achievement for both first and fourth grades were of no significance.

All comparison of social adjustment for children having had kindergarten experience and children not having had kindergarten experience was of no significance, with the exception of a few categories on the sociogram. This was true for the first grade children tested as well as the fourth grade children who were tested.

\section{Conclusions}

This research indicated that the extent to which school beginners had developed in the skills and abilities that contribute to readiness for first grade instruction was greater for those children who had had kindergarten 


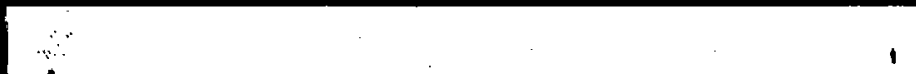

experiences. However, the advantage of those having kindergarten experience was not maintained through the fourth grade. 
Andrews liniversity

School of Graduate Studies

THE EFFECT OF KINDERGARTEN ATTENDANCE

ON LATER SCHOOL EXPERIENCES

\author{
A Thesis \\ Presented in Partial Fulfillment \\ of the Requirements for the Degree \\ Master of Arts
}

by

Janice Louise Trevan.

May 1972.

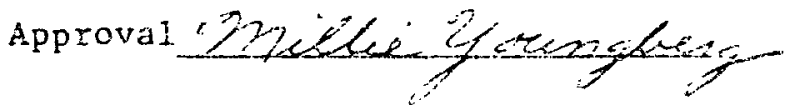




\title{
Andrews University
}

School of Graduate Studies

\section{THE EFFECT OF KINDERGARTEN ATTENDANCE}

ON LATER SCHOOL EXPERIENCES

\author{
An Abstract \\ Presented in Partial Fulfillment \\ of the Requirements for the Degree \\ Master of Arts
}

by

Janice Louise Trevan

May 1972

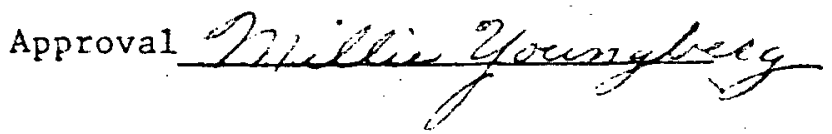




\section{ABSTRACT}

It is estimated that about one-half of our nation's sixyear-olds receive their initial formal education when entering first grade. Many authorities in the field of education feel that an early childhood educational experience may be a causative factor in a child's later academic and social adjustment in school.

The purpose of this study was to: (1) compare the academic achievement and social adjustment of first grade children who have had kindergarten experience and first grade children who have not had kindergarten experience; and (2) compare the academic achievement and social adjustment of fourth grade children who have had kindergarten experience and fourth grade children who have not had kindergarten experience to find if there is a significant difference which has an effect as late as fourth grade.

One-hundred-seventy-two children from public schools were used for this study: ninety-three from the Osceola School and seventy-nine from the Moran School. Each child was given the SRA Primary Mental Abilities Test and the California Test of Personality. Each first grade child was given the Metropolitan Readiness Test. All of the children in both first and fourth grade participated in the composition of a sociogram for their individual rooms. Each student in both the first grade and the fourth grade was given a character trait rating and also a rating 
for achievement academically in the areas of reading, writing and mathematics. These ratings were teacher opinion ratings.

It was found in this study that there is a significant

difference in the readiness of children entering first grade, the difference being in the favor of the child who has had kindergarten experience. There was varied evidence for the comparison of mental abilities of children entering first grade. However, all comparisons of achievement for both first and fourth grades were of no significance.

Al1 comparison of social adjustment for children having had kindergarten experience and children not having had kindergarten experience was of no significance, with the exception of a few categories on the sociogram. This was true for the first grade children tested as well as the fourth grade children who were tested. 


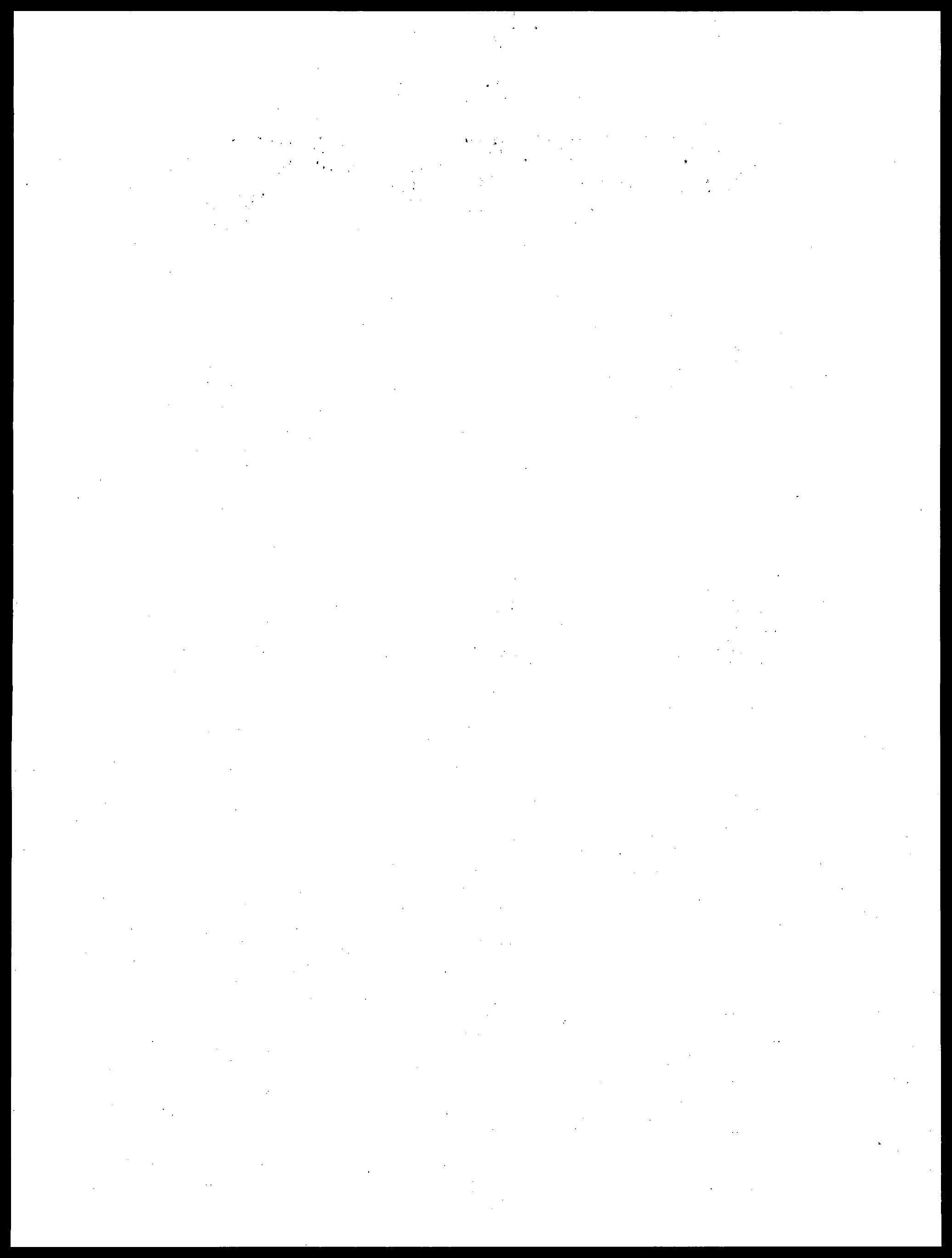


PREFACE

This research was carried out to satisfy the desire of the author to make an additional contribution to educational research evidence relating to the effect of kindergarten experience upon later school adjustment and achievement.

As a public school teacher who has had thirteen years of experience teaching children entering public school for the first time, my interest is more than merely a casual one.

The author has attempted to do a comparative study of children having had kindergarten experience and children not having had kindergarten experience as related to their subsequent social adjustment and also their achievement academically in later school experiences.

The Penn-Harris-Madison School Corporation has ten elementary schools, four of which house students in grades four, five and six, five of which house students in grades one, two and three, and one of which houses first grade through sixth grade students. The children in the four first grades at the Osceola School and the children in the three fourth grades housed in the Moran School were chosen as the sample for this study.

I am greatly indebted to my principal, Miss Fern Hunsberger, for her generous cooperation and constant support. The four teachers of first grade students, Mrs. Marilyn McCarthy, Mrs. Carole McPhail, Mrs. Bonieta Myers, and Mrs. Thelma Myers, havë my deepest gratitude 
for their great kindness and cooperation in allowing me to use the children in their classrooms for my research. Even more, I am grateful for their confidence in me and their moral support when I felt in need of encouragement.

I am most grateful to the three fourth gxade teachers, Mr. Cyril Cole, Mrs. Sarah Evans and Mrs. Dorothy Miller, who gave their wholehearted cooperation to the research program. I feel that these teachers are the greatest to be found anywhere.

To the committee who has helped in guiding my research project, I am greatly indebted. Dr. Wilfred Futcher so graciously and unselfishly spent many hours with me on the statistics portion of my research. Dr. Ruth Murdoch has been, and will continue to be, a great inspiration to those who are privileged to know her. To be able to draw from her great storehouse of knowledge, dispensed with loving sensitivity and concern, was indeed a privilege. The contributions made by $\mathrm{Dr}$. Millie Urbish Youngberg are far greater than she will ever know. From her I have found great insight into the possibilities of humanism as displayed in interpersonal relationships, and also the inspiration to "become" or aspire.

To all my friends who have encouraged me with their interest in my research project and their faith in my ability to achieve my goals, I am indeed indebted.

I am most grateful to my family for their great encouragement, love and compassion as they played a supporting role throughout my research project. I have experienced great encouragement and compassion from my parents and the parents of my husband. My 
sister-in-law, Kaye, and her family have given me great physical support in my endeavor. Last, but by no means least, I wish to mention the continuous physical, emotional and moral support of my husband, Bill. Without this "helpmeet" I could never have accomplished the task I had set before me. I am deeply grateful for his loving assistance in all of the endeavors of his wife.

All the assistance received from the various sources here mentioned have been valuable and I take this opportunity to acknowledge their aid. My desire is that the product of my research endeavor may in turn be of service to others. 
TABLE OF CONTENTS

Page

PREFACE ......................... . . . 11

LIST OF TABLES ..................... . . vii

Chapter

I. INTRODUCTION .................. 1

Statement of the Problem . . . . . . . . 1

Rationale.................... 2

Purpose of the Study ............. 3

Definition of Terms............. 3

Statement of the Hypotheses.......... 3

Organization ............... 5

II. REVIEW OF LITERATURE . . . . . . . . . . . 7

III. RESEARCH DESIGN . . . . . . . . . . . 19

Population and Sample............ . . 19

The Method .................. 20

Tests.................... 21

Procedures ............... . . 22

Variables................. 28

Methods of Analysis............. 31

IV. PRESENTATION AND ANALYSIS OF DATA . . . . . . . 32

Comparison of School Readiness . . . . . . . 32

Comparison of Intelligence Quotients . . . . . 37

Comparison of Sociogram . . . . . . . . . . 39

Comparison of Character Trait Ratings . . . . . . 40

Comparison of Nine Weeks Achievement Ratings . . . 51

Comparison of Personal and Social Adjustment . . 55

Comparison of Achievement Scores .. . . . . . 61

Comparison of Kindergarten Attendance and

Socio-Economic Level ........... 61

v. CONCLUSIONS . . . . . . . . . . . . . . 64 


\section{TABLE OF CONTENTS (CONTINUED)}

Chapter

Page

VI. SURMARY AND RECORMENDATIONS ............ 69

Sumary .................... 69

Recomnendations ............ . . . 74

APPENDIX . . . . . . . . . . . . . . 75

BIBLIOGRAPHY .................. 149 
LIST OF TABLES

Table

Page

1. SCHOOL READINESS - TOTAL SCORES .......... 33

2. SUMMARY ANALYSIS OF VARIANCE - SCHOOL READINESS . . . 33 SCHOOL READINESS:

3. Word Meaning .............. 34

4. Listening ................ . . 34

5. Matching ................ 35

6. Alphabet ................ 35

7. Numbers ..................... 36

8. Copying ................... . . . 36

INTELLIGENCE QUOTIENT SCORES:

9. Grade One . . . . . . . . . . . . . 38

10. Grade Four ................ 38

SOCIAL ADJUSTMENT:

11. Grade One................. 39

12. Grade Four ............... 40

FIRST GRADE CHARACTER TRAIT RATINGS:

13. Self-Confidence . . . . . . . . . . . . . 41

14. Ability to Mix ............... 41

15. Friendliness ............. . . . 42

16. Interest ................. 42

17. Attention ................. . . 43

18. Ability to Think .. . . . . . . . . . . 43

19. Originality .................. . . 44

20. Response to Directions . . . . . . . . . . 44

21. Oral Expression ............. . . 45

22. Ability to Play .............. 45

FOURTH GRADE CHARACTER TRAIT RATINGS:

23. Self-Confidence . . . . . . . . . . 46

24. Ability to $\mathrm{Mix}$............... 47

25. Friendilness ............... 47 
26. Interest ................ . . 48 48

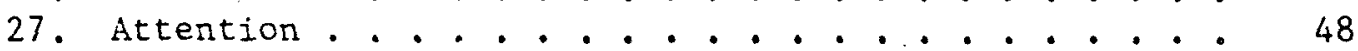

28. Ability to Think ............. . . 49

29. Originality .................. 49

30. Response to Directions ............ 50

31. Oral Expression................. 50

32. Ability to Play .............. 51

NINE WEEKS ACHIEVEMENT RATINGS - FIRST GRADE:

33. Reading ................. 52

34. Writing .................. 52

35. Mathematics .............. 53

NINE WEEKS ACHIEVEMENT RATINGS - FOURTH GRADE:

36. Reading . . . . . . . . . . . . 53

37. Writing . . . . . . . . . . . . . 53

38. Mathematics ................ . . 54

39. NINE WEEKS ACHIEVEMENT RATINGS - GRADE ONE AVERAGES . 54

PERSONAL AND SOCIAL ADJUSTMENT - FIRST GRADE:

40. Total Personal Worth ............. 55

41. Total Personal Adjustment ........... 56

42. Total School Relations ............. 56

43. Total Social Adjustment ............ 57

44. Total Adjustment ............. . . 57

PERSONAL AND SOCIAL ADJUSTMENT - FOURTH GRADE:

45. Total Personal Worth .. . . . . . . . . 58

46. Total Personal Adjustment.......... 59

47. Total School Relations ............ 59

48. Total Social Adjustment............ . 60

49. Total Adjustment ............... . 60

50. ACHLEVEMENT TEST .................... 61

KINDERGARTEN ATTENDANCE AND SOCIO-ECONOMIC LEVEL:

51. First Grade . . . . . . . . . . . . . . 62

52. Fourth Grade . . . . . . . . . . . . 62 
CHAPTER I

\section{INTRODUCTION}

\section{Statement of the Problem}

Public opinion seems to be growing in regards to the idea that a kindergarten experience should be available for every child. Educational research reveals considerable evidence concerning the significance of early childhood and the importance of providing education for young children. Because early life experiences are cumulative they tend to influence later development. "The beginnings for a child are the stuff upon which later development hinges" (Sabath, 1965-66, p. 32).

There is much controversial research concerning preschool education but the review of literature is limited to kindergarten education.

The first public kindergarten in America was established in 1873, almost one-hundred years ago. Public kindergartens, at the present time, provide for the needs of about forty per cent of our five-year-olds (Hymes, 1969, p. 5). About ten per cent of our five-year-olds are in private kindergartens. This means that approximately one-half of our nation's six-year-olds receive their first formal education when entering first grade. 
Based on the converging evidence that researchers have accumulated concerning the positive effect of early childhood education upon later school adjustment and achievement, it becomes apparent to the author that the pre-school age group should receive great attention by educators. These years from one to five are the most important developmental years mentally, physically and psychologically. Bloom (1964, p. 110) has predicted that fifty per cent of the intelligence measured at age seventeen is developed by age four. The available evidence suggests that a quality kindergarten program favorably influences later academic achievement, safeguards health, fosters social development, has desirable effects upon personality growth, and increases opportunities for acquiring skills necessary for intelligent behavior. Not all evidence is uncontested, nor has it been accumulated faultlessly as to research methods, but even so, the evidence is significant and impressive (Fuller, 1961, pp. 18-19).

The relationship between kindergarten attendance and success in later school experiences is discussed further in Chapter II.

\section{Rationale}

Adjustment to formal learning situations is a major problem for children entering our schools today. The results of a poor initial adjustment are apt to affect the child's subsequent success in future school experiences. Many educators feel that an early childhood education will provide the necessary ingredients to more nearly guarantee a good adjustment as the child later enters a more 
formal educational atmosphere. This study was conducted to discover what effect, if any, a kindergarten experience had upon later school experiences.

\section{Purpose of the Study}

The purpose of this study was to discover what relationships might exist between kindergarten experience and subsequent academic achievement and social adjustment in later school experiences.

\section{Definition of Terms}

1. Kindergarten - pertains to those children who have had an experience in a pre-school educational situation designed for five-year-olds.

2. Non-Kindergarten - pertains to those children who have not had an experience in a pre-school educational situation designed for five-year-olds.

\section{Statement of the Hypotheses}

The following hypotheses are expressed in the null form.

1. There is no significant difference in the school readiness of first grade children who have had kindergarten experience and the school readiness of first grade children who have not had kindergarten experience.

2. There is no significant difference in the mean intelligence quotient of first grade children who have had kindergarten experience and the mean intelligence quotient of first grade children who have not had kindergarten experience. 
3. There is no signficant difference in the mean intelligence quotient of fourth grade children who have had kindergarten experience and the mean intelligence quotient of fourth grade children who have not had kindergarten experience.

4. There is no significant difference in the social adjustment of first grade children who have had kindergarten experience and the social adjustment of first grade children who have not had kindergarten experience.

5. There is no significant difference in the social adjustment of fourth grade children who have had kindergarten experience and the social adjustment of fourth grade children who have not had kindergarten experience.

6. There is no significant difference in teacher judged character trait ratings for first grade children who have had kindergarten experience and teachex judged character trait ratings for first grade children who have not had kindergarten experience.

7. There is no significant difference in teacher judged character trait ratings for fourth grade children who have had kindergarten experience and teacher judged character trait ratings for fourth grade children who have not had kindergarten experience.

8. There is no significant difference in teacher opinion achievement ratings for first grade children who have had kindergarten experience and teacher opinion achievement ratings for first grade children who have not had kindergarten experience.

9. There is no significant difference in teacher opinion achievement ratings for fourth grade children who have had kindergarten 
experience and teacher opinion achievement ratings for fourth grade children who have not had kindergarten experience.

10. There is no significant difference in the personal and social adjustment of first grade children who have had kindergarten experience and the personal and social adjustment of first grade children who have not had kindergarten experience.

11. There is no significant difference in the personal and social adjustment of fourth grade children who have had kindergarten experience and the personal and social adjustment of fourth grade children who have not had kindergarten experience.

12. There is no significant difference in probability of later school success (fewer repetitions of grade levels) for children who have had kindergarten experience and probability of later school success for children who have not had kindergarten experience.

13. There is no significant difference in achievement test scores of fourth grade children who have had kindergarten experience and achievement test scores of fourth grade children who have not had kindergarten experience.

14. There is no significant difference in socio-economic background for those children having had kindergarten experience and socio-economic background for those children not having had kinder.. garten experience.

\section{Organization}

In Chapter I, the introduction and a statement of the problem studied was presented, followed by the rationale explaining the reason 
for the study, and the purpose of the study. The next section presented a definition of terms used, followed by a list of the fourteen hypotheses to be tested by the research. The organization of the study concludes this chapter.

In Chapter II, a review of the literature is presented. Chapter III explains the research design. This design describes the sample used in the research, the tests used, the testing procedures, and the methods of analyzing the results of these tests.

Chapter IV contains the presentation and analysis of the data obtained in the testing procedures described in Chapter III. Chapter $V$ sets forth a summary of the findings of this study and the recommendations of the researcher as a result of this study. Following Chapter $\mathrm{V}$ are the appendices and bibliography. 


\section{REVIEW OF LITERATURE}

Many studies have been made in which children who have attended kindergarten are compared with those who have not attended kindergarten. Some of these studies compare kindergarten and non-kindergarten influences upon progress in one subject, usually reading, or adjustment in a single area, usually social, or compare total growth.

Kindergarten is a term used to describe a learning program primarily for five-year-olds. This program is often within the public school or under the jurisdiction of the public school. Some kindergartens are run by private organizations and it is estimated that about ten per cent of our five-year-olds are in private kindergartens (Frazier, 1968, p. 6). Some private kindergartens are good, especially where there can be public supervision so that similar standards are assured.

However, private education always means that only a limited number of families can afford the opportunity. Often these children are already privileged with many cultural enrichments which facilitate learning. Also, it is expensive to serve young children well. Tuition alone cannot be depended upon to meet the financial needs to cover costs of private kindergarten. The private kindergarten is then 
forced to cut conners and this always results in having too large classes (Hymes, 1969, p. 106).

"Why don't all public schools have kindergartens?"

According to Schloss and Pect the majority of Americans do not understand the value of kindergarten and do not even know what takes place in one (Encyclopedia of Educational Research, 1969, p. 327).

Data collected by the Bureau of Census in 1964 was analyzed by Samue1 Schloss (Encyclopedia of Educational Research, 1969, p. 327) and he found that of all the children enrolled in kindergarten, 83 per cent were in public schools. Only one-half of the states in 1965 provided for kindergarten on the same basis as other grades in public schools, and seven states had no public kindergartens.

Kindergartens have been a part of the public schools in some parts of the United States for over 100 years. However, public kindergartens at the present time are providing for the needs of about 40 per cent of our five-year-olds (Hymes, 1969, pp. 1-6).

As a result of the growing need and the inadequate provision made by public schools, the private pre-schools have experienced rapid growth. According to a recent study (Leeper, Dales, Skipper and Witherspoon, 1968) this rapid expansion raises questions as to the types of schools, quality of programs, and the preparation of the teachers.

In early childhood education there are various proposals for change. Some proposals would introduce formal instruction in the academic areas to very young children while others maintain that the 
program can continue to meet the needs of children and at the same time offer "content."

In discussing the two positions, Almy (1964, p. 24) reviews research which suggests that acceleration in a particular subject area sometimes results in pseudoconcepts. The child knows the answer only under conditions that are like those in which he learned them. Concepts acquired when the child is more mature tend to be more stable and can be applied in different situations. According to Almy, "It seems doubtful, therefore, that early childhood education programs that are narrowly focused or designed primarily for acceleration in a particular area will have much beneficial effect on later intellectual development."

Educational research shows a clear relationship between early childhood education and formal learning. Rudolph and Cohen, (1964, p. 4) have said that even though the kindergarten year must have serious meaning, this seriousness of purpose does not mean a mechanical acceleration of the existing curriculum by starting preparation for advanced skills by handling specific aspects of the three $R^{\prime} s$. Educational research reveals considerable evidence as to the significance of early childhood and the importance of providing education for young children. The first years of a child's life are a crucial time for learning. Important learning occurs from the very beginning of life. Early life experiences influence later development, as the child's development builds upon previous contributions of learning. Nore than a million children starting school each fall in the United States are so disadvantaged that failure is a natural. consequence (Frost and Hawkes, 1966). 
The most important developmental years, physically and psychologically are the years one to five. Bloom (1965, p. 127) has predicted that 50 per cent of the intelligence measured at age seventeen is developed by age four.

Indeed, kindergarten is almost too late to lay the groundwork for original thinking and scientific problem solving needed in our time, according to Rudolph and Cohen (1964). Research has shown that what happens to children long before they dream of entering school markedly influences their capacity to grow in school.

Knoblock and Pasamanick (Rudolph and Cohen, 1964, p. 5) tested some three hundred children, half Negro, half white. They found no difference in intelligence scores between white and nonwhite babies at forty weeks of age. But when tested again at age three the environmentally less favored Negro children showed less responsiveness and curiosity; their language intelligence scores were as much as sixteen points lower than those of the white children with whom they had been on a par as babies.

On the other hand, Irwin (1961, pp. 187-190) persuaded a group of mothers whose husbands were unskilled, semiskilled and skilled workers to read to their children ten minutes a day from the time they were one. Not only were the mothers, who ordinarily would not have read to their children, amazed to find a strong interest in books among their little ones, but Irwin found a measurable difference in the speech development of these children as compared with that of a control group of similar background. And this difference showed up when the children were as young as twenty nonths. 
Esther Milner's study (1951, pp. 95-112) of three groups of Negro first-graders revealed a definite relationship between children's ability to read in the first grade and two factors, a) the warmth of affectional relationship (parents and children. chatted at meals together), and b) the degree of intellectual stimulation (not only were there books in the house but even the punishment was verbal.)

It becomes quite evident that the pre-school age group should receive great attention. According to Rudolph and Cohen (1964), a child's life condition must offer stimulation and interest within an emotional climate of love and support, or he will not grow in capacity to learn.

Some researchers believe that lack of opportunity in early childhood and its resultant damage, cannot be overcome. But others are inclined to the view that if a stimulating environment counteracts this void in the early years much can be done to reverse the downward trend.

The fact that environment can play so dramatic a role in children's capacity to learn, and the frighteningly early state at which children can show the effects of inadequate experience, points up the responsibility of the teacher of young children in a way we have not fully recognized before. According to Rudolph and Cohen (1964), kindergarten, the earliest school experience for large numbers of children, may be seen as strategic in relation to their future educational progress. In some cases it may be crucial. 
The decision to utilize pre-school enrichment as an antidote to cultural deprivation and failure in school achievement culminated in federally funded pre-school summer programs in 1965. These programs were known as Project Headstart. As a part of the anti-poverty program under the Johnson administration, over half a million children were enrolled in programs which provided medical, dental and educational services of a highly personal, but professional nature. The children were given a wide variety of group experiences, emphasis was placed on enhancement of the child's self-image as the result of his acceptance by his teachers and his increasing competence in coping with the school environment. The project reported gains of 8 to 10 IQ points in six weeks (Keliher, 1966, P. 1).

At the University of Texas a group of Head Start children were compared with a group of non-Head Start children who would have been eligible for Head Start to determine whether Head Start children functioned more effectively in first grade. All of the instruments administered to Head Start children, except the Peabody. Picture Verbal Test, showed them to be functioning at a higher level in the first grade than did the comparison sample of non-Head Start children (Gotts and Pierce-Jones, 1966, Pp. 305-313).

Even though Head Start makes reports of substantial increase in school readiness other basic questions remain at issue. No attention has been given to the parental environmental setting and its predictive relation to the disadvantaged child's functioning. In addition, little is known of the persistence of changes observed in 
Head Start-trained youngsters (Gotts and Pierce-Jones, 1966, pp. 305-313) .

Experiments by Deutsch (1964) indicated that pre-school, kindergarten, or day-care experience or a combination of these, are associated with higher scores on intelligence tests than are achieved by children without such experience. Regardless of social-class affiliation, the advantage of pre-school attendance is evident at first-grade level and even more at grade five, he found.

As early as 1914 a study was made of 380 grade school children in Edgewater, Pennsylvania. The method of comparison between kindergarten and no kindergarten was based on teachers' estimates of certain traits of character. Children who had had kindergarten experience excelled in areas which effect sociability, originality, observation, response to ideas, oral expression and ability to think (Marsh, 1915, pp. 543-50).

Another study of 293 pupils in the first five grades of a school in Monticello, Indiana, indicated that kindergarten training manifests itself not only in the first grade, but also in succeeding grades (Reisser, 1927, pp. 286-89). One of the general conclusions from this study was, "The standards of work in the elementary school may be raised by requiring all children to attend kindergarten before entering the first grade." This study was made over fifty years ago and still only approximately eighty-three per cent of all fiveyear-olds today will experience a kindergarten education (United States Office of Education, 1969, p. 64). 
In general, most investigators agree in reporting less retardation among kindergarten-trained than among non-kindergartentrained pupils. An extensive investigation in elementary schools of Michigan disclosed that the proportion of "repeaters" in towns and cities without kindergartens was 69 per cent greater than in communities having kindergartens (Encyclopedia of Educational Research, 1950, pp. 651-52). The same study reported that "sixty per cent of the children entering first grade without kindergarten training in Pawtucket, Rhode Island, failed."

Most first grade teachers do report that at the start of school they can spot in a favorable way the children who have gone to kindergarten. This gets more and more difficult to do, however, as the year moves along. And while some more controlled studies show lasting differences in achievement and behavior, as many other studies show no such measurable impact" (Hymes, 1969, p. 5).

Much of the research which compares achievement in first grade of children who attended kindergarten and those who did not, favors those with kindergarten experience. One study by Fast (1957, pp. 52-57) indicated that not only did kindergarten attendance facilitate academic performance in grade one, but also that evidence of this facilitation could be found as late as grade eleven.

None of the research evidence gives contradiction to the effect of early childhood experiences upon future social adjustment and academic achievement. What research does imply is that rich experiences in early childhood enhance a child's intellectual activity, 
self-assurance and social skills. Since learning experiences tend to build upon past experiences, it seems self evident that a rich preschool environment provided by a warm and wise teacher, enhances the growth of the pre-school child (Fast, 1957).

"There is no clear cut proof that kindergarten gets the children ready for first grade or that it contributes to later school success" (Hymes, 1969, p. 5).

Most of the difficulties children have when they enter school reflect their pre-school experiences. Feelings of discouragement, timidity, resistance, and hostility toward adults, which they display to teachers and all school learning, are also a result of early childhood experiences, according to Frank (1959).

Before kindergarten the child has lived largely within his family group. There have been brief and sporadic periods of widening his social field, but not until he begins his first school experience does he really change his role (Hefferman, 1960, pp. 41-42).

Research implicates that a child's social adjustment to school is the main reason for having a kindergarten. Social adjustment is part of the readiness for formal learning and lack of readiness may cause a child's failure in first grade. He is then spending so much of his.time and effort with his social adjustment that there is little energy left for academic achievement (Bergamini, 1954, pp. 54-55). In answer to a parent's question about the necessity of a kindergarten experience for her child, Louise Bates Ames (1967, p. 108) says, "Kindergarten is not essential and children will live and learn without it. But we are for it, 100 percent." She feels that the 
flexible atmosphere of a kindergarten permits the child to be in school but allows him to behave at a level of maturity and cooperativeness for which he is ready. Demands can be less rigid than those of first grade, so that the child can begin school more or less in his own way, at his own pace. According to Ames (1967, p. 109), "First-grade adjustment is immeasurably helped in most cases by the kindergarten experience."

Research findings in the area of early childhood education seem to be either strongly or mildly in support of kindergarten education. There are no findings which even suggest that the kindergarten experience could have a negative effect. One sometimes wonders, however, if a case might not be made for the negative effects of some types of kindergarten experience (Headley, 1965, p. 34).

The narrower the scope of a study, the more prone the research worker is to lavish claims one way or the other as to contributions (or lack of them) of kindergartens. The effects of kindergarten education appear to be in proportion to the quality of the program (Fuller, 1961, pp. 18-19).

The available evidence suggests that a quality kindergarten program favorably influences later academic achievement, safeguards health, fosters social development, has desirable effects upon personality growth, and increases opportunities for acquiring skills necessary for intelligent behavior. According to Fuller (1961, pp. 18-19), all evidence is not uncontested, nor has it been accumulated faultlessly as to research methods; but, even so, the evidence is significant and impressive. 
What then should a kindergarten program provide for children? Our first concern should be for the building of healthy personalities, to develop feelings of self-worth and adequacy in children. These, in turn, will influence every area of their immediate and future lives (Todd and Hefferman, 1964).

Widner (1967, pp. 210-216) sees the kindergarten year as a transition year between home and school and stresses the importance of readiness activities which will be helpful in first grade.

Shaftel (Encyclopedia of Educational Research, 1969, p. 327) sees four major tasks for kindergarten teaching: (1) helping the child develop feelings of competence and adequacy; (2) fostering intellectual development; (3) building feelings of mutual helpfulness; and (4) developing the skills for observation, communication, motor competency and manipulation.

According to Spodek (1965, p. 325) kindergarten should provide children with the understanding that would increase their ability to cope with the present world.

Maria Montessori predicted that this century would be "the century of the child" and truly the past forty to fifty years have been a golden era for childhood.

A general feeling is developing among educators and lay public that early childhood education. is not merely a social convenience or an antidote for poverty. According to Frazier (1.968, pp. 1-6) early childhood education is coming to be seen less as a privilege and more as an individual right and possibly as a responsibility which society owes to all her children. 
Our entire nation is concerned with the problem of mental health. "We have long known," say Rudolph and Cohen (1964, p. 12), "that early childhood experiences throw a far shadow, although not an unchangeable one over later behavior."

According to Rudolph and Cohen (1064, p. 12) it is true that the home plays the primary role in regards to childhood experiences but the school plays the next single largest influence in any child's life, and school begins in the kindergarten. 
CHAPTER III

\section{RESEARCH DESIGN}

This is a descriptive type of research, the purpose of which is to discover whether or not there is a significant difference in the social adjustment and academic achievement of first grade children who have had kindergarten experience prior to attending first grade and first grade children who have not had kindergarten experience prior to attending first grade. It was also the purpose of this research study to determine the persistence of the difference, if any, in the social adjustment and academic achievement of fourth grade children who have had kindergarten experience prior to attending first grade and fourth grade children who have not had kindergarten experience prior to attending first grade.

\section{Population and Sample}

For the purposes of this study the sample chosen was the approximately 3,115 elementary children enrolled in the PennHarris-Madison School Corporation. The children were chosen because of their avilaability and because it was felt they were fairly representative. The schools are located in St. Joseph County in the State of Indiana.

The Penn-Harris-Madison School Corporation has ten elementary schools, four of which house students in grades four, five and six, 
five of which house.students in grades one, two and three, and one of which houses first grade through sixth grade students. The children in the four first grades at the Osceola School and the children in the three fourth grades housed in the Moran School were chosen as the sample for this study. In general the children from the sample group come from middle income families.

\section{The Method}

The approximately 110 first grade children were already assigned to one of the four first grade rooms by the principal. This placement is traditionally based on the child's score obtained from the Goodenough "draw-a-man test" which he drew during an interview with his prospective teacher at pre-school round-up in the spring prior to his initiation into first grade. This score is based on a three-point scale:

Poor Risk - the child will most likely succeed in first grade

Medium Risk - the child probably will succeed in first grade

High Risk - it is very unlikely that the child will succeed in first grade

The boys and girls are then placed according to sex, and according to their score on the Goodenough "draw-a-man" test so that each teacher has, as nearly as possible, the same amount of boys and girls and an equal number of "high," "medium," and "low" risks. There has never been any attempt to evenly distribute the boys and girls entering first grade according to their pre-school experience.

The approximately twelve children who are repeating first grade were not included in this study. It is felt that the total school 
experience of the repeating first graders will have been of such a different nature than those children who were initially entering first grade that to use them in the sample may cause a distortion of facts.

In similar fashion the children enrolled in fourth grade who had a repetition of any of the grades from one through four were not included in the sample for this research study.

The students in the sample were categorized according to whether or not they had had kindergarten experience prior to first grade.

\section{Tests}

A number of instruments were used to test the hypotheses. Each first grade student was given the following tests: (1) the Metropolitan Readiness Test, (2) the SRA - Primary Mental Abilities Test for Grades $\underline{\mathrm{K}-1}$, and (3) the California Test of Personality. The Metropolitan Readiness Test was used to obtain a standardized measurement of initial school readiness. The SRA - Primary Mental Abilities Test was used as a standardized measurement of intelligence and the California Test of Personality was used as a measurement of the child's personal and social adjustment.

Each of the first grade children also participated in the construction of a sociogram. The sociogram was used as a measurement for peer evaluation of each child's social adjustment.

Each first grade student was given character trait ratings by his teacher. This character trait rating was used as a measurement 
for the teacher's opinion of the child's social and personal adjustment in the school situation.

Each fourtin grade student was given the California Test of Personality. This test was used as a standardized measurement of the child's personal and social adjustment.

There were fifty-five of the fourth grade students who had been given the SRA Primary Mental Abilities Test for Grades K-1 when they initially entered first grade. (These were the children who had started first grade at Osceola School.) The results of this test were used as a measurement of intelligence in first grade.

The scores of the SRA Achievement Test administered in third grade were obtained for the same fifty-five fourth grade children. The results of this test were used for a standardized measurement of achievement.

Each of the fourth grade students also participated in the construction of a sociogram. The sociogram was used as a measurement for peer evaluation of each child's social adjustment.

Each fourth grade student was given character trait ratings by his teacher. This character trait rating was used as a measurement for the teacher's opinion of the child's social and personal adjustment in the school situation.

\section{Procedures}

- The researcher met with the four first grade teachers two weeks prior to the beginning of school. The purpose of this meeting was to acquaint the teachers with the research study and to solicit 
their cooperation. At this time it was decided that the researcher would use the supervision of playground at the morning recess for the purpose of getting acquainted with the new first graders and thus making them feel more at ease in the subsequent testing situations with her.

There was not the same need for the researcher to nake an effort to become acquainted with the fourth grade students because her former position as first grade teacher for four years in the Osceola School gave an already familiar relationship.

The following procedures will be stated for the fourteen hypotheses written in Chapter 1:

(1) The Metropolitan Readiness Test was administered to the four first grades by the researcher during the second week of school. Prior to this she had spent one recess period each day supervising the students on the playground. In addition to this, twenty minutes were spent in each of the four first grade rooms as a "getting acquainted" measure in preparation for administering the Metropolitan Readiness Test the following week. "Caps for Sale" was used for a storytime situation, after which each of the children made caps to display on a "Caps for Sale" bulletin board shared by all four first grades. Each of the "getting acquainted" experiences mentioned above served to allow the testees to become better acquainted with the administrator and therefore to be more relaxed in the testing situation. The administrator was able to become more aware of each individual classroom setting and was also able to discern, ahead of the testing, those children who might be in need of special assistance. The test 
was administered on three successive days, each sitting of twenty minutes duration.

(2) The SRA Primary Abilities Test was administered by each of the individual first grade teachers on two successive days the fourth week of school. Half of each class stayed home the first day, while half of each class was given the test. The second half of each class was given the test on the second day, while the children tested the first day stayed home. This enabled the administrators to more easily meet the demands of those children who require more personal assistance.

(3) The scores of those fifty-five fourth grade children who began school in the first grade at Osceola four years previously, were compiled from the records by the researcher.

(4) and (5) During the sixth week of school the researcher constructed a sociogram on the basis of information tabulated from the first grade children's and the fourth grade children's responses to three choices. The choices were asked each of the first grade students personally by the researcher and their responses were recorded individually. The fourth grade students were able to write their responses to the three choices. The choices for the student's responses were:

1) With whom would you choose to sit?

2) With whom would you choose to work?

3) With whom would you choose to play?

(6) and (7) The eighth week of school each of the four first grade teachers and each of the three fourth grade teachers were asked to judge certain character traits of their students. They scored the children on a three-point scale; very high $=1$, 
moderate $=2$, and low $=3$. At no time were the teachers made aware of the purpose to compare the ratings of kindergarten children with the ratings received by non-kindergarten children. The teachers were not aware of those children who had had kindergarten experience and those who had not had kindergarten experience. This information is not required at the time of the child's registration and therefore not available.

To avoid confusion in teacher's judgment of the above character traits, the researcher listed behavioral objectives to serve as a guide in making these judgments. Listed below are the character traits which were judged and the behavioral objectives which the teachers used as a guide in making their judgments:

1) Self-confidence: as shown by the child's ability to complete a given task without requesting approval until task is completed.

2) Ability to mix: as shown by the child's ability to relate positively to any group of children.

3) Friendliness:

as shown by the child's making an effort to provide for the well-being of his fellow classmates.

4) Interest:

as shown by the child's voluntarily offering to take an active part in activities in the classroom.

5) Attention:

a) as shown by the child's ability to concentrate upon a specific task for a given period of time.

b) as shown by the child's ability to concentrate while a story is being told, film shown, record played, etc.

6) Ability to think: as shown by the child's ability to of
ideas through oral and written expression. 
7) Originality:

as shown by the child's ability to work at a

task without referring to someone else's work.

8) Response to directions:

as shown oy the child's ability to follow through a series of one, two or three directions given at the same time. Ex. Put your name at the top, right hand corner of your paper, fold it in half, and place your paper on the library table.

9) Oral expression:

a) as shown by the child's ability to make his needs clearly understood.

b) as shown by the child's ability to clearly relate the main idea of a story or picture, etc.

10) Ability to play:

as shown by the child's ability to find constructive recreational activity during free time, such as recess, etc.

(8) and (9) Each of the four first grade teachers and each

of the three fourth grade teachers were asked to rate each student's academic achievement in the areas of reading, writing and mathematics. This rating was given at the end of the first nine weeks of school. The teachers were asked to assign numerical values to grades so that comparisons might more readily be made. These numerical values are as follows; $A=4, B=3, C=2, D=1$, and $F=0$.

(10) and (11) The California Test of Personality was administered by the researcher during the tenth week of school. The researcher used forty-five minute periods each morning for three successive days to test the three fourth grade classes. The researcher took a forty-five minute period each afternoon for four successive days to test the four first grade classes.

The researcher noted some confusion in comprehension of meaning of some of the terminology used in sections of this test. This 
confusion was prevalent with the less capable first graders. When confused as to meaning, these less capable students tended to look to their neighbor for assistance.

Some of the fourth grade students desired a third response somewhere between the required "yes" or "no." Some tended to be confused at being presented questions which covered the opinion others had of them. Frequent verbal responses were, "How do I know what 'they' think?" and "I can't see what goes on inside people's heads." Every effort was made by the examiner to obtain scores as accurate as possible, despite the obvious confusion on the part of some of the testees concerning certain questions on the test. Each test question was read to all students being tested by the examiner so as to take into consideration the widespread reading abilities of each individual tested and to more fully guarantee clarity of meaning.

(12) The researcher compiled a list of children in grade one during the 1970-71 school year who had to repeat first grade in the school year 1971-72. Of those with kindergarten experience, six out of forty-five, or 13.3 per cent had to repeat. of those without kindergarten experience, eight out of forty-six, or 17.4 per cent, had to repeat first grade.

(13) The four individual third grade teachers administered the SRA Achievement Test some time during the second semester of third grade. The researcher compiled the scores from the records of the fifty-five fourth graders who, four years previously, began first grade at Osceola School. 
(14) A questionnaire was sent by the researcher to the homes of all the first grade students and to the homes of all the fourth grade students who were included in the research study. This questionnaire was sent to the parents through the courtesy of each student.

The questionnaire was used to determine the relationship, if any, of kindergarten attendance and social class. (A copy of the questionnaire may be found in the appendix.)

To questionnaires sent home with sixty-five first graders who had had kindergarten experience, the researcher received fifty-five responses. To questionnaires sent home with twenty-seven first graders who had no kindergarten experience, she received twenty-two responses.

To questionnaires sent home with fifty-two fourth graders who had had kindergarten experience, the researcher received forty-four responses. To questionnaires sent home with twenty-seven fourth graders who had not had kindergarten experience, she received eighteen responses.

Out of a total of 171 questionnaires sent home with 171 first grade and fourth grade students, 139 responses were received by the researcher. This means that she received a response from 81 per cent of the sample population chosen for the research study.

\section{Variables}

One of the variables influencing the results of this project is the difference in personality and teaching methods of the seven 
individual teachers involved in the study. Their teaching techniques, their teaching experience, their command of subjects on the level they teach, the quality of rapport between teacher and child, teacher and researcher, researcher and student; all will. affect the results of the research study. The individual teacher's attitude towards the research project itself will also have its effect upon the results of the study.

The fact that the kindergarten experience was not taken into consideration when placement of the first grade students was made could have had an effect on the outcome of the research study. There being an uneven number of children with kindergarten experience in one room as compared with the number of children with kindergarten experience in any one of the other three first grade rooms, this too, could affect the results of the study.

It could also be possible that an individual teacher works better with children who have had kindergarten experience prior to entering first grade, or that a teacher works better with those children who have not had kindergarten experience prior to entering first grade. This might produce a "halo effect" on the part of that particular teacher as she views any comparison of the two groups.

There was some variation in socio-economical backgrounds which influenced the decision as to whether the child had or had not had kindergarten experience. However, in the main, the sample is drawn from a community where children are usually sent to kindergarten when their parents feel they need extra assistance in preparing their child for first grade. 
The author recognizes the subjectiveness of Methods 6 and

7. There was some variation between the individual teacher's judgment of character traits for her students even though every effort, on the part of the researcher, was made to make the judgments as similar as possible. Individual teachers view children in different ways and this variable cannot be avoided.

The researcher also recognizes the subjectiveness of Methods 8 and 9. Teachers evaluate achievement differently; some higher, some lower. Some teachers tend to evaluate achievement according to their students' progress as compared with the total group. Some teachers compare the child's progress with his former achievement. Some teachers express achievement ratings in terms of effort expended by the student to make improvement over former academic performance. These variables are factors over which the researcher had no control. Naturally there will be a variation in the extent to which each of the feeder kindergartens has prepared the child for first grade instruction. This will be due, in part, to the difference in philosophies and educational goals of the various feeder kindergartens in the community where the research study has taken place. However, the researcher did not intend that this research be a study of the effectiveness of the various private kindergartens which provide first-grade readiness for children in the Osceola School area. The study was intended only to compare the social adjustment and academic achievement of those first grade children who have had kindergarten experience and those first grade children who have not had kindergarten experience. 
No attempt was made to access the richness or deprivation of the individual child's environmental setting. This variable is recognized as a definite contributing factor to the child's ability to adjust socially and to learn in later environments.

\section{Methods of Analysis}

In order to test Hypothesis $1,2,3,10,11$, and 13 the method of statistical analysis used was the Lindquist's Groups-Within Treatments Analysis of Variance Design (1953, pp. 172-189) because complete classes were used as the basic unit.

Hypotheses $5,7,8,9$, and 14 were tested by means of a Chisquare for a contingency table.

An analysis of significance of the difference between independent proportions was the method of statistical analysis used in testing Hypotheses 4, 5, and 12 .

In every test a probability $\leq .05$ was set as the criterion for significance. 
CHAPTER IV

PRESENTATION AND ANALYSIS OF DATA

\section{Comparison of School Readiness}

Table 1 shows the comparison of total scores obtained from the Metropolitan Readiness Test given to the four first grades. A one-way analysis of variance, using Lindquist's Groups Within Treatments Design, was carried out and is shown in Table 2. The value of $F$ is 19.830 , which is well above the 5.99 required for significance at the .05 level. There was a highly significant difference in the extent to which school beginners had developed in the skills and abilities that contribute to readiness for first grade instruction. A comparison of the readiness scores of children entering first grade with prior kindergarten experience and children entering first grade without prior kindergarten experience shows the significance to be in the favor of the child who has had kindergarten experience. An asterisk here and in succeeding tables indicates where the value of $F$ was significant.

Tables $3,4,5,6,7$, and 8 show the comparison of scores for Tests 1, 2, 3, 4, 5, and 6 of the Metropolitan Readiness Test. The separate test scores for children who have had kindergarten experience and for children who have not had kindergarten experience showed that the greatest significant difference in readiness for first grade 
TABLE 1

SCHOOL READINESS

\begin{tabular}{c|c|c}
\hline & \multicolumn{2}{|c}{ Total Scores } \\
\hline Room & Kindergarten & Non-Kindergarten \\
\hline 1 & 56.2 & 54.2 \\
\hline 2 & 62.5 & 50.0 \\
\hline 3 & 57.6 & 46.7 \\
\hline 4 & 58.4 & 51.6 \\
\hline Mj & 58.68 & 50.63 \\
\hline
\end{tabular}

TABLE 2

SUMMARY ANALYSIS OF VARIANCE

SCHOOL READINESS

\begin{tabular}{l|c|c|c|c}
\hline $\begin{array}{l}\text { Source of } \\
\text { Variation }\end{array}$ & $\begin{array}{l}\text { Sum of } \\
\text { Squares }\end{array}$ & df & $\begin{array}{c}\text { Mean } \\
\text { Square }\end{array}$ & F \\
\hline $\begin{array}{l}\text { Between } \\
\text { Treatments }\end{array}$ & 155.827 & 1 & 155.827 & $+19.830 *$ \\
$\begin{array}{l}\text { Groups Within } \\
\text { Treatments }\end{array}$ & 47.148 & 6 & 7.858 & \\
\hline \hline
\end{tabular}


TABLE 3

SCHOOL READINESS

\begin{tabular}{c|c|c}
\hline \multirow{2}{*}{ Room } & \multicolumn{2}{|c|}{ Test 1 - Word Meaning } \\
\cline { 2 - 3 } & Kindergarten & Non-Kindergarten \\
\hline 1 & 9.066 & 7.857 \\
\hline 2 & 9.888 & 8.200 \\
\hline 3 & 9.230 & 8.800 \\
\hline 4 & 9.210 & 7.200 \\
\hline Mj & 9.3485 & 8.0142 \\
\hline
\end{tabular}

TABLE 4

SCHOOL READINESS

\begin{tabular}{c|c|c}
\hline \multirow{2}{*}{ Room } & \multicolumn{2}{|c|}{ Test 2 - Listening } \\
\cline { 2 - 3 } & Kindergarten & Non-Kindergarten \\
\hline 1 & 10.400 & 9.286 \\
\hline 2 & 9.555 & 9.000 \\
\hline 3 & 9.846 & 7.800 \\
\hline 4 & 9.737 & 9.600 \\
\hline Mj & 9.8845 & 8.9215 \\
\hline
\end{tabular}


TABLE 5

SCHOOL READINESS

\begin{tabular}{l|c|c}
\hline \multirow{2}{*}{ Room } & \multicolumn{2}{|c}{ Test 3 - Matching } \\
\cline { 2 - 3 } & Kindergarten & Non-Kindergarten \\
\hline 1 & 8.866 & 7.714 \\
\hline 2 & 8.111 & 6.800 \\
\hline 3 & 7.230 & 6.600 \\
\hline 4 & 7.684 & 7.800 \\
\hline Mj & 7.9727 & 7.2285 \\
\hline
\end{tabular}

TABLE 6

SCHOOL READINESS

\begin{tabular}{l|c|c}
\hline \multirow{2}{*}{ Room } & \multicolumn{2}{|c}{ Test 4 - Alphabet } \\
\cline { 2 - 3 } & Kindergarten & Non-Kindergarten \\
\hline 1 & 12.200 & 10.143 \\
\hline 2 & 12.444 & 6.800 \\
\hline 3 & 11.231 & 6.800 \\
\hline 4 & 11.526 & 8.400 \\
\hline $\mathrm{Mj}$ & 11.8502 & 8.357 \\
\hline
\end{tabular}


TABLE 7

SCHOOL READINESS

\begin{tabular}{l|c|c}
\hline \multirow{2}{*}{ Room } & \multicolumn{2}{|c}{ Test 5 - Numbers } \\
\cline { 2 - 3 } & Kindergarten & Non-Kindergarten \\
\hline 1 & 14.600 & 11.857 \\
\hline 2 & 15.000 & 13.923 \\
\hline 3 & 13.900 & 10.900 \\
\hline 4 & 12.894 & 12.800 \\
\hline Mj & 14.0985 & 12.3700 \\
\hline
\end{tabular}

TABLE 8

SCHOOL READINESS

\begin{tabular}{c|c|c}
\hline \multirow{2}{*}{ Room } & \multicolumn{2}{|c}{ Test 6 - Copying } \\
\cline { 2 - 3 } & Kindergarten & Non-Kindergarten \\
\hline 1 & 7.733 & 7.571 \\
\hline 2 & 7.555 & 7.000 \\
\hline 3 & 6.154 & 5.800 \\
\hline 4 & 7.263 & 5.800 \\
\hline Mj & 7.17625 & 6.54275 \\
\hline
\end{tabular}


lies in Test 1, Word Meaning and Test 4, Alphabet. The analysis of test scores showed no significant difference in Test 2, Listening; Test 3, Matching; Test 5, Numbers; and Test 6, Copying.

In order not to multiply tables, the tables for the analysis of variance are not shown for this data, however; the value of $F$ is shown below each table.

\section{Comparison of Intelligence Quotients}

Table 9 shows the comparison of total I.Q. scores obtained from the SRA Primary Mental Abilities Test given to the four first grades. The value of $F$ is 21.20 which is well above the 5.99 required for significance at the .05 level. There was a highly significant difference in the Intelligence Quotient Scores of children entering first grade at the Osceola School for the school year 197i-72, the significance being in the favor of the children having had kindergarten experience.

Table 10 shows the comparison of total I.Q. scores obtained from the SRA Primary Abilities Test administered to the fifty-five fourth grade students who enrolled in first grade at Osceola School for the year 1967-68. In the comparison of total I.Q. scores obtained from the SRA Primary Abilities Test for this group of students, the value of $F$ is 2.15 which falls below the $5.99 \mathrm{re}-$ quired for significance at the .05 level. 
TABLE 9

INTELLIGENCE QUOTIENT SCORES

FOR FIRST GRADE STUDENTS

1971-72

\begin{tabular}{l|c|c}
\hline \multirow{2}{*}{ Room } & \multicolumn{2}{|c}{ Total I.Q. Scores } \\
\cline { 2 - 3 } & Kindergarten & Non-Kindergarten \\
\hline 1 & 103.3333 & 100.2857 \\
\hline $2 \ldots$ & 103.0556 & 100.4000 \\
\hline 3 & 101.4615 & 98.9000 \\
\hline 4 & 103.6316 & 98.0000 \\
\hline Mj & 102.8705 & 99.3964 \\
\hline
\end{tabular}

TABLE 10

INTELLIGENCE QUOTIENT SCORES

FOR FIRST GRADE STUDENTS

1967-68

\begin{tabular}{c|c|c}
\hline \multirow{2}{*}{ Room } & \multicolumn{2}{|c|}{ Total I.Q. Scores } \\
\cline { 2 - 3 } & Kindergarten & Non-Kindergarten \\
\hline 1 & 100.9 & 106.25 \\
\hline 2 & 107.69 & 99.71 \\
\hline 3 & 103.67 & 99.60 \\
\hline Mj & 104.09 & 101.85 \\
\hline
\end{tabular}




\section{Comparison of Sociogram}

Table 11 shows a comparison of results of a sociogram constructed from information provided by the four first grades. Table 11 shows a significance in the proportion of stars, the significance being in the favor of the child having had kindergarten experience. A "star" is identified as a child who has been chosen by six or more of nis fellow students. There was no significant difference in the comparison of proportion of averages, neglectees and isolates. An "average" is identified as a child who has had either two, three, four, or five fellow students who chose him. A "neglectee" is identified as a child who has been chosen by only one of his fellow students and an "isolate" is identified as a child who has had none of his fellow students choose him.

TABLE 11

FIRST GRADE SOCIAL ADJUSTMENT

\begin{tabular}{l|c|c|c|c}
\hline & $\mathrm{K}$ & $\mathrm{NK}$ & $\mathrm{Z}=\frac{\mathrm{p}_{1}-\mathrm{p}_{2}}{\mathrm{P}_{1}-\mathrm{p}_{2}}$ & $\begin{array}{c}\text { Significance } \\
\mathrm{S}(\mathrm{p}<.05)\end{array}$ \\
\hline Stars & .212 & .037 & 2.08 & $\mathrm{S*}$ \\
Averages & .515 & .667 & 1.34 & $\mathrm{NS}$ \\
Neglectees & .212 & .259 & 0.49 & $\mathrm{NS}$ \\
Isolates & .061 & .037 & 0.47 & NS \\
\hline
\end{tabular}


Table 12 shows a comparison of results of a sociogram constructed from information provided by the three fourth grades. Table 12 shows a significance in the proportion of neglectees, the significance being in the favor of the child who has not had kindergarten experience. Table 12 also shows a significance in the proportion of averages, the significance being in favor of the child who has had kindergarten experience. Table 12 shows no significance in the proportion of stars and isolates for fourth grade children who have had kindergarten experience as compared to the proportion of stars and isolates for fourth grade children who have not had kindergarten experience.

TABLE 12

FOURTH GRADE SOCIAL ADJUSTMENT

\begin{tabular}{l|c|c|c|c}
\hline & $\begin{array}{c}\mathrm{K} \\
\mathrm{p}_{1}\end{array}$ & $\begin{array}{c}\mathrm{NK} \\
\mathrm{p}_{2}\end{array}$ & $\mathrm{Z}=\frac{\mathrm{p}_{1}-\mathrm{p}_{2}}{\mathrm{Sp_{1 } - \mathrm { p } _ { 2 }}}$ & $\begin{array}{c}\text { Significance } \\
\mathrm{S}(\mathrm{p}<.05)\end{array}$ \\
\hline Stars & .096 & .259 & 1.92 & $\mathrm{NS}$ \\
Averages & .673 & .370 & 2.58 & $\mathrm{~S} *$ \\
Neglectees & .096 & .296 & 2.265 & $\mathrm{~S} *$ \\
Isolates & .135 & .074 & 0.808 & $\mathrm{NS}$ \\
\hline
\end{tabular}

Comparison of Character Trait Ratings

Tables 13, 14, 15, 16, 17, 18, 19, 20, 21, and 22 show the comparison of character trait ratings received from teachers by the children in the four first grades. There was no significant difference in the character trait ratings for those first graders who had had kindergarten experience and those first graders who had not had 
kindergarten experience. The value of $x^{2}$ is shown with the individual character trait tables.

TABLE 13

CHARACTER TRAIT RATINGS

(FIRST GRADE)

\begin{tabular}{c|c|c|c|c}
\hline \multirow{2}{*}{ Group } & \multicolumn{3}{|c|}{ Self-Confidence } & Total \\
\cline { 2 - 5 } & 1 & 2 & 3 & 65 \\
\hline K & 25 & 31 & 9 & 27 \\
\hline NK & 12 & 10 & 5 & 92 \\
\hline Total & 37 & 41 & 14 & \\
\hline
\end{tabular}

The value of $x^{2}$ is .28 which falls short of the value of 5.99 required for significance at the .05 level.

TABLE 14

CHARACTER TRAIT RATINGS

(FIRST GRADE)

\begin{tabular}{c|c|c|c|c}
\hline \multirow{2}{*}{ Group } & \multicolumn{3}{|c|}{ Ability to Mix } & \multirow{2}{*}{ Total } \\
\cline { 2 - 5 } $\mathrm{K}$ & 1 & 2 & 3 & 65 \\
\hline NK & 12 & 48 & 5 & 27 \\
\hline Total & 5 & 17 & 5 & 92 \\
\hline
\end{tabular}

The value of $x^{2}$ is .000 which falls short of the value of 5.99 required for significance at the .05 level. 
TABLE 15

CHARACTER TRAIT RATINGS

(FIRST GRADE)

\begin{tabular}{c|c|c|c|c}
\hline \multirow{2}{*}{ Group } & \multicolumn{3}{|c|}{ Friend1iness } & \multirow{2}{*}{ Total } \\
\cline { 2 - 5 } & 1 & 2 & 3 & 65 \\
\hline $\mathrm{K}$ & 24 & 32 & 9 & 27 \\
\hline NK & 7 & 12 & 8 & 92 \\
\hline Total & 31 & 44 & 17 & \\
\hline
\end{tabular}

The value of $x^{2}$ is 3.29 which falls short of the value of 5.99 required for significance at the .05 level.

TABLE 16

CHARACTER TRAIT RATINGS

(FIRST GRADE)

\begin{tabular}{c|c|c|c|c}
\hline \multirow{2}{*}{ Group } & \multicolumn{3}{|c|}{ Interest } & Total \\
\cline { 2 - 5 } K & 1 & 2 & 3 & 65 \\
\hline NK & 29 & 26 & 10 & 27 \\
\hline Total & 8 & 13 & 6 & 92 \\
\hline
\end{tabular}

The value of $x^{2}$ is 1.92 which falls short of the value of 5.99 required for significance at the .05 level. 
TABLE 17

CHARACTER TRAIT RATINGS

(FIRST GRADE)

\begin{tabular}{c|c|c|c|c}
\hline \multirow{2}{*}{ Group } & \multicolumn{3}{|c|}{ Attention } & \multirow{2}{*}{ Tota1 } \\
\cline { 2 - 5 } K & 1 & 2 & 3 & 65 \\
\hline NK & 18 & 29 & 18 & 27 \\
\hline Total & 10 & 10 & 7 & 92 \\
\hline
\end{tabular}

The value of $x^{2}$ is .744 which falls short of the value of 5.99 required for significance at the .05 level.

TABLE 18

CHARACTER TRAIT RATINGS

(FIRST GRADE)

\begin{tabular}{c|c|c|c|c}
\hline \multirow{2}{*}{ Group } & \multicolumn{3}{|c|}{ Ability to Think } & \multirow{2}{*}{ Tota1 } \\
\cline { 2 - 5 } K & 1 & 2 & 3 & 65 \\
\hline NK & 29 & 31 & 5 & 27 \\
\hline Total & 6 & 13 & 8 & 92 \\
\hline
\end{tabular}

The value of $x^{2}$ is 4.544 which falls short of the value of 5.99 required for significance at the .05 leve1. 
TABLE 19

CHARACTER TRAIT RATINGS

(FIRST GRADE)

\begin{tabular}{c|c|c|c|c}
\hline \multirow{2}{*}{ Group } & \multicolumn{3}{|c|}{ Originality } & Total \\
\cline { 2 - 5 } $\mathrm{K}$ & 1 & 2 & 3 & 65 \\
\hline $\mathrm{NK}$ & 23 & 29 & 13 & 27 \\
\hline Total & 31 & 14 & 5 & 92 \\
\hline
\end{tabular}

The value of $x^{2}$ is .767 which falls short of the value of 5.99 required for significance at the .05 level.

TABLE 20

CHARACTER TRAIT RATINGS

(FIRST GRADE)

\begin{tabular}{|c|c|c|c|c}
\hline \multirow{2}{*}{ Group } & \multicolumn{3}{|c|}{$\begin{array}{c}\text { Response to } \\
\text { Directions }\end{array}$} & \multirow{2}{*}{ Total } \\
\cline { 2 - 5 } & 1 & 2 & 3 & 65 \\
\hline $\mathrm{K}$ & 17 & 28 & 20 & 27 \\
\hline NK & 6 & 12 & 9 & 92 \\
\hline Total & 23 & 40 & 29 & 9 \\
\hline
\end{tabular}

The value of $x^{2}$ is .169 which falls short of the value of 5.99 required for significance at the .05 level. 
TABLE 21

\section{CHARACTER TRAIT RATINGS}

(FIRST GRADE)

\begin{tabular}{c|c|c|c|c}
\hline \multirow{2}{*}{ Group } & \multicolumn{3}{|c|}{ Oral Expression } & \multirow{2}{*}{ Total } \\
\cline { 2 - 5 } & 1 & 2 & 3 & 65 \\
\hline $\mathrm{K}$ & 26 & 28 & 11 & 27 \\
\hline NK & 6 & 15 & 6 & 92 \\
\hline Total & 32 & 43 & 17 & \\
\hline
\end{tabular}

The value of $x^{2}$ is 3.67 which falls short of the value of 5.99 required for significance at the .05 level.

TABLE 22

\section{CHARACTER TRAIT RATINGS} (FIRST GRADE)

\begin{tabular}{c|c|c|c|c}
\hline \multirow{2}{*}{ Group } & \multicolumn{3}{|c|}{ Ability to Play } & \multirow{2}{*}{ Total } \\
\cline { 2 - 5 } K & 1 & 2 & 3 & 65 \\
\hline NK & 13 & 45 & 7 & 27 \\
\hline Total & 6 & 21 & 0 & 97 \\
\hline
\end{tabular}

The value of $x^{2}$ is .05 which falls short of the value of 5.99 required for significance at the .05 level. 
Tables $23,24,25,26,27,28,29,30,31$ and 32 show the comparison of character trait ratings received from teachers by the children in the three fourth grades. There was no significant difference in the character trait ratings for those fourth graders who have had kindergarten and those fourth graders who had not had kindergarten experience, except in Table 30, Response to Directions. The value of $x^{2}$ in Table 30 is 7.087 , which is well above the 5.99 required at the .05 level. There was a significant difference in Response to Directions for children in fourth grade, the difference being in the favor of the child who had not had kindergarten experience.

\section{TABLE 23}

CHARACTER TRAIT RATINGS

(FOURTH GRADE)

\begin{tabular}{c|c|c|c|c}
\hline \multirow{2}{*}{ Group } & \multicolumn{3}{|c|}{ Self-Confidence } & Total \\
\cline { 2 - 5 } K & 1 & 2 & 3 & 52 \\
\hline NK & 22 & 21 & 9 & 27 \\
\hline Total & 15 & 6 & 6 & 79 \\
\hline
\end{tabular}

The value of $x^{2}$ is 2.605 which falls short of the value of 5.99 required for significance at the .05 level. 
TABLE 24

CHARACIER TRAIT RAIINGS

(FOURTH GRADE)

\begin{tabular}{c|c|c|c|c}
\hline \multirow{2}{*}{ Group } & \multicolumn{3}{|c|}{ Ability to Mix } & \multirow{2}{*}{ Total } \\
\cline { 2 - 5 } & 1 & 2 & 3 & 52 \\
\hline $\mathrm{K}$ & 17 & 27 & 8 & 27 \\
\hline NK & 13 & 13 & 1 & 79 \\
\hline
\end{tabular}

The value of $x^{2}$ is 1.80 which falls short of the value of 5.99 required for significance at the .05 level.

TABLE 25

CHARACTER TRAIT RAIINGS

(FOURTH GRADE)

\begin{tabular}{l|c|c|c|c}
\hline \multirow{2}{*}{ Group } & \multicolumn{3}{|c|}{ Friendliness } & \multirow{2}{*}{ Total } \\
\cline { 2 - 5 } & 1 & 2 & 3 & 52 \\
\hline $\mathrm{K}$ & 29 & 19 & 4 & 27 \\
\hline NK & 16 & 11 & 0 & 79 \\
\hline
\end{tabular}

The value of $x^{2}$ is 0.088 which falls short of the value of 5.99 required for significance at the .05 level. 
TABLE 26

CHARACTER TRAIT RATINGS

(FOURTH GRADE)

\begin{tabular}{c|c|c|c|c}
\hline \multirow{2}{*}{ Group } & \multicolumn{3}{|c|}{ Interest } & Total \\
\cline { 2 - 5 } K & 1 & 2 & 3 & 52 \\
\hline NK & 31 & 19 & 2 & 27 \\
\hline Tota1 & 20 & 7 & 0 & 79 \\
\hline
\end{tabular}

The value of $x^{2}$ is 1.49 which falls short of the value of 5.99 required for significance at the .05 level.

TABLE 27

CHARACTER TRAI'T RATINGS

(FOURTH GRADE)

\begin{tabular}{|c|c|c|c|c}
\hline \multirow{2}{*}{ Group } & \multicolumn{3}{|c|}{ Attention } & Total \\
\cline { 2 - 5 } & 1 & 2 & 3 & 52 \\
\hline $\mathrm{K}$ & 20 & 27 & 5 & 27 \\
\hline Total & 16 & 8 & 3 & 79 \\
\hline
\end{tabular}

The value of $x^{2}$ is 3.07 which falls short of the value of 5.99 required for significance at the .05 level. 
TABLE 28

CHARACTER TRAIT RATINGS

(FOURTH GRADE)

\begin{tabular}{l|c|c|c|c}
\hline \multirow{2}{*}{ Group } & \multicolumn{3}{|c|}{ Ability to Think } & \multirow{2}{*}{ Total } \\
\cline { 2 - 5 } \multicolumn{1}{c|}{1} & 1 & 2 & 3 & 52 \\
\hline NK & 28 & 18 & 6 & 27 \\
\hline Total & 15 & 8 & 4 & 79 \\
\hline
\end{tabular}

The value of $x^{2}$ is .020 which falls short of the value of 5.99 required for significance at the .05 level.

TABLE 29

CHARACTER TRAIT RATINGS

(FOURTH GRADE)

\begin{tabular}{|c|c|c|c|c}
\hline \multirow{2}{*}{ Group } & \multicolumn{3}{|c|}{ Originality } & Total \\
\cline { 2 - 5 } $\mathrm{K}$ & 1 & 2 & 3 & 52 \\
\hline NK & 23 & 22 & 7 & 27 \\
\hline Total & 32 & 12 & 6 & 79 \\
\hline
\end{tabular}

The value of $x^{2}$ is .9035 which falls short of the value of 5.99 required for significance at the .05 level. 
TABLE 30

CHARACTER TRAIT RATINGS

(FOURTH GRADE)

\begin{tabular}{c|c|c|c|c}
\hline \multirow{2}{*}{ Group } & \multicolumn{3}{|c|}{$\begin{array}{c}\text { Response to } \\
\text { Directions }\end{array}$} & \multirow{2}{*}{ Total } \\
\cline { 2 - 5 } & 1 & 2 & 3 & 52 \\
\hline $\mathrm{K}$ & 14 & 30 & 8 & 27 \\
\hline NK & 15 & 6 & 6 & 79 \\
\hline
\end{tabular}

The value of $x^{2}$ is 7.087354 which is well above the 5.99 required at the .05 level. The significant difference is in the favor of the non-kindergarten child.

TABLE 31

CHARACTER TRAIT RATINGS

(FOURTH GRADE)

\begin{tabular}{l|c|c|c|c}
\hline \multirow{2}{*}{ Group } & \multicolumn{3}{|c|}{ Oral Expression } & \multirow{2}{*}{ Tota1 } \\
\cline { 2 - 5 } $\mathrm{K}$ & 1 & 2 & 3 & 52 \\
\hline $\mathrm{NK}$ & 28 & 18 & 6 & 27 \\
\hline Total & 14 & 8 & 5 & 79 \\
\hline
\end{tabular}

The value of $x^{2}$ is .0278 which falls short of the value of 5.99 required for significance at the .05 level. 
TABLE 32

CHARACTER TRAIT RATINGS

(FOURTH GRADE)

\begin{tabular}{c|c|c|c|c}
\hline \multirow{2}{*}{ Group } & \multicolumn{3}{|c|}{ Ability to Play } & \multirow{2}{*}{ Total } \\
\cline { 2 - 5 } $\mathrm{K}$ & 1 & 2 & 3 & 52 \\
\hline NK & 27 & 22 & 3 & 27 \\
\hline Tota1 & 14 & 13 & 0 & 79 \\
\hline
\end{tabular}

The value of $x^{2}$ is 0.0 which falls short of the value

of 5.99 required for significance at the .05 level.

\section{Comparison of Nine Weeks Achievement Ratings}

Tables 33, 34, and 35 show the comparison of achievement ratings received in the areas of reading, writing and mathematics by the children in the combined four first grades. These are teacher opinion achievement ratings. The numerical values of these ratings are as follows: $A=4, B=3, C=2, D=1$, and $F=0$. There was no significant difference in those ratings received by children who had kindergarten experience and those ratings received by children who had not had kindergarten experience.

Tables 36,37 , and 38 show the comparison of achievement ratings received by the children in the three fourth grades. There was no significant difference in ratings received by fourth graders who had kindergarten experience prior to first grade and ratings received by fourth graders who had no kindergarten experience. 
As all the differences, though not separately statistically significant, favored the children who had had kindergarten experience, it was decided to carry out a multivariate analysis of variance, considering the ratings as a continuous variable. Class means were used for the analysis, the data for which is given in Table 39.

The multivariate analysis yielded a Hotellings $\mathrm{T}^{2}$ of 34.5445 and and $F$ of 7.67 with 3 and 4 d.f. This is significant at the .05 level.

TABLE 33

NINE WEEKS ACHIEVEMENT RATINGS

(FIRST GRADE)

\begin{tabular}{l|c|c|c|c|c|c}
\hline \multirow{2}{*}{ Group } & \multicolumn{5}{|c|}{ Reading } & Tota1 \\
\cline { 2 - 7 } $\mathrm{K}$ & 0 & 1 & 2 & 3 & 4 & 65 \\
\hline NK & 1 & 10 & 12 & 4 & 0 & 27 \\
\hline Total & 3 & 22 & 45 & 14 & 8 & 92 \\
\hline
\end{tabular}

TABLE 34

NINE WEEKS ACHIEVEMENT RATINGS

(FIRST GRADE)

\begin{tabular}{c|c|c|c|c|c|c}
\hline \multirow{2}{*}{ Group } & \multicolumn{5}{|c|}{ Writing } & \multirow{2}{*}{ Total } \\
\cline { 2 - 7 } K & 0 & 1 & 2 & 3 & 4 & 65 \\
\hline NK & 2 & 10 & 35 & 16 & 2 & 27 \\
\hline Tota1 & 1 & 8 & 15 & 2 & 1 & 92 \\
\hline
\end{tabular}

$x^{2}=4.84$ 
TABLE 35

NINE WEEKS ACHIEVEYENT RATINGS

(FIRST GRADE)

\begin{tabular}{l|c|c|c|c|c|c}
\hline \multirow{2}{*}{ Group } & \multicolumn{5}{|c|}{ Nathematics } & Tota1 \\
\cline { 2 - 7 } & 0 & 1 & 2 & 3 & 4 & 65 \\
\hline $\mathrm{K}$ & 3 & 7 & 26 & 24 & 5 & 27 \\
\hline NK & 3 & 4 & 9 & 9 & 2 & 92 \\
\hline Total & 6 & 11 & 35 & 33 & 7 & 27 \\
\hline
\end{tabular}

$x^{2}=1.35$

TABLE 36

NINE WEEKS ACHIEVEMENT RATINGS

(FOURTH GRADE)

\begin{tabular}{c|c|c|c|c|c|c}
\hline \multirow{2}{*}{ Group } & \multicolumn{5}{|c|}{ Reading } & Total \\
\cline { 2 - 7 } & 0 & 1 & 2 & 3 & 4 & 52 \\
\hline $\mathrm{K}$ & 1 & 2 & 11 & 23 & 15 & 27 \\
\hline NK & 0 & 0 & 9 & 13 & 5 & 79 \\
\hline Total & 1 & 2 & 20 & 36 & 20 & $\mathrm{x}^{2}=1.15$
\end{tabular}

TABLE 37

NINE WEEKS ACHIEVEMENT RATINGS (FOURTH GRADE)

\begin{tabular}{l|c|c|c|c|c|c}
\hline \multirow{2}{*}{ Group } & \multicolumn{5}{|c|}{ Writing } & \multirow{2}{*}{ Total } \\
\cline { 2 - 7 } & 0 & 1 & 2 & 3 & 4 & 52 \\
\hline $\mathrm{K}$ & 0 & 2 & 11 & 25 & 14 & 27 \\
\hline NK & 0 & 1 & 7 & 11 & 8 & 79 \\
\hline Total & 0 & 3 & 18 & 36 & 22 & .41 \\
\hline
\end{tabular}


TABLE 38

NIAE WEEKS ACHIEVEYENT RATINGS

(FOURTH GRADE)

\begin{tabular}{l|c|c|c|c|r|c}
\hline \multirow{2}{*}{ Group } & \multicolumn{5}{|c|}{ Nathematics } & Tota1 \\
\cline { 2 - 7 } $\mathrm{K}$ & 0 & 1 & 2 & 3 & 4 & 52 \\
\hline $\mathrm{NK}$ & 0 & 2 & 13 & 19 & 18 & 27 \\
\hline Total & 0 & 1 & 5 & 11 & 10 & 79 \\
\hline
\end{tabular}

$x^{2}=.45$

TABLE 39

NINE WEEK'S ACHIEVEMENT RATINGS

GRADE ONE AVERAGES

DATA FOR MULTIVARIANCE

\begin{tabular}{lccc|ccc}
\hline & \multicolumn{3}{c|}{ Kindergarten } & \multicolumn{3}{c}{ Non-Kindergarten } \\
\hline & Reading & Writing & Math & Reading & Writing & Yiath \\
& 2.385 & 1.846 & 2.462 & 1.500 & 1.600 & 1.800 \\
& 2.056 & 2.111 & 2.000 & 1.800 & 1.800 & 2.000 \\
& 2.000 & 2.000 & 2.053 & 1.800 & 1.800 & 2.200 \\
& 2.267 & 2.400 & 2.933 & 1.857 & 2.000 & 2.571 \\
\hline Tota1 z & 8.708 & 8.357 & 9.448 & 6.957 & 7.2 & 8.571 \\
n & 4 & 4 & 4 & 4 & 4 & 4 \\
Grand & 2.177 & 2.089 & 2.362 & 1.739 & 1.800 & 2.143 \\
Mean & & & & & & \\
\hline
\end{tabular}


Comparison of Personal and Social Adjustment

Tables $40,41,42,43$ and 44 show the comparison of scores obtained from the California Test of Personality which was given to the four first grades. The $F$ values of each of the tables are less than the 5.99 needed for significance at the .05 level. There was no significant difference in the scores received by first grade children having had kindergarten experience and first grade chfldren who had not had kindergarten experience prior to entering first grade.

TABLE 40

PERSONAL AND SOCIAL ADJUSTMENT (FIRST GRADE)

\begin{tabular}{c|c|c}
\hline \multirow{2}{*}{ Room } & \multicolumn{2}{|c}{ Total Personal Worth } \\
\cline { 2 - 3 } & Kindergarten & Non-Kindergarten \\
\hline 1 & 5.93 & 6.00 \\
\hline 2 & 5.66 & 7.40 \\
\hline 3 & 5.75 & 5.60 \\
\hline 4 & 5.22 & 6.60 \\
\hline$M j$ & 5.64 & 6.40 \\
\hline
\end{tabular}

$F=3.28$ 
TABLE 41

PERSONAL AND SOCIAL ADJUSTMENT

(FIRST GRADE)

\begin{tabular}{c|c|c}
\hline \multirow{2}{*}{ Room } & \multicolumn{2}{|c}{ Total Personal Adjustment } \\
\cline { 2 - 3 } 1 & Kindergarten & Non-Kindergarten \\
\hline 2 & 27.00 & 28.42 \\
\hline 3 & 27.66 & 30.40 \\
\hline 4 & 29.33 & 32.00 \\
\hline Mj & 30.50 & 29.11 \\
\hline & 28.62 & 29.98 \\
\hline
\end{tabular}

TABLE 42

PERSONAL AND SOCIAL ADJUSTMENT (FIRST GRADE)

\begin{tabular}{c|c|c}
\hline \multirow{2}{*}{ Room } & Total School Relations \\
\cline { 2 - 3 } & Kindergarten & Non-Kindergargen \\
\hline 1 & 5.61 & 6.40 \\
\hline 2 & 5.42 & 5.70 \\
\hline 3 & 5.00 & 5.86 \\
\hline 4 & 5.00 & 5.40 \\
\hline Mj & 5.25 & 5.84 \\
\hline
\end{tabular}


TABLF: 43

PERSONAL AND SOCIAL ADJUSTMENT (FIRST GRADE)

\begin{tabular}{c|c|c}
\hline \multirow{2}{*}{ Room } & \multicolumn{2}{|c|}{ Total Social Adjustment } \\
\cline { 2 - 3 } 1 & Kindergarten & Non-Kindergarten \\
\hline 2 & 31.40 & 34.71 \\
\hline 3 & 30.50 & 34.90 \\
\hline 4 & 36.08 & 34.80 \\
\hline Mj & 32.55 & 34.20 \\
\hline & 32.63 & 34.65 \\
\hline
\end{tabular}

TABLE 44

PERSONAL AND SOCIAL ADJUSTMENT (FIRST GRADE)

\begin{tabular}{c|c|c}
\hline \multirow{2}{*}{ Room } & \multicolumn{2}{|c}{ Total Adjustment } \\
\cline { 2 - 3 } & Kindergarten & Non-Kindergarten \\
\hline 1 & 58.40 & 62.14 \\
\hline 2 & 58.16 & 67.20 \\
\hline 3 & 66.58 & 64.90 \\
\hline 4 & 61.88 & 66.20 \\
\hline$M j$ & 61.255 & 65.11 \\
\hline
\end{tabular}


Tables $45,46,47,48$, and 40 show the comparison of scores obtained from the California Test of Personality which was given to the three fourth grades. The $F$ values of each of the tables are less than the 5.99 needed for significance at the .05 level. There was no significant difference in the scores received by fourth grade children having had kindergarten experience and fourth grade children who had. not had kindergarten experience prior to entering first grade.

TABLE 45

PERSONAL AND SOCIAL ADJUSTMENT (FOURTH GRADE)

\begin{tabular}{c|c|c}
\hline \multirow{2}{*}{ Room } & \multicolumn{2}{|c}{ Total Personal Worth } \\
\cline { 2 - 3 } & Kindergarten & Non-Kindergarten \\
\hline 1 & 7.55 & 7.80 \\
\hline 2 & 8.21 & 7.44 \\
\hline 3 & 7.00 & 7.69 \\
\hline $\mathrm{Mj}$ & 7.59 & 7.64 \\
\hline
\end{tabular}

$\mathrm{F}=.018$ 
TABLE 46

PERSONAL AND SOCIAL ADJUSTMENT (FOURTH GRADE)

\begin{tabular}{c|c|c}
\hline \multirow{2}{*}{ Room } & \multicolumn{2}{|c}{ Total Personal Adjustment } \\
\cline { 2 - 3 } & Kindergarten & Non-Kindergarten \\
\hline 1 & 42.85 & 45.00 \\
\hline 2 & 43.63 & 40.10 \\
\hline 3 & 40.69 & 45.77 \\
\hline Mj & 42.39 & 43.62 \\
\hline \multicolumn{2}{c}{} & $F=.2307$
\end{tabular}

TABLE 47

PERSONAI AND SOCIAL ADJUSTMENT (FOURTH GRADE)

\begin{tabular}{c|c|c}
\hline \multirow{2}{*}{ Room } & \multicolumn{2}{|c}{ Total School Relations } \\
\cline { 2 - 3 } & Kindergarten & Non-Kindergarten \\
\hline 1 & 7.55 & 7.60 \\
\hline 2 & 7.42 & 5.88 \\
\hline 3 & 6.15 & 8.00 \\
\hline Mj & 7.04 & 7.16 \\
\hline
\end{tabular}


TABLE 48

PERSONAL AND SOCIAL ADJUSTMENT

(FOURTH GRADE)

\begin{tabular}{c|c|c}
\hline \multirow{2}{*}{ Room } & \multicolumn{2}{|c|}{ Total Social Adjustment } \\
\cline { 2 - 3 } & Kindergarten & Non-Kindergarten \\
\hline 1 & 50.20 & 52.00 \\
\hline 2 & 48.15 & 45.77 \\
\hline 3 & 48.30 & 47.38 \\
\hline Mj & 48.88 & 48.38 \\
\hline
\end{tabular}

TABLE 49

PERSONAL AND SOCIAL ADJUSTMENT (FOURTH GRADE)

\begin{tabular}{c|c|c}
\hline \multirow{2}{*}{ Room } & \multicolumn{2}{|c|}{ Total Adjustment } \\
\cline { 2 - 3 } & Kindergarten & Non-Kindergarten \\
\hline 1 & 93.05 & 97.00 \\
\hline 2 & 91.78 & 84.77 \\
\hline 3 & 89.77 & 93.15 \\
\hline Mj & 91.53 & 91.64 \\
\hline
\end{tabular}




\section{Comparison of Achievement Scores}

Table 50 snows the comparison of raw scores obtained from the SRA Standard Achievement Test given to the three fourth grades the second semester of their third year in school. The value of $F$ is 2.15 which falls short of the 5.99 required for significance at the .05 leve1. There was no significant difference in the achievement scores of children who had had kindergarten experience and achievement scores of children who had not had kindergarten experience prior to entering first grade.

TABLE 50

ACHIEVEMENT TEST (FOURTH GRADE)

\begin{tabular}{c|c|c}
\hline \multirow{2}{*}{ Room } & \multicolumn{2}{|c}{ Raw Scores } \\
\cline { 2 - 3 } 1 & Kindergarten & Non-Kindergarten \\
\hline 2 & 121.08 & 130.00 \\
\hline 3 & 129.77 & 115.43 \\
\hline Mj & 128.11 & 123.80 \\
\hline & 126.320 & 123.076 \\
\hline
\end{tabular}

Comparison of Kindergarten Attendance and Socio-Economic Level

Table 51 shows the relationship between socio-economic level and kindergarten attendance for the children who were enrolled in first grade during the school year 1971-72. 
TABLE 51

KINDERGARTEN ATTENDANCE AND SOCIO-ECONOMIC LEVEL

\begin{tabular}{l|c|c|c}
\hline Leve1 & $\mathrm{K}$ & $\mathrm{NK}$ & Total \\
\hline Upper & 30 & 9 & 39 \\
Lower & 25 & 13 & 38 \\
\hline Total & 55 & 22 & 77 \\
\hline
\end{tabular}

The value of chi square for Table 51 is 1.17 , which is below the value of 3.84 required for significance at the .05 level.

Table 52 shows the relationship between socio-economic level and kindergarten attendance for the children who were enrolled in first grade during the school year 1967-68. These children are now the fourth graders at Moran School.

TABLE 52

\section{KINDERGARTEN ATTENDANCE AND SOCIO-ECONOMIC LEVEL}

\begin{tabular}{l|lr|r}
\hline \multirow{2}{*}{ Level } & \multicolumn{2}{|c|}{ Fourth Grade } & \\
\cline { 2 - 4 } Upper & $\mathrm{K}$ & $\mathrm{NK}$ & Total \\
\hline Lower & 23 & 4 & 27 \\
\hline Tota1 & 21 & 14 & 35 \\
\hline
\end{tabular}

The value of chi square for Table 52 is 4.69 , which is above the 3.84 required for significance at the .05 level. This table shows a difference in the socio-economic level of children who had 
kindergarten experience and the socio-economic level of children who had not had kindergarten experience. A significant proportion of children who had kindergarten were of the upper socio-economic level. 
CHAPTER V

CONCLUSIONS

The data presented in the previous chapter is here related to the fourteen hypotheses.

Hypothesis 1.--There is no significant difference in the school readiness of first grade children who have had kindergarten experience and school readiness of children who have not had kindergarten experience. This hypothesis was not upheld. There was a highly significant difference in school readiness of children enrolled in the first grade at the Osceola School during the school year 197172, the significance being in the favor of the child who had had kindergarten.

Hypothesis 2.--There is no significant difference in the mean intelligence quotient of first grade children who have had kindergarten experience and the mean intelligence quotient of first grade children who have not had kindergarten experience. This hypothesis was not upheld. There was a highly significant difference in intelligence quotients of children enrolled in the first grade at the Osceola School during the school year 1971-72, the significance being in the favor of the child who had had kindergarten.

Hypothesis 3.--There is no significant difference in the mean intelligence quotient of fourth grade children who have had kindergarten experience and the mean intelligence quotient of fourth grade 
children who have not had kindergarten experience. This hypothesis was upheld.

Hypothesis 4.--There is no significant difference in the social adjustment of first grade children who have had kindergarten experience and the social adjustment of first grade children who have not had kindergarten experience. This hypothesis was not upheld. There was a significant difference in the proportion of "stars", the significance being in the favor of the child who had had kindergarten. There was no significant difference in the proportion between children who had had kindergarten and children who had not had kindergarten of "averages", "neglectees", or "isolates." A "star" is identified as a child who has been chosen by six or more of his fellow students, an "average" is identified as a child who had either two, three, four, or five fellow students who chose him. A "neglectee" is identified as a child who has been chosen by only one of his fellow students and an "isolate" is identified as a child who has had none of his fellow students choose him:

Hypothesis 5.--There is no significant difference in the social adjustment of fourth grade children who have had kindergarten experience and the social adjustment of fourth grade children who have not had kindergarten experience. This hypothesis was not upheld. There was a significant difference in the proportion of "averages" and "neglectees." The significance in the proportion of "neglectees" was in the favor of the children who had not had kindergarten experience. The significance in the proportion of "averages" was in the favor of the child who had had kindergarten experience. 
Hypothesis 6.--There is no significant difference in teacher judged character trait ratings for first grade children who have had kindergarten experience and teacher judged character trait ratings for first grade children who have not had kindergarten experience. This hypothesis was upheld.

Hypothesis 7. - There is no significant difference in teacher judged character trait ratings for fourth grade children who have had kindergarten experience and teacher judged character trait ratings for fourth grade children who have not had kindergarten experience. This hypothesis was not upheld. There was a significant difference in teacher ratings for the trait, Response to Directions, the significance being in the favor of the child who had not had kindergarten experience.

Hypothesis 8.--There is no significant difference in teacher opinion achievement ratings for first grade children who have had kindergarten experience and teacher opinion achievement ratings for first grade children who have not had kindergarten experience. This hypothesis was upheld.

Hypothesis 9.--There is no significant difference in teacher opinion achievement ratings for fourth grade children who have had kindergarten experience and teacher opinion achievement ratings for fourth grade children who have not had kindergarten experience. This hypothesis was upheld.

Hypothesis 10. --There is no significant difference in the personal and social adjustment of first grade children who have 
had kindergarten experience and the personal and social adjustment of first grade children who have not had kindergarten experience. This hypothesis was upheld.

Hypothesis 11.--There is no significant difference in the personal and social adjustment of fourth grade children who have had kindergarten experience and the personal and social adjustment of fourth grade children who have not had kindergarten experience. This hypothesis was upheld.

Hypothesis 12.--There is no significant difference in probability of later school success (fewer repetitions of grade levels) for children who have had kindergarten experience and probability of later school success for children who have not had kindergarten experience. This hypothesis was upheld.

Hypothesis 13.--There is no significant difference in achievement test scores of fourth grade children who have had kindergarten experience and achievement test scores of fourth grade children who have not had kindergarten experience. This hypothesis was upheld. Hypothesis 14.--There is no significant difference in socioeconomic background for those children having had kindergarten experience and socio-economic background for those children not having had kindergarten experience. This hypothesis was not upheld. There was no significant difference in the comparison of socioeconomic backgrounds and kindergarten or non-kindergarten attendance for the children enrolled in first grade during the year 1971-72. However, the comparison of socio-economic backgrounds and kindergarten or non-kindergarten attendance for the children who had been 
enrolled in the first grade for the year of 1967-68 did show a significance in the favor of the child who had had kindergarten experience prior to entering first grade. These are the 1971-72 fourth graders. 
CHAPTER VI

SUMMARY AND RECOMMENDATIONS

Summary

Adjustment to formal learning situations is a major problem for children entering our schools today. The results of a poor initial adjustment may effect the child's subsequent success in future school experiences. Some educators feel that an early childhood education will provide the ingredients necessary to guarantee a good adjustment as the child later enters a more formal educational atmosphere.

The purpose of this study was to discover what effect, if any, a kindergarten experience has upon the child's academic achievement and social adjustment in later school experiences.

One-hundred-seventy-one children were selected from the Penn-Harris-Madison School Corporation: ninety-two from the first grade at the Osceola School, and seventy-nine from the fourth grade at Moran School.

Each first grade child was given the Metropolitan Readiness Test and the SRA Primary Abilities Test for $\mathrm{K}-1$. Scores for the SRA Primary Abilities Test they were given as first graders in 1967-68 were compiled from the records of each fourth grade child.

Each first grade child and each fourth grade child participated in the construction of a sociogram. Teacher opinion ratings for ten 
character traits were given each of the first grade students and each of the fourth grade students. Teacher opinion nine weeks achievement grades were given for each of the first grade students and each of the fourth grade students.

Each of the first graders and each of the fourth graders was given the California Test of Personality. Scores were compiled for each fourth grade child for the SRA Achievement Test they were given as third grade students the year of 1970-71.

Readiness Test.--It was found in this study that there was a significant difference in the extent to which school beginners had developed in the skills and abilities that contribute to readiness for first grade instruction. A comparison of readiness scores for children entering first grade with prior kindergarten experience and children entering first grade without prior kindergarten experience shows the significance to be in the favor of the child who had had kindergarten experience. The analysis of the scores for separate tests showed that the greatest significant difference in readiness for first grade was in Test 1, Word Meaning and Test 4, Alphabet. There was no significant difference in the analysis of scores for the tests for Listening, Matching, Numbers and Copying.

Intelligence Quotient Scores.--The analysis of scores obtained from the SRA Primary Abilities Test for children in the first grade during the year 1971-72 showed a highly significant difference in the intelligence quotient scores of children who had had kindergarten experience prior to first grade and children who had not had kindergarten experience prior to first grade. This significance was in the 
favor of the child who had had kindergarten experience. The analysis of the scores obtained from the SRA Prinary Abilities Test for children in the first grade during the year 1967-68, who were the 197172 fourth graders, showed no significant difference in the intelligence quotient scores of children who had had kindergarten experience prior to first grade and children who had not had kindergarten experience prior to first grade.

Sociogram.--It was found in this study that there was a significance in the proportion of stars on a sociogram constructed from information provided the researcher by first grade students. This significance was in the favor of the child who had had kindergarten experience. There was no significant difference in the proportion of averages, neglectees, and isolates for first graders. There was a significance in the proportion of neglectees on a sociogram constructed from information provided the researcher by fourth grade children, the significance being in the favor of the child who had not had kindergarten. This study also shows a significance in the proportion of averages, the significance being in favor of the child who had had kindergarten. It was found in this study that there was no significance in the proportion of stars and isolates for fourth grade children who had had kindergarten experience and fourth grade children who had not had kindergarten experience. (A "star" is identified as a child who has been chosen by six or more of his fellow students. An "average" is identified as a child who has been chosen by either two, three, four, or five of his fellow students. A "neglectee" is identified as a child who has been chosen by only one of his fellow students 
and an "isolate" is identified as a child who had none of his fellow students choose him.)

Character Irait Ratings.--It was found in this study that there was no significant difference in ratings of ten character traits for first grade children who had kindergarten experience and first grade children who had not had kindergarten experience. This study also found no significant difference in teacher opinion ratings of ten character traits for fourth grade children who had kindergarten experience and fourth grade children who had not had kindergarten experience, except in Response to Directions. The significant difference in Response to Directions for fourth grade children was in the favor of the child who had not had kindergarten experience.

Nine Weeks Grades.--This research study found no significant difference in a comparison at the end of the first nine weeks of teacher opinion achievement ratings for children in the first grade who had kindergarten and children who had not had kindergarten prior to first grade. There was also no significant difference in a comparison at the end of the first nine weeks of teacher opinion achievement ratings for children in the fourth grade who had had kindergarten and children who had not had kindergarten prior to entering first grade.

California Personality Test.--It was found in this study that there was no significant difference in the personal and social adjustment of first graders who had kindergarten experience and first graders who had not had kindergarten experience. It was also 
found that there was no significant difference in the personal and social adjustment of fourth graders who had kindergarten experience and fourth graders who had not had kindergarten experience.

Achievement Test. - - It was found in this study that there was no significant difference in achievement for third graders who had kindergarten experience and for third graders who had not had kindergarten experience.

Socio-Economic Level and Kindergarten Attendance.--It was found in this study that there was no significant difference in proportion of chlldren attending kindergarten and socio-economic level for children in first grade during the year 1971-72. However, there was a significant difference in proportion of children attending kindergarten and socio-economic level for the fourth grade students who had been enrolled in first grade during the school year 1967-68. The findings in this study agree with the literature that a quality pre-school experience for children can enhance their total adjustment in future school experiences. The findings of this study would concur with the literature that a good kindergarten experience does contribute to the extent to which school beginners have developed in the skills and abilities that contribute to readiness for first grade instruction. The findings of this study do not disagree with the literature that feels more attention should be given to the parental environmental setting and its predictive relation to the child's functioning. The findings of this research study would agree with the literature that feels there are factors other than 
kindergarten experience which contribute to a child's success in educational experiences. This study would also agree with the literature that more should be known about the persistence of changes observed in children who have had pre-school education.

\section{Recommendations}

Due to the significant difference in readiness for first grade, it is recommended that all first grade children have the opportunity to attend kindergarten prior to entering first grade. It is recommended that a public kindergarten experience be available to all children so that the socio-economic level of the child will not prohibit his attending kindergarten. It is further recommended that, where public kindergarten is not available, the teachers of first grade children incluaje in their first grade program the development of skills which contribute to readiness for first grade.

This research indicated that the extent to which school beginners had developed in the skills and abilities that contribute to readiness for first grade instruction was greater for those children who had had kindergarten experience. However the advantage of those having kindergarten experience was not maintained through to the fourth grade. The reason for failure to maintain the advantages is not clear. Two explanations are possible. It may be that kindergarten experience provides a sort of "hot house" acceleration which further maturation in the 6 or 7 year old obliterates or perhaps the present school system fails to capitalize on the foundations laid. Further study of these possible explanations is recommended. 
A P P E N D I X 
APPENDIX A

METROPOLITAN READINESS TEST

INDIVIDUAL TEST SCORES 


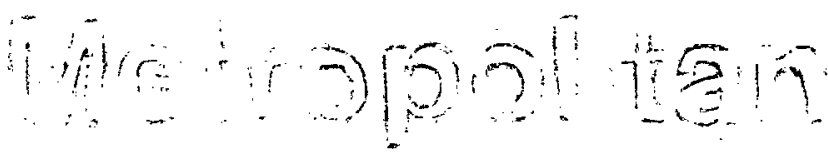

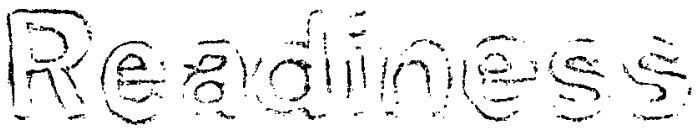

70

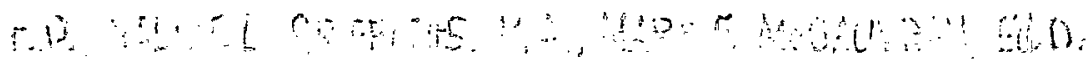

NAME

TEACHER $S C H O O L$

BOY GIRL DATE OF TESTING DATE OF BIRTH

CITY COUNTY STATE NUMBER OF MONTHS KINDERGARTEN TRAINING

GRADE

\begin{tabular}{|l|l|}
\hline \multicolumn{1}{|c|}{ TEST } & RAW SCORE \\
\hline 1. WORD MEANING & \\
\hline 2. LISTENING & \\
\hline 3. MATCHING & \\
\hline 4. ALPHABET & \\
\hline 5. NUMBERS & \\
\hline 6. COPYING & \\
\hline Total Score, Tests 1-6 & \\
\hline Percentile Rank & \\
\hline Letter Rating & \\
\hline
\end{tabular}

Readiness status, recommendation, other scores, remarks:

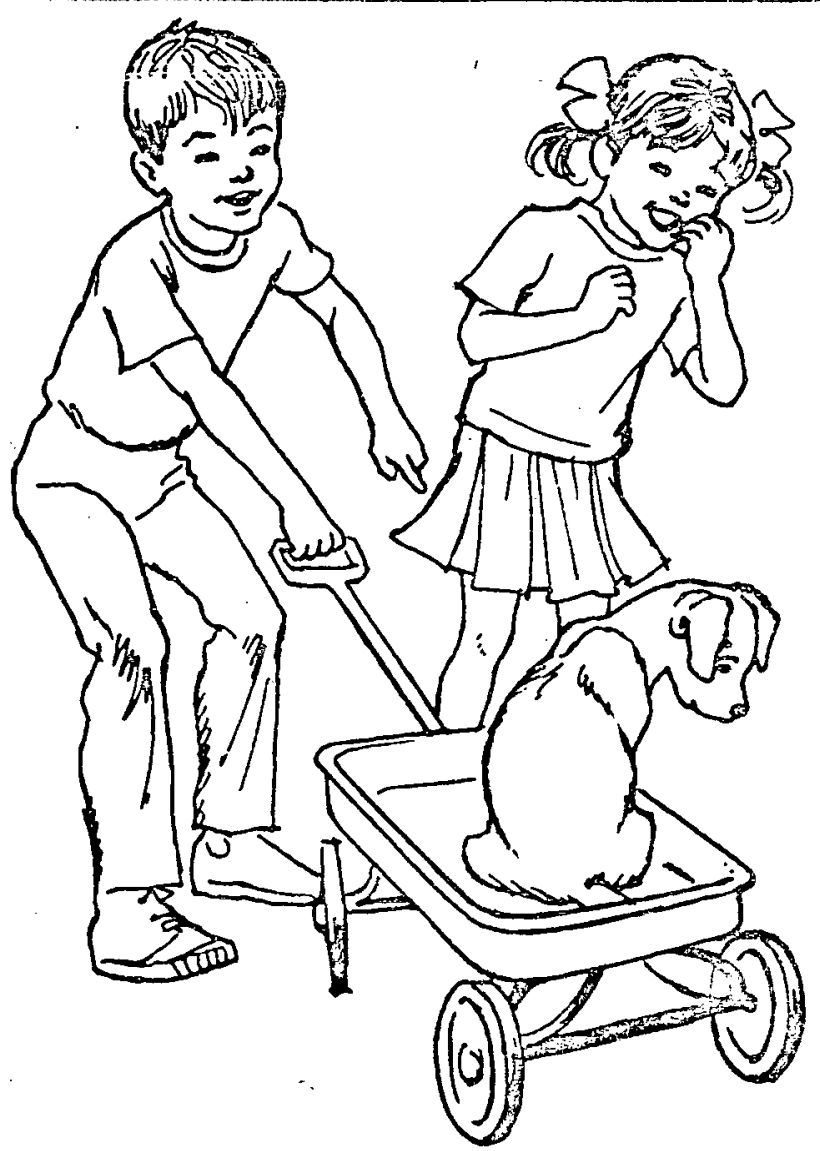

$+\cdots+\cdots$

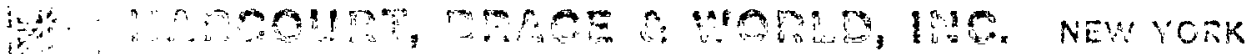





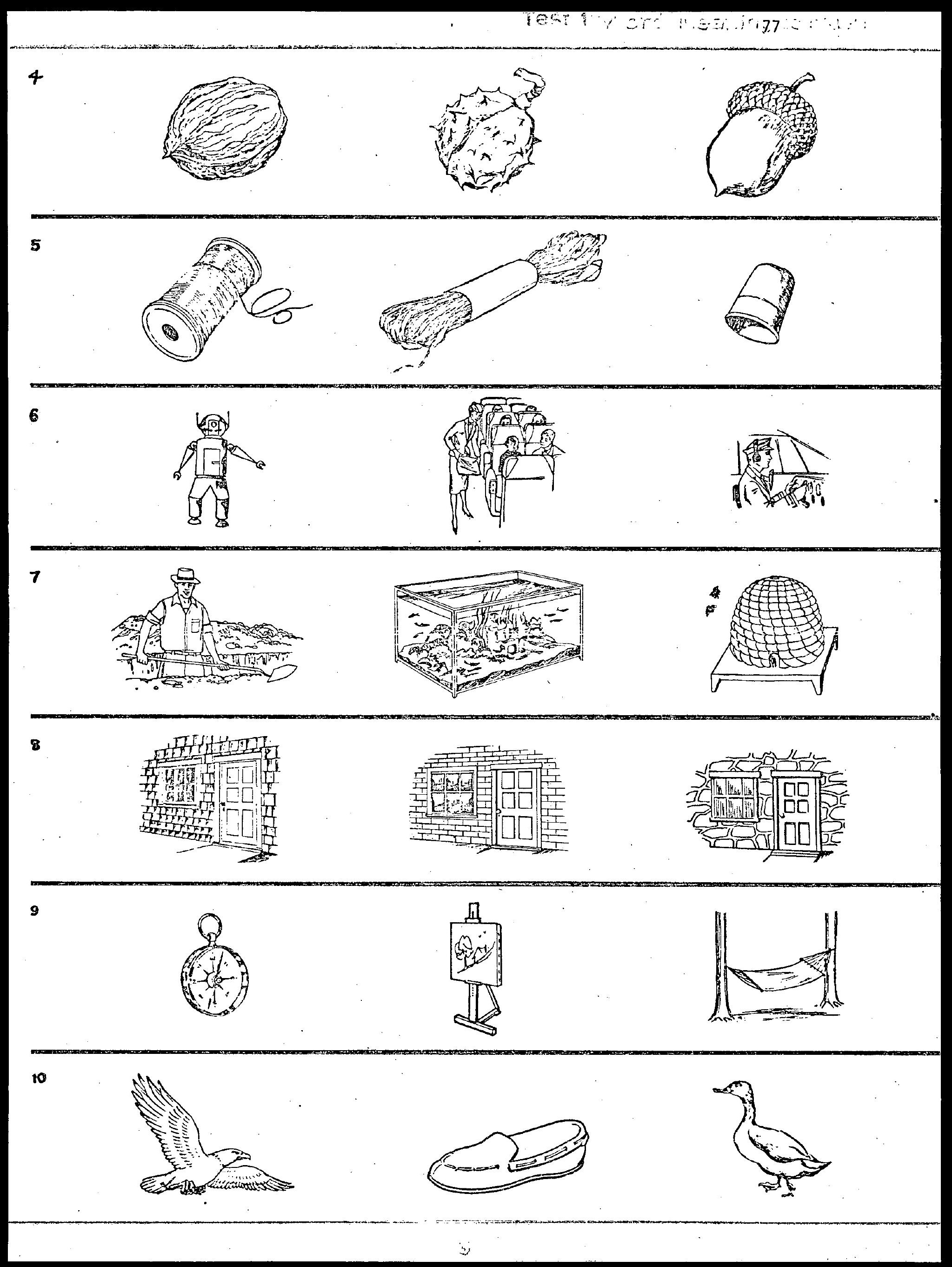


11
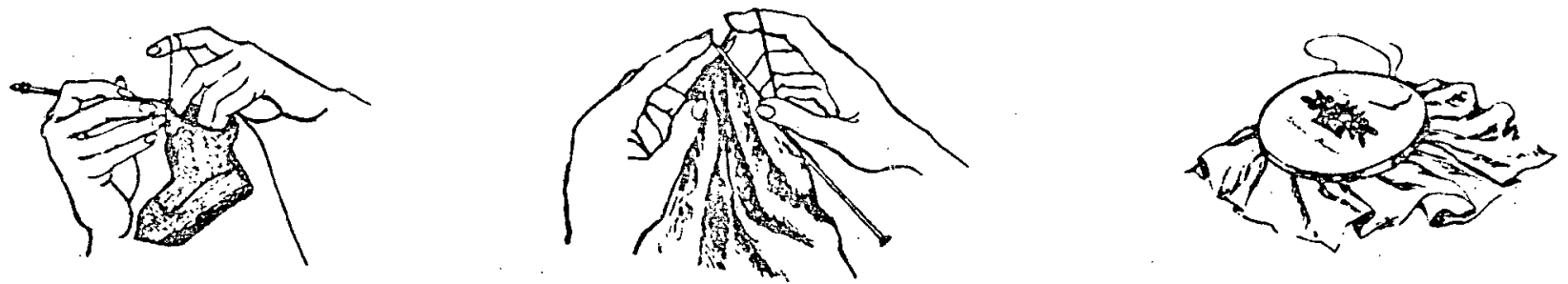

12
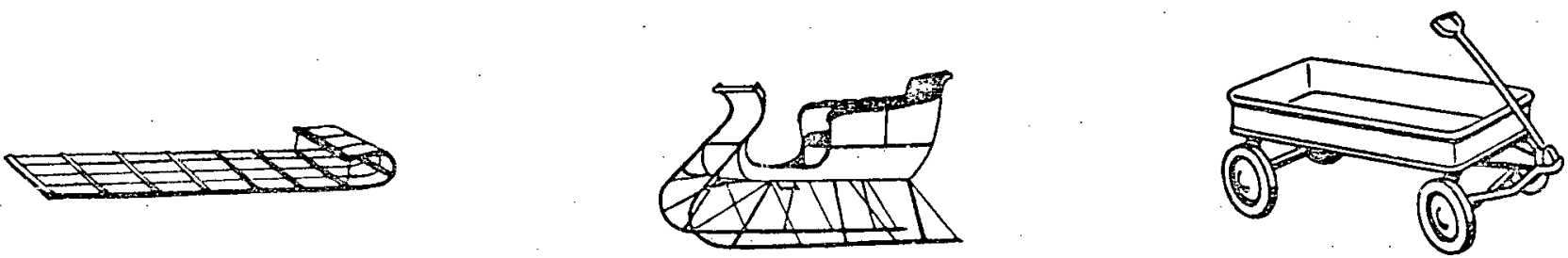

13
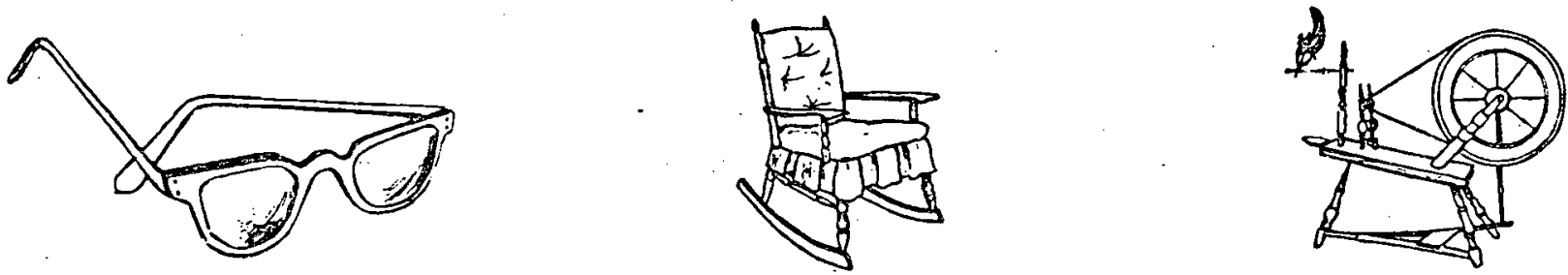

14
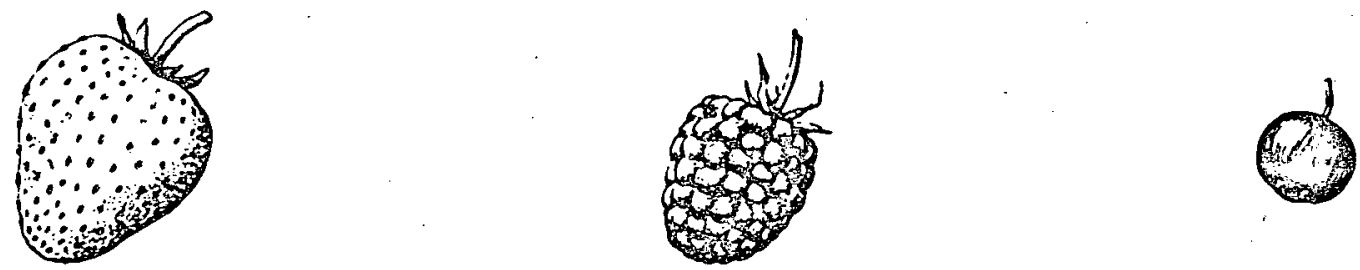

15
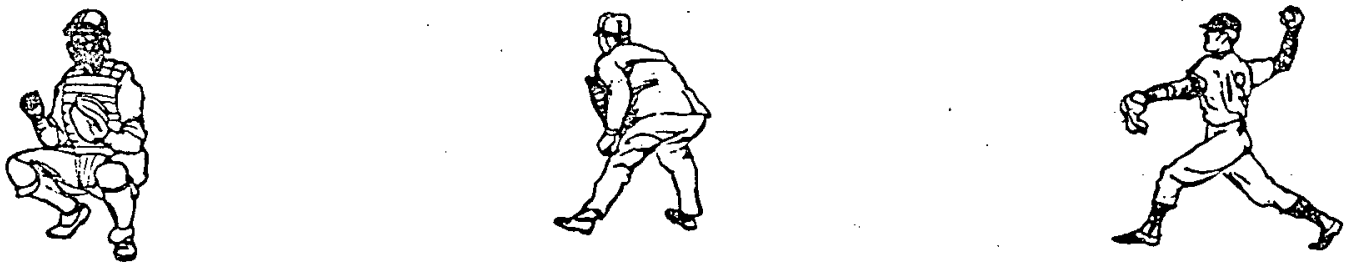

16
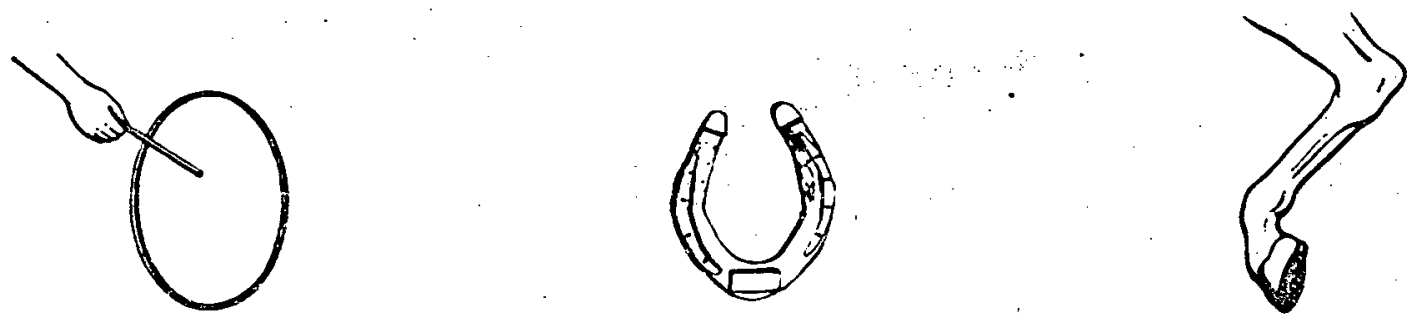
B

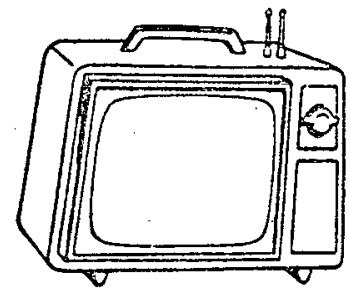

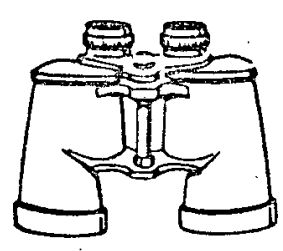

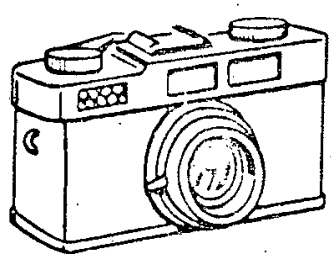

b
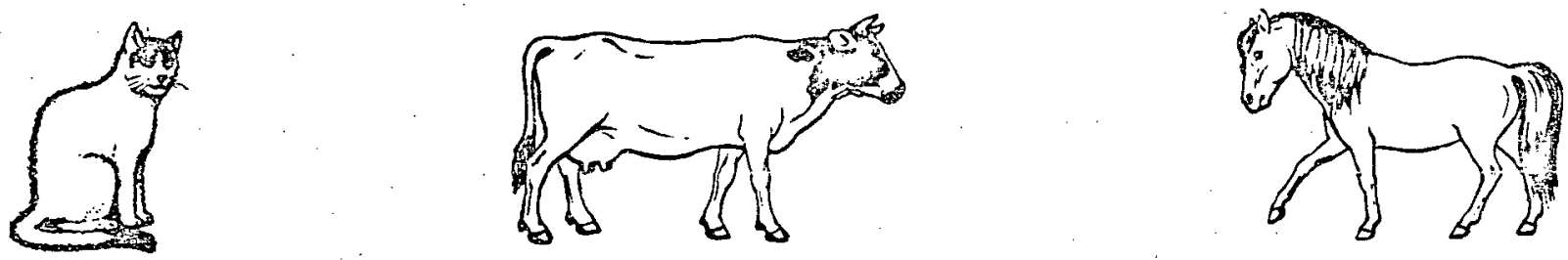

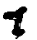
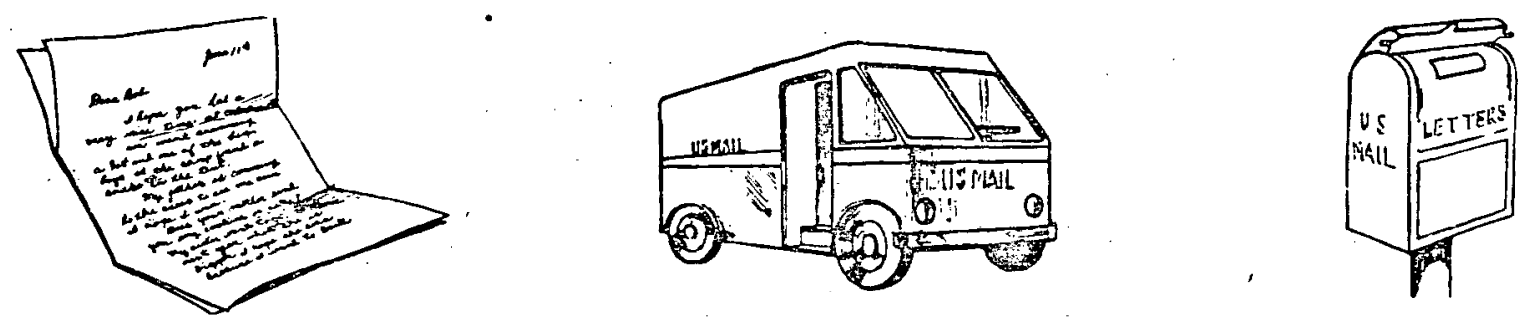

2
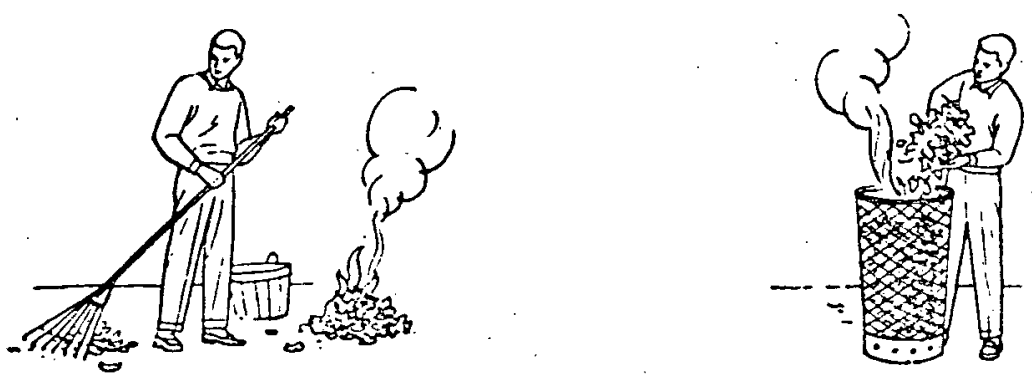

3
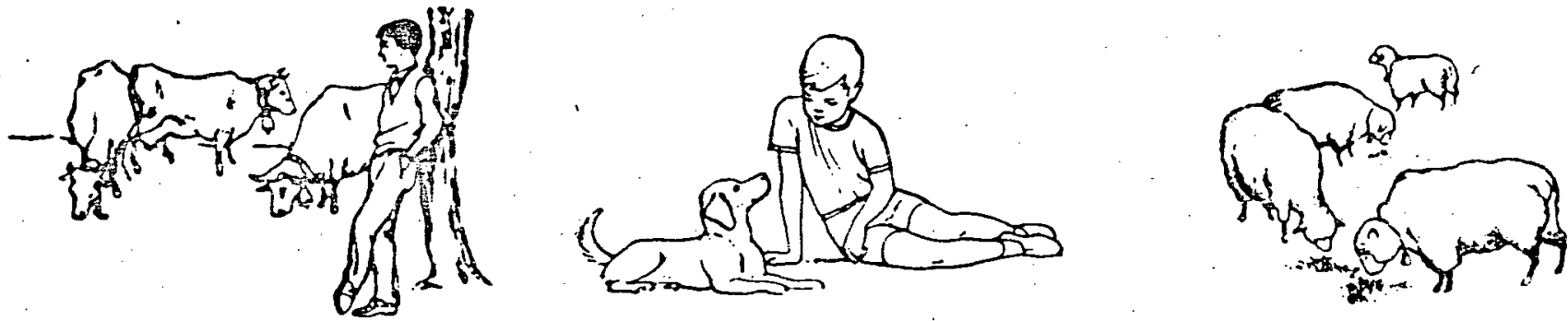
Tese 2 MATCHINOH

a
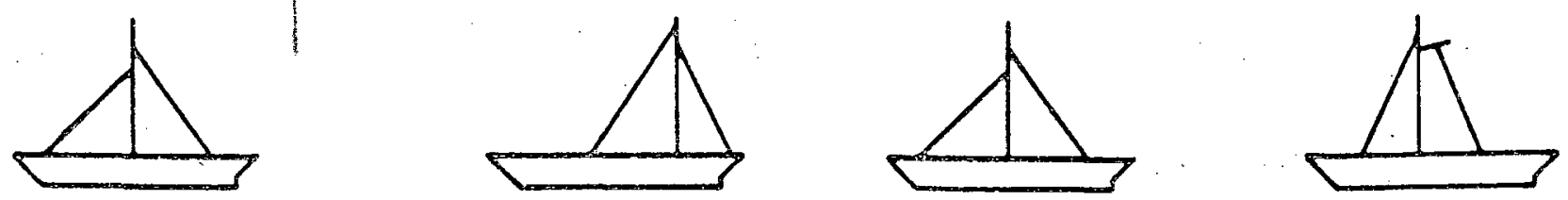

b

00

00

07

ON

$t$

WALK

WALK WAKL

TALK

2

STOP

TOPS

STOP.

2TOP

3

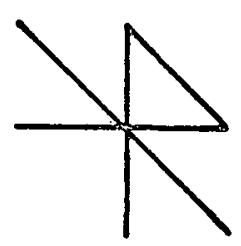

4

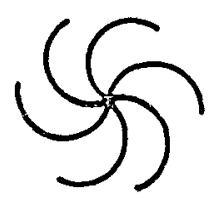

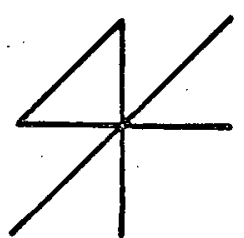
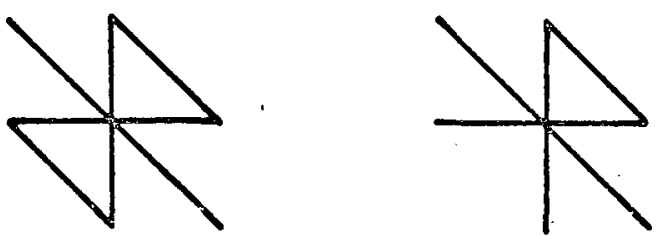

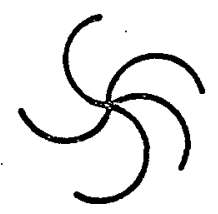

5
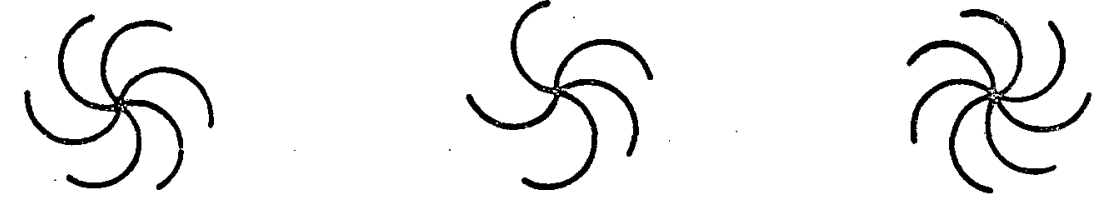

bard

darb

drab

6

STREET

\section{STREET \\ TREATS \\ STREAM}


7
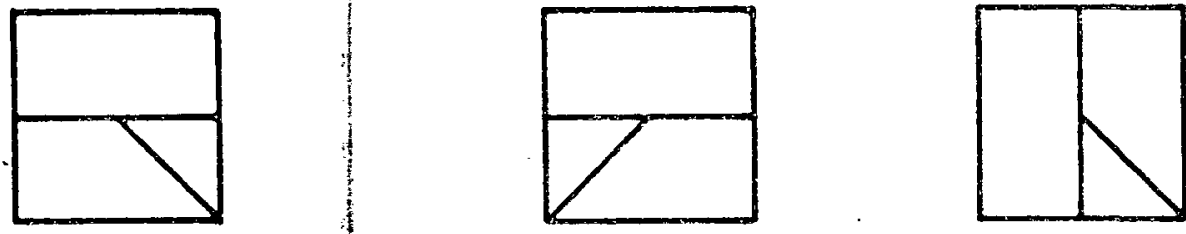

Eriven

8

park

prak

park

karp

9
winter
writer
winter
winret

10

TELEPHONE

TELEPHONE TELEGRAM

BLEPHANT

11

grad

grab

yard

grad

12
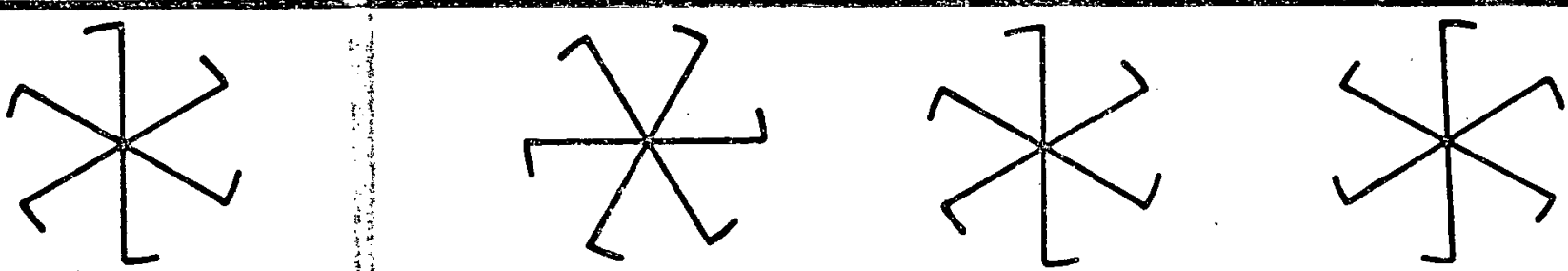

13
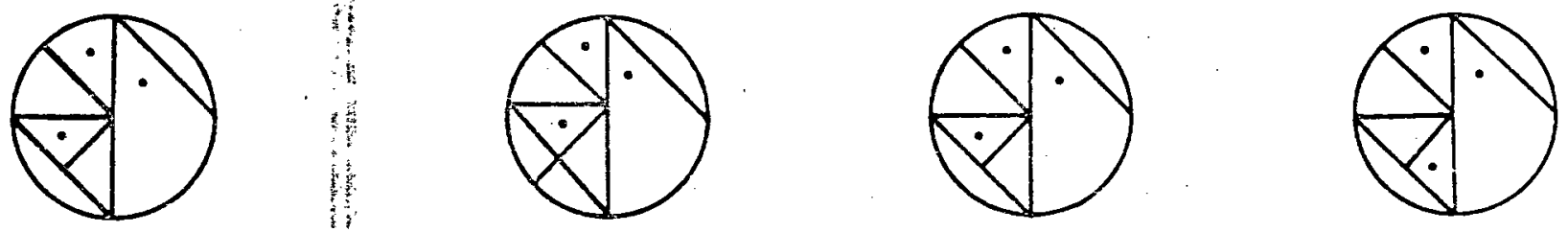

14
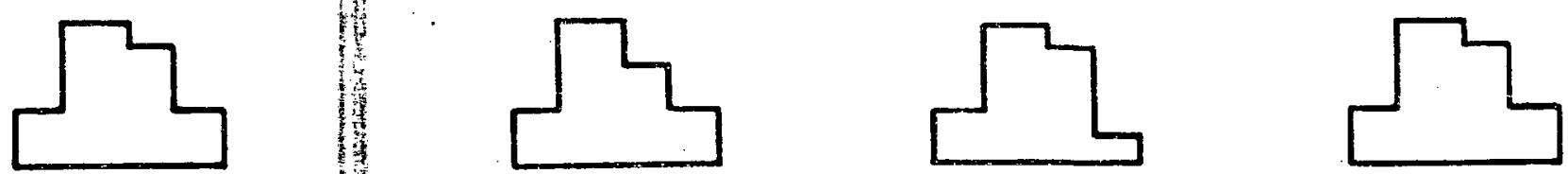

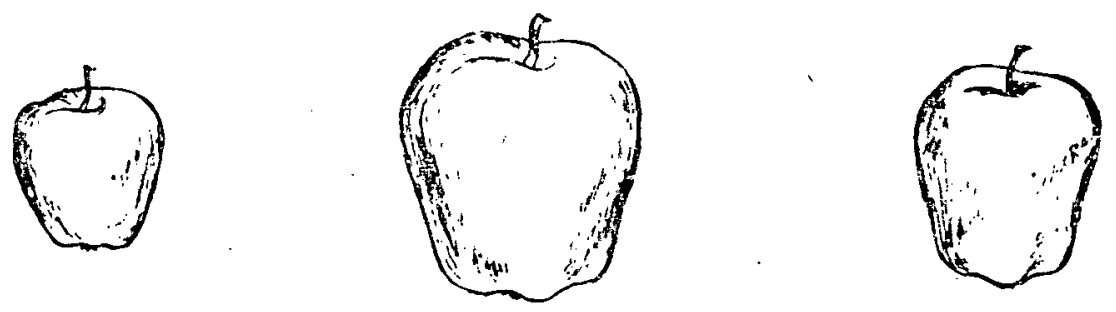

85

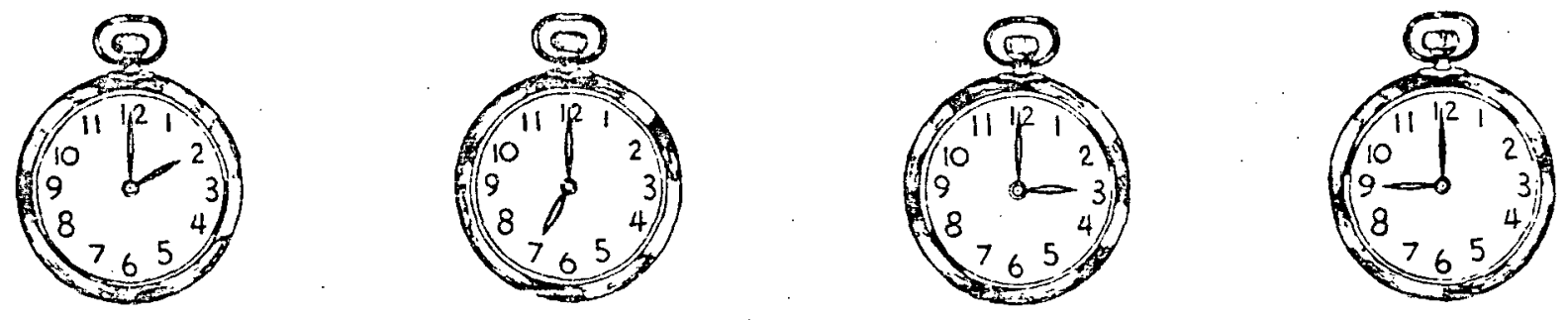

3
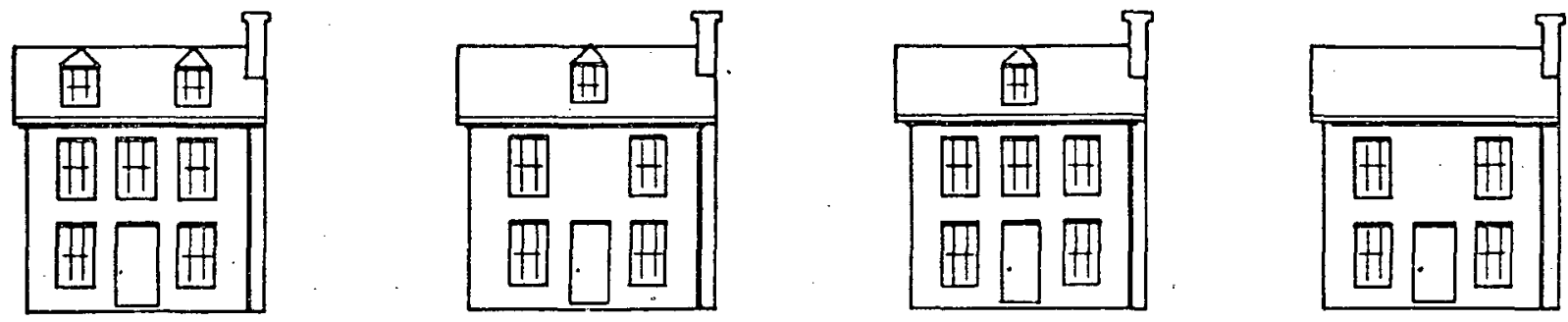

4
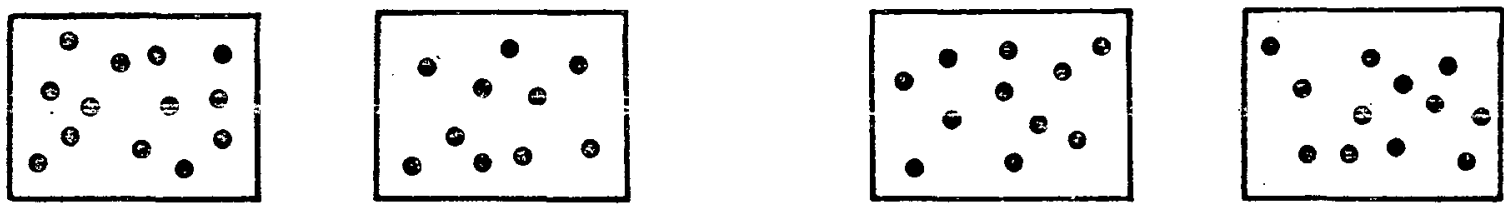

5
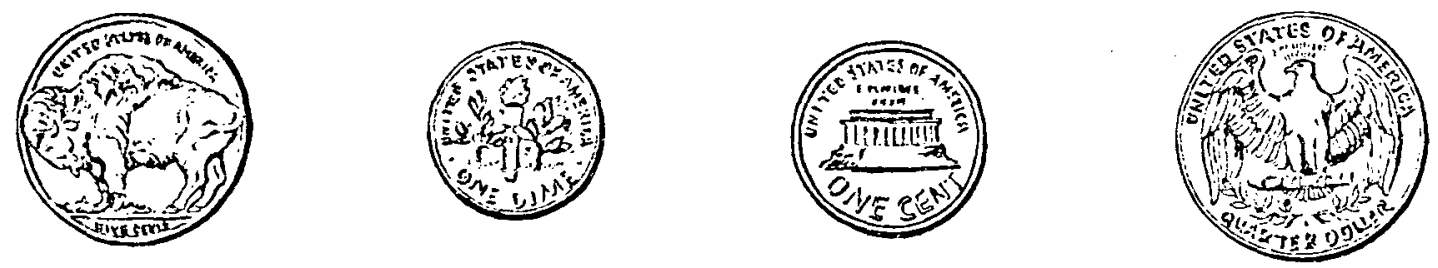

6
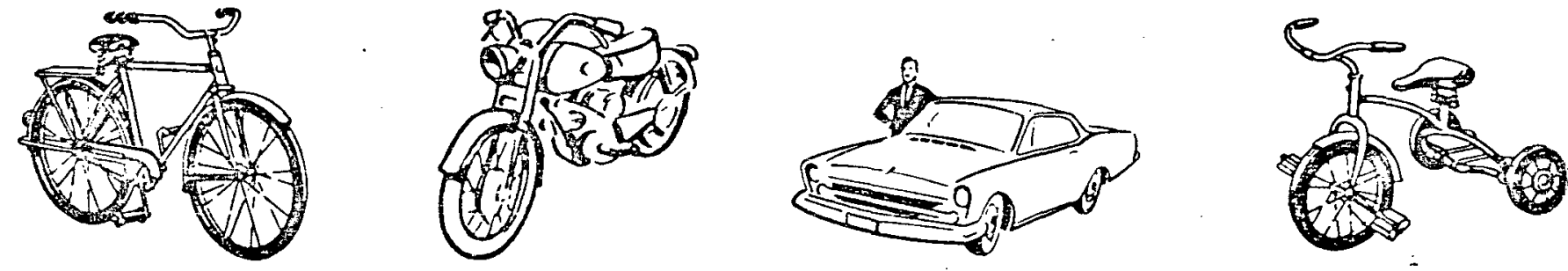

7

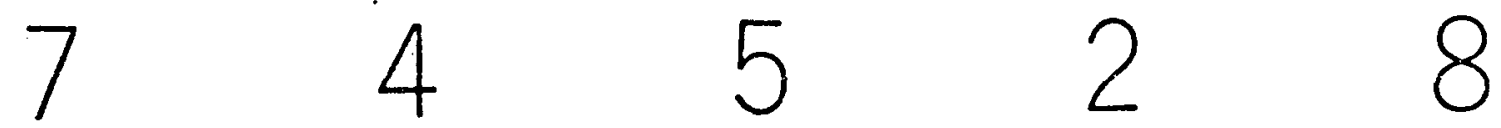


8

(3)
56

6
62

68
9

86
10

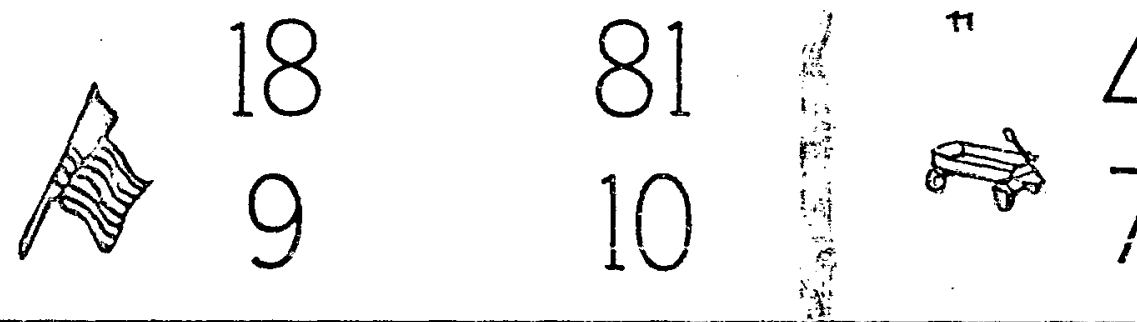

4

$7 \checkmark$
6

8

12

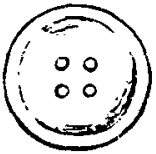

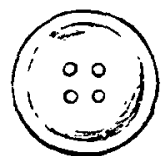
(1)

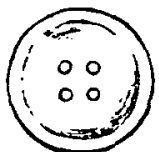
$\left(\begin{array}{lll}1 & 0 \\ 1 & 0 & 0 \\ 1 & 0 & 0\end{array}\right.$

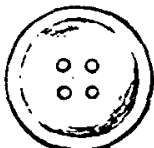
(1)

TS

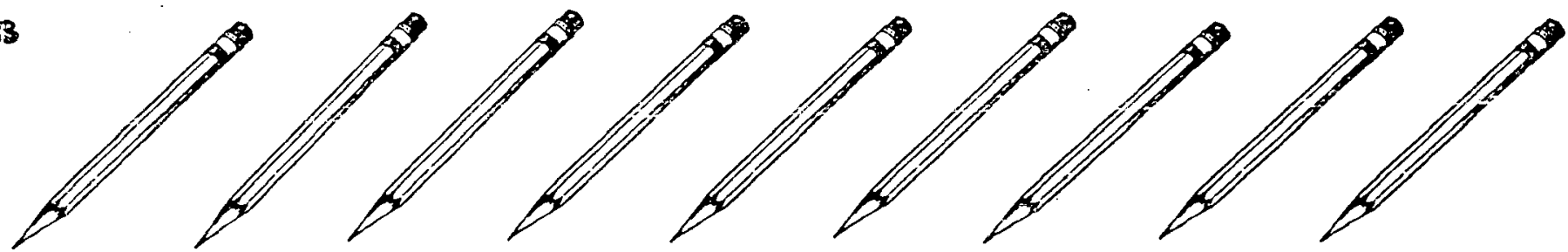

14

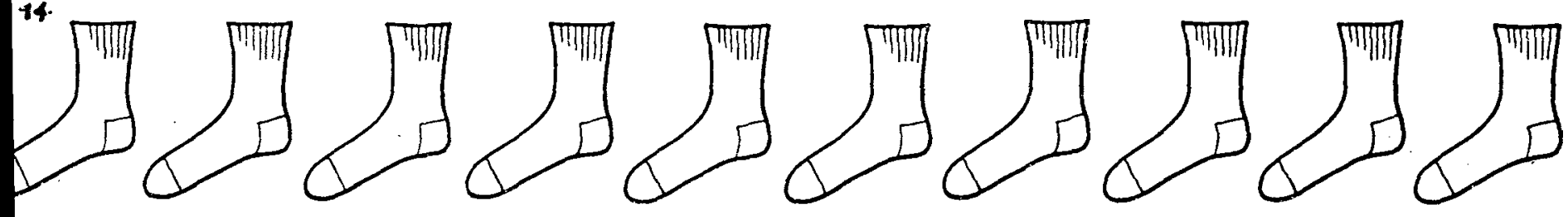

25
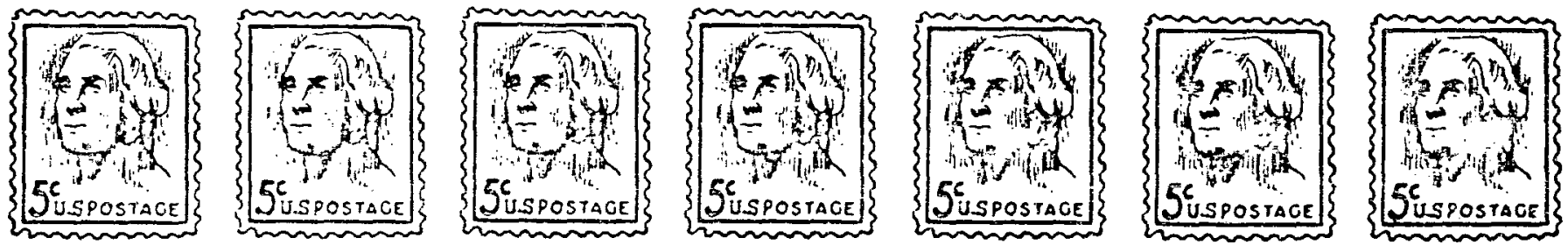

16
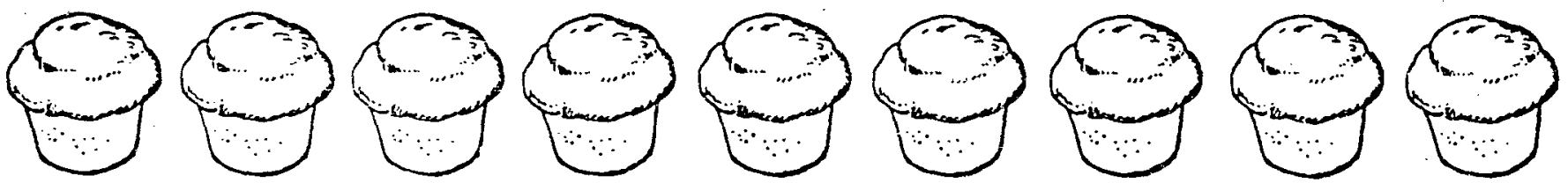


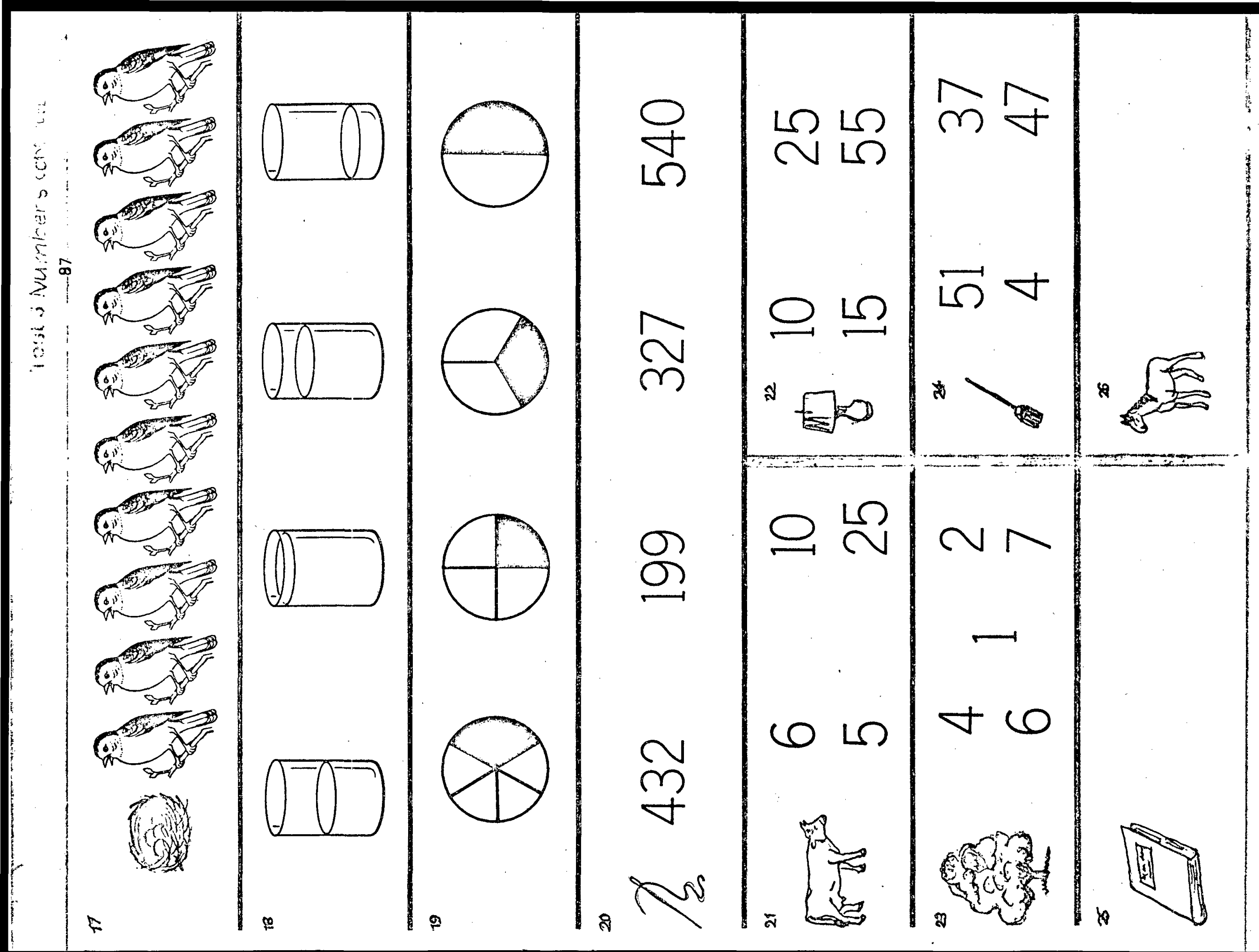


LEY'YlUL

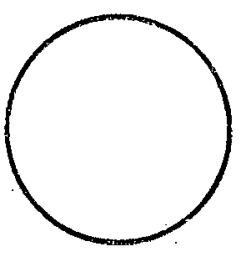

1

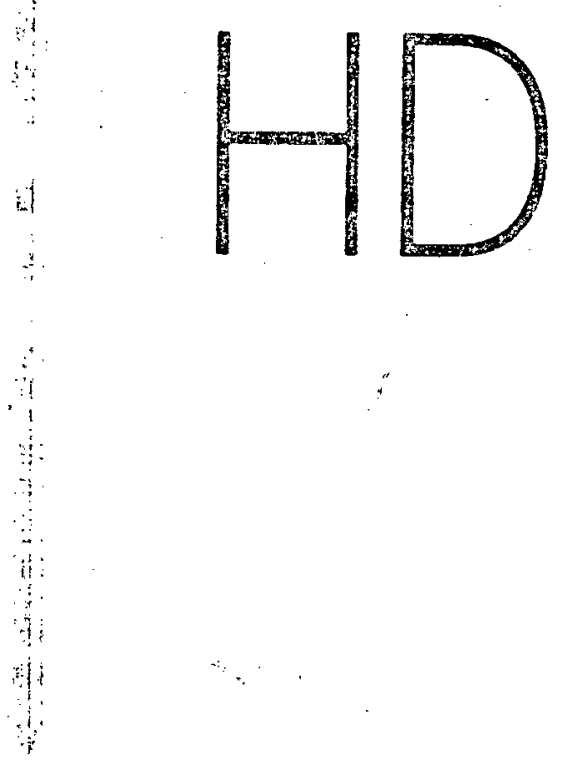

4.

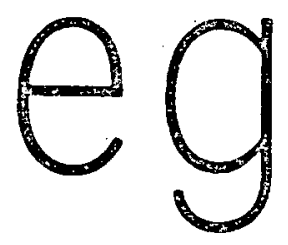

2

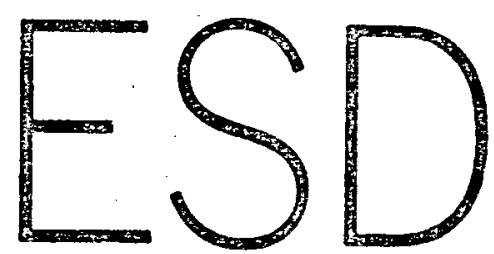

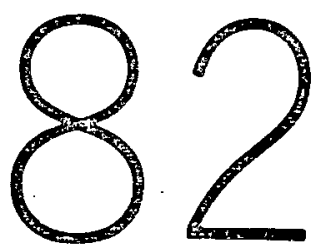

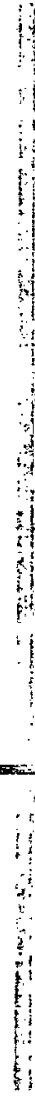

5

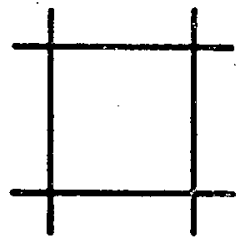

7

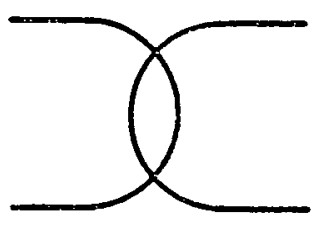

0

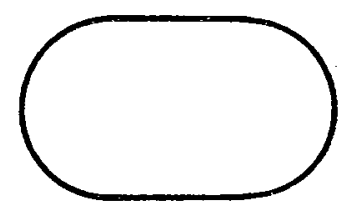

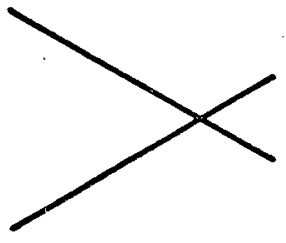


This space is to be used for drawing a man.

I MAN TEST 
METROPOLITAN READINESS TEST

INDIVIDUAL TEST SCORES

TOTAL SCORES

$K^{\text {Room }} \frac{1}{N K}$

$55 \quad 68$

78

79

61

56

68

72

66

32

57

63

75

61

66

54
53

46

59

59

54

62

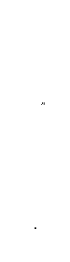

$\mathrm{K}^{\text {Room }} \underset{\mathrm{NK}}{1}$

$\begin{array}{rr}9 & 9 \\ 12 & 10 \\ 10 & 6 \\ 8 & 7 \\ 9 & 8 \\ 10 & 5\end{array}$

1110

11

4

8
9

10

6

10
9

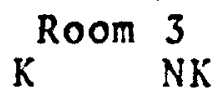

$64 \quad 41$

59

44

51

76

61

53

82

36

74

70

55

24

53

60

72

53

60

66 $\begin{array}{ll}\text { Room } & 4 \\ & \text { NK }\end{array}$

56

50

66

59

52

26

39

53

74

62

24

37

56

58

55

57

28

80

43

44

75

62

79

60

58

65

47

66

70

WORD MEANING

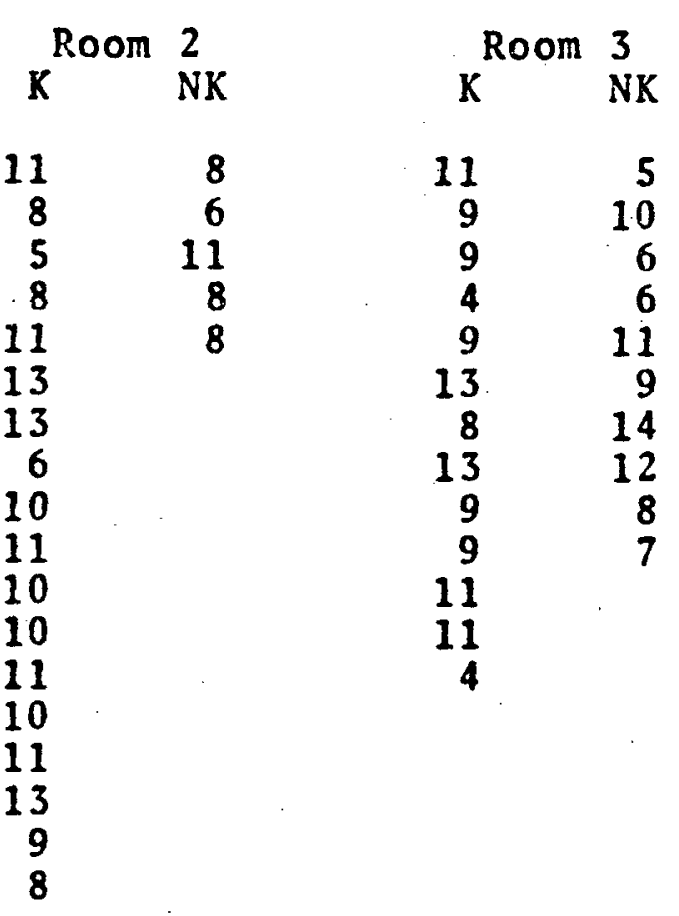

$\mathrm{K}^{\text {Room }} \stackrel{4}{\mathrm{NK}}$

$\begin{array}{rr}9 & 8 \\ 13 & 8 \\ 8 & 2 \\ 8 & 6 \\ 11 & 12\end{array}$

14

12

9

6

8

9

8

12

14

8

8
15 
METROPOLITAN READINESS TEST

INDIVIDUAL TEST SCORES

\section{LISTENING}

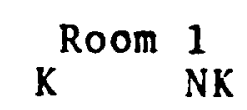

$\begin{array}{rr}11 & 10 \\ 10 & 10 \\ 10 & 7 \\ 11 & 13 \\ 10 & 8 \\ 11 & 7 \\ 9 & 10\end{array}$

12

11

12

11

8

12
9

$\mathrm{K}^{\text {Room }} \underset{\mathrm{NK}}{2} \quad \mathrm{~K}^{\text {Room } 3} \mathrm{NK}$

11

12

10
7

4

8

8.

10

12

15

9

8

12

8

8

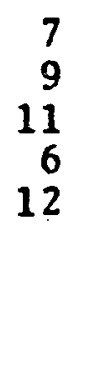

9
11
6
12
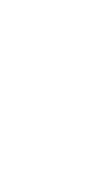

9

12.

12
119

$10 \quad 9$

$\begin{array}{rr}10 & 7 \\ 9 & 10\end{array}$

1466

107

$8 \quad 9$

12

7

13

8 $\begin{array}{ll}\text { Room } & 4 \\ & \text { NK }\end{array}$

9213

$7 \quad 10$

11

9

8

8

13

\section{MATCHING}

$\mathrm{K}^{\text {Room }} \stackrel{1}{\mathrm{NK}}$

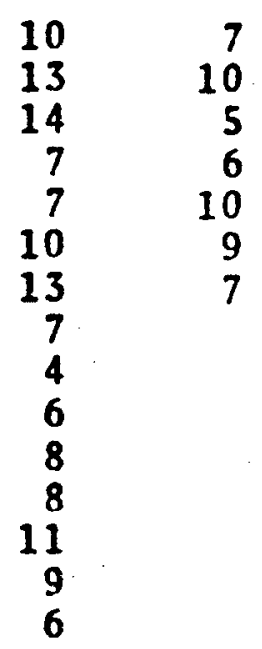

$\mathrm{K}^{\text {Room }} \underset{\mathrm{NK}}{2}$

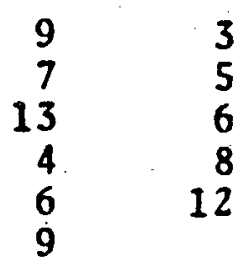

11

8

9
10

10

9

4

6

11

5

12
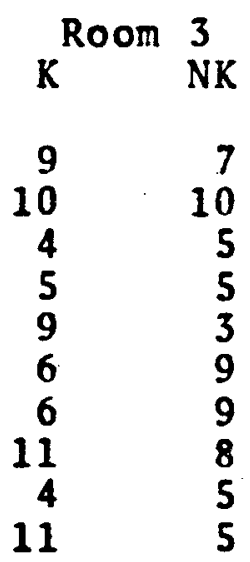

9.

9

1

\section{$\begin{array}{ll}\text { Room } & 4 \\ \text { NK }\end{array}$}

$5 \quad 11$

9

6

9

9

6

4

9

2

5

10

10

13

9 


\section{METROPOLITAN READINESS TEST \\ INDIVIDUAL TEST SCORES}

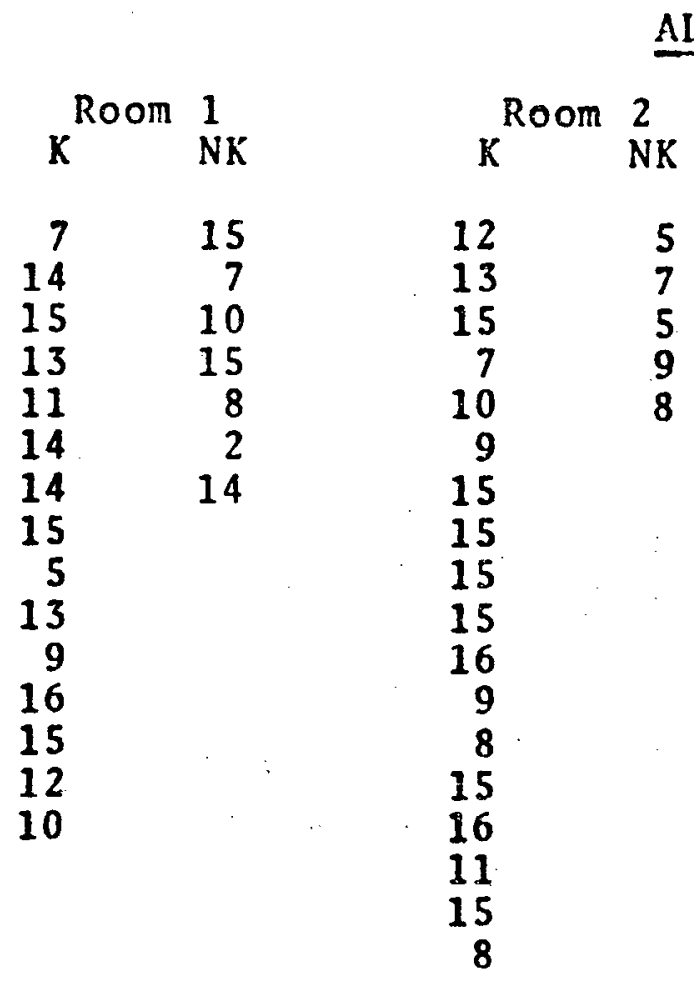

\section{ALPHABET}

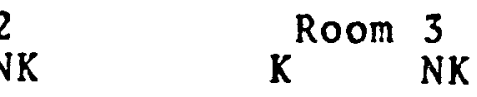

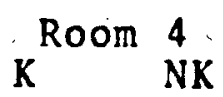
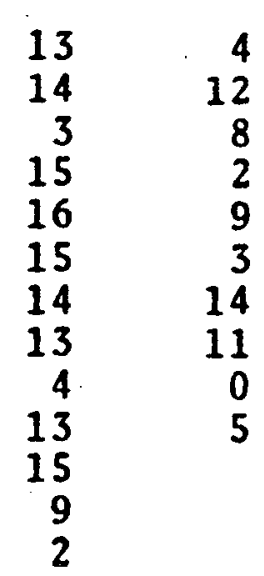

$12 \quad 15$

11

14

12

10.

14

4

16

15

3

16

8

15

12

10

11

8

13

15

\section{NUMBERS}

$K^{\text {Room }} \frac{1}{N K}$<smiles>[R]O[R]O[Na]</smiles>

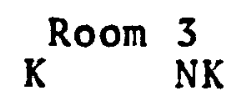

$12 \quad 16$

$16 \quad 10$

19

18

20

19

6

13

15

13

13

17

18

17

18

19

15

15

19

16

17

11

\section{NMERS}

18

6

13

15

17

11

$\begin{array}{rl}17 & 10 \\ 9 & 11\end{array}$

7

16

$\begin{array}{ll}13 & 2 \\ 21 & 7\end{array}$

$13 \quad 17$

$14 \quad 18$

$24 \quad 17$

8
17

$\begin{array}{ll}\text { Room } & 4 \\ \text { NK }\end{array}$

21

11

$\begin{array}{rr}15 & 17 \\ 8 & 9 \\ 9 & 7 \\ 15 & 14 \\ 8 & 17\end{array}$

11

$2 \frac{1}{2}$

22
12

13

18 
METROPOLITAN READINESS TEST

INDIVIDUAL TEST SCORES

\section{COPYING}

$K^{\text {Room }} \underset{\text { NK }}{1}$

$\begin{array}{rr}6 & 11 \\ 13 & 6\end{array}$

$11 \quad 10$

$5 \quad 5$

6.11

$\begin{array}{ll}8 & 3 \\ 7 & 7\end{array}$

4

5

10

10

11

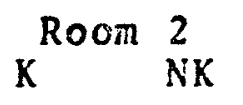

14
9

10

4
7

8

9

10

8

11

5

3

4

5

5

11

7
8
11
1
8

11
1
8

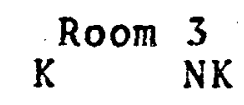

$\begin{array}{ll}4 & 8\end{array}$

$3 \quad 10$

9

4

$1 \frac{1}{6}$

6
4 $\begin{array}{ll}\text { Room } & 4 \\ & \text { NK }\end{array}$

$\begin{array}{rr}7 & 6 \\ 1 & 4 \\ 10 & 3 \\ 4 & 8 \\ 7 & 8\end{array}$

6

2

12

3

6

12

11

10

8

5

10

6

13 
APPENDIX B

PMA PRIMARY MENTAL ABILITIES TEST K-1

INDIVIDUAL TEST SCORES 


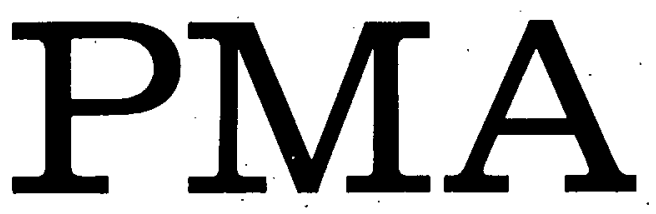

\section{Primary Mental}

\section{Abilities}

for Grades

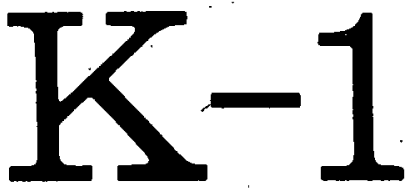

Revised 1962

\section{\begin{tabular}{l|l|l}
$\mathbf{S}$ & $\mathbf{R}$ & $\mathbf{A}$
\end{tabular}}

Science Research Associates, Inc.

259 East Erie Street, Chicago, Illinois 60611

A Subsidiary of IBM 


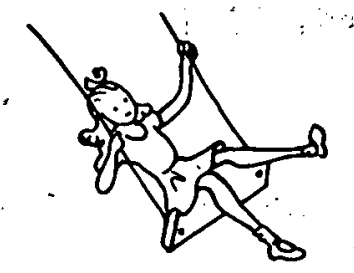

Verbal

Meaning

Test

Page 3
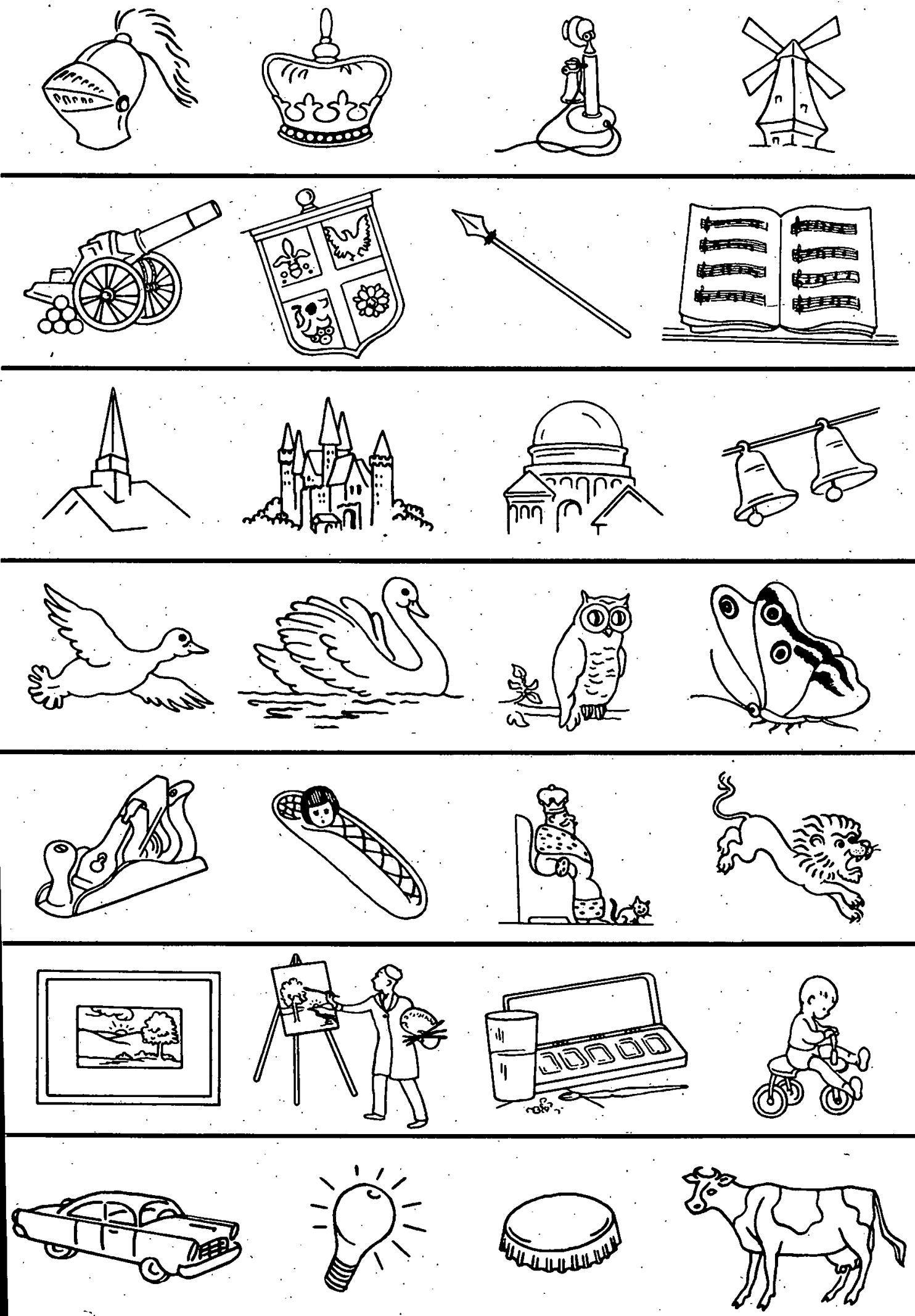


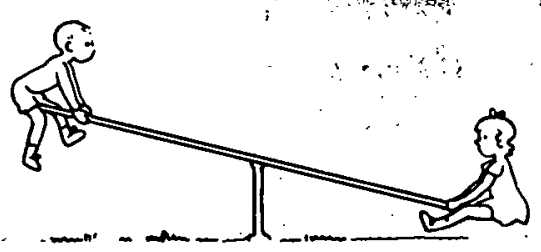

Verbal

Meaning

Test

Page 7
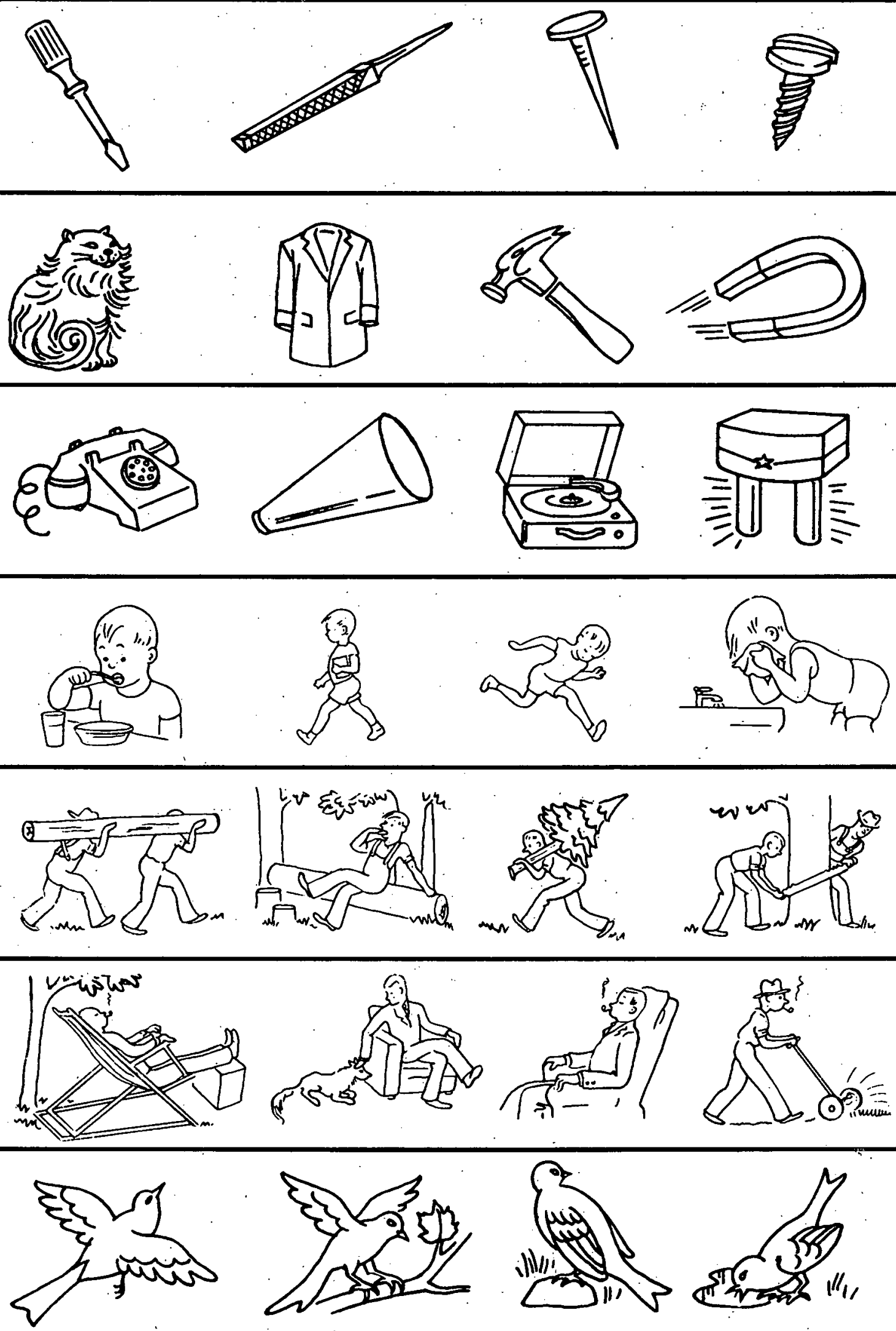


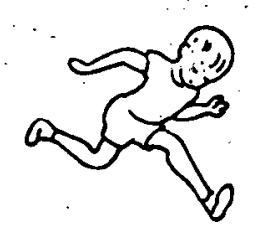
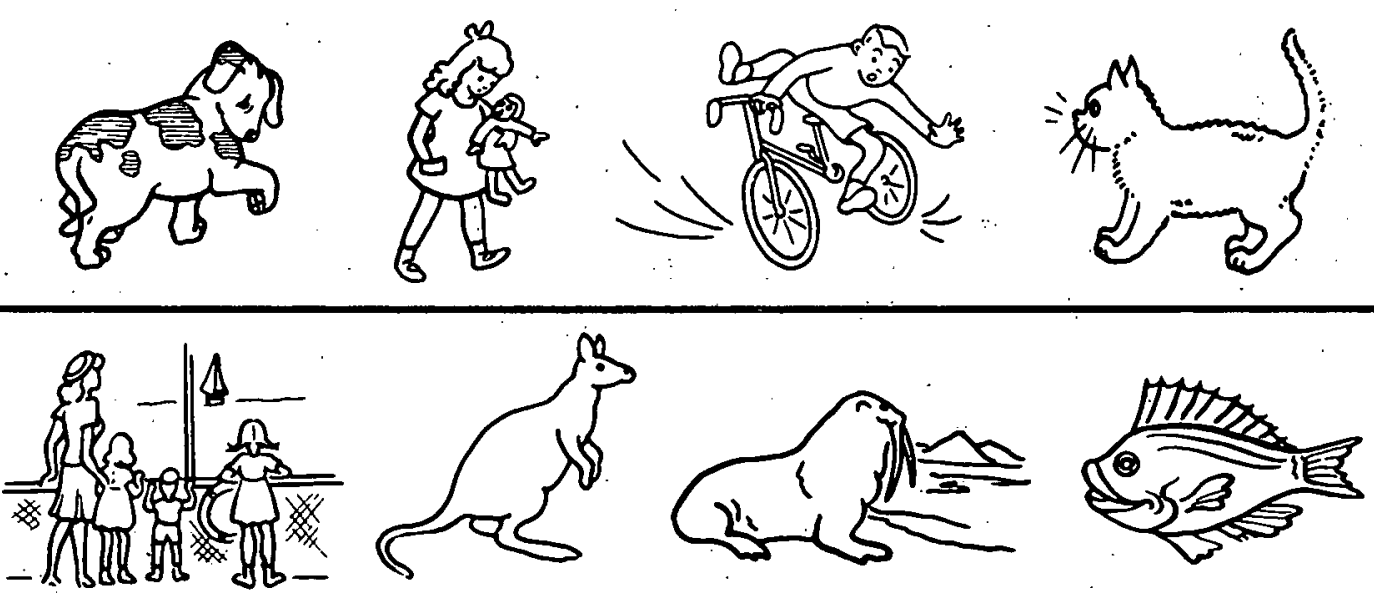

(200
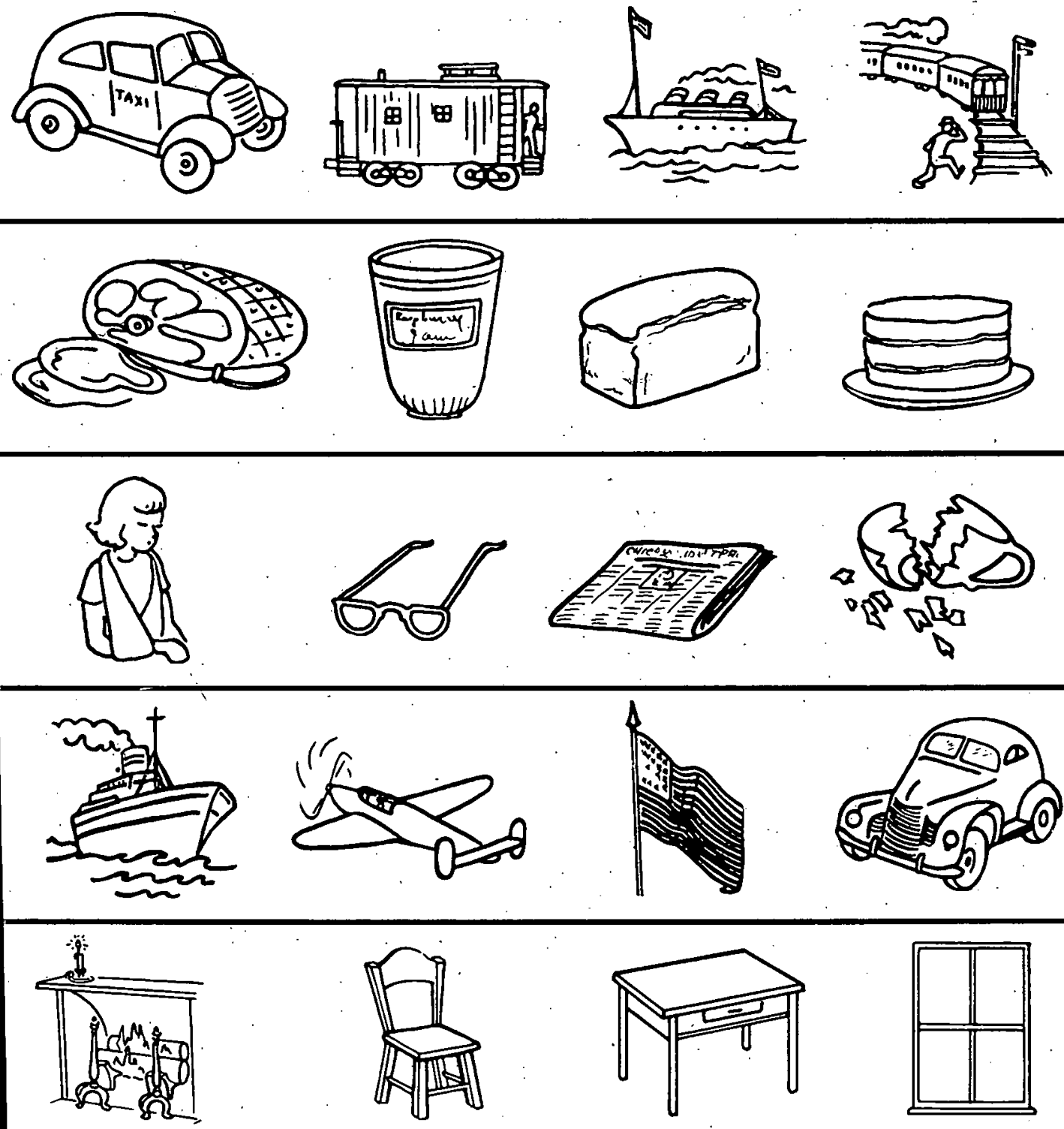


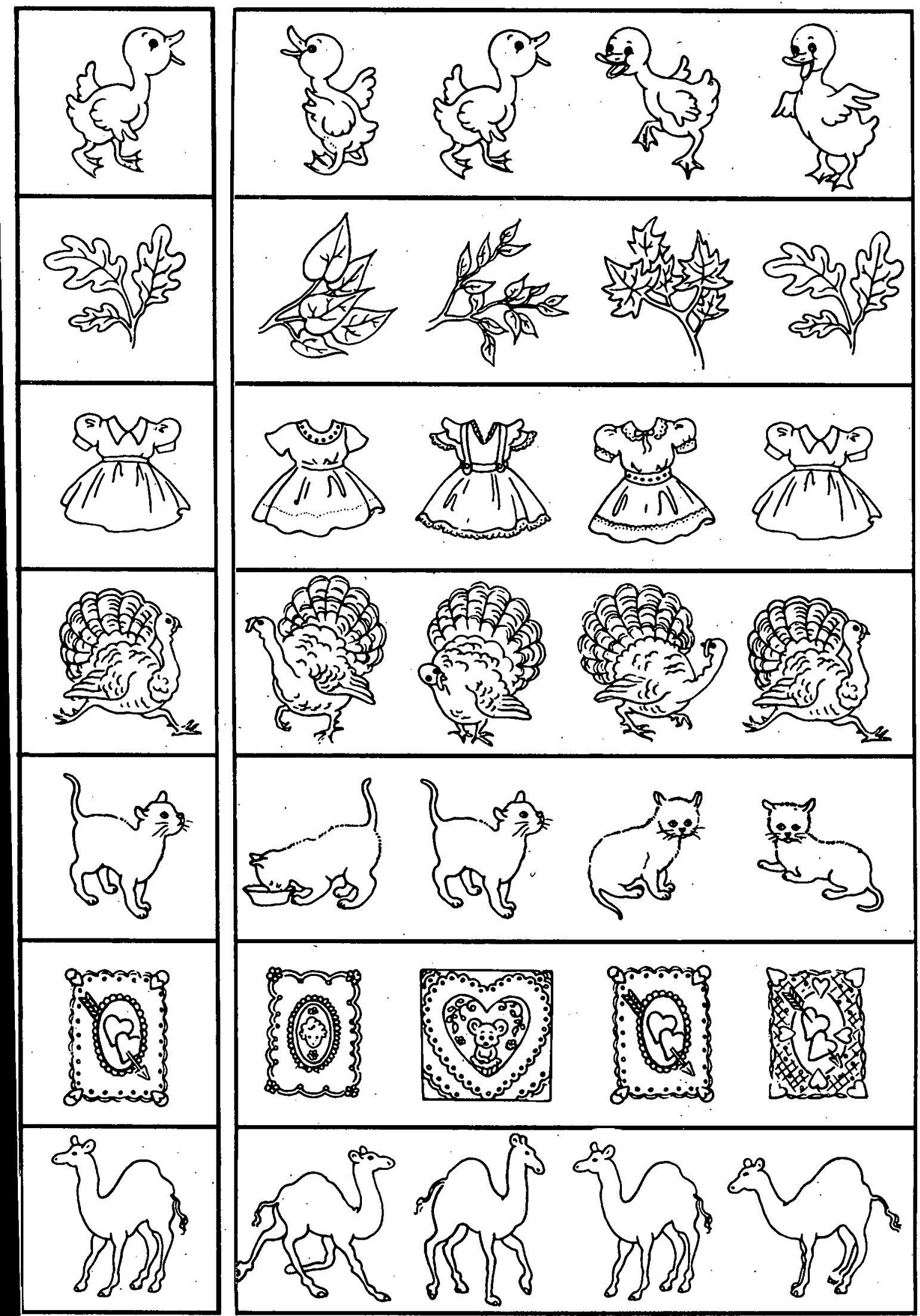




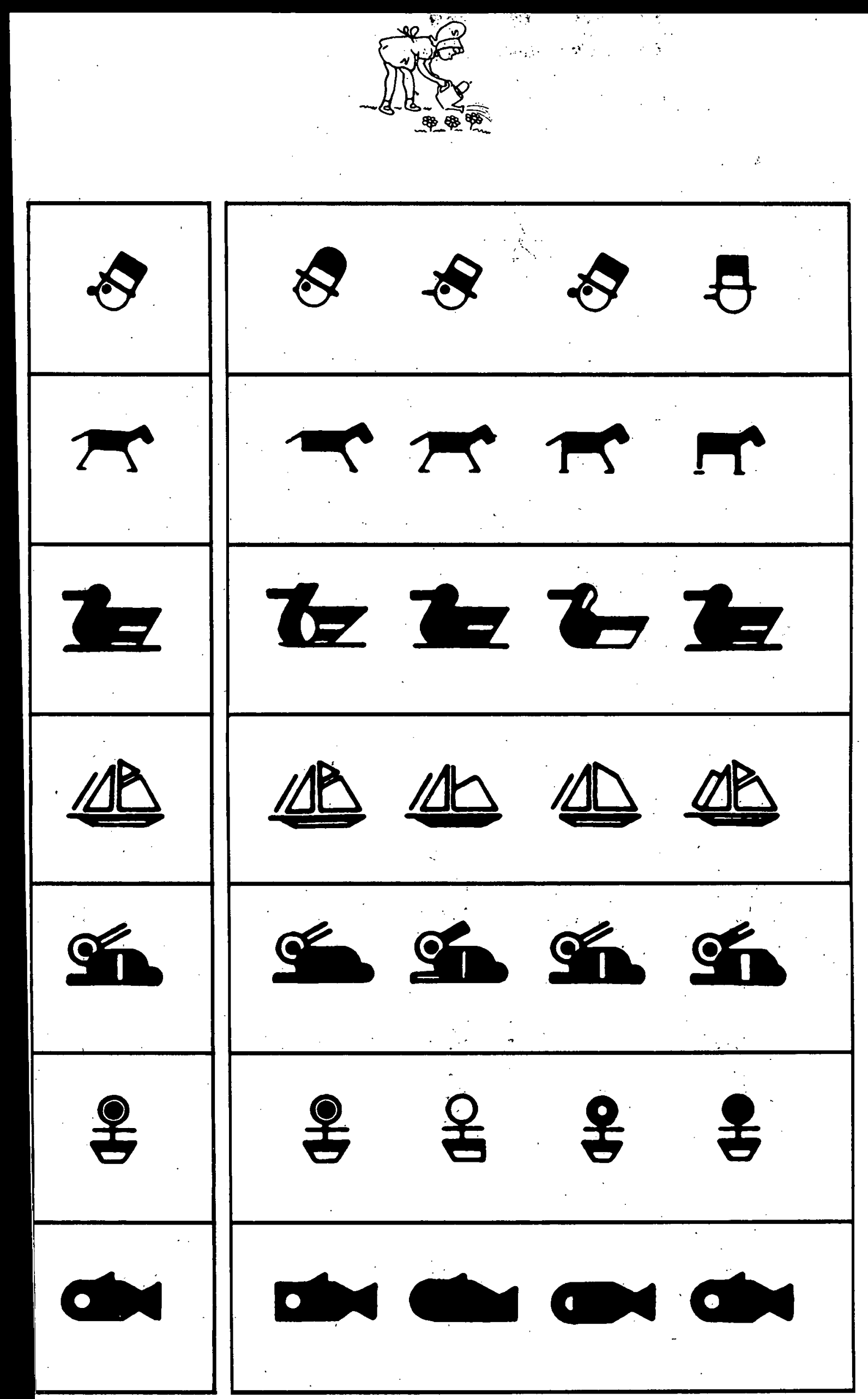

Perceptual Speed Test

Page 13 


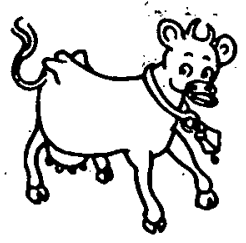

E

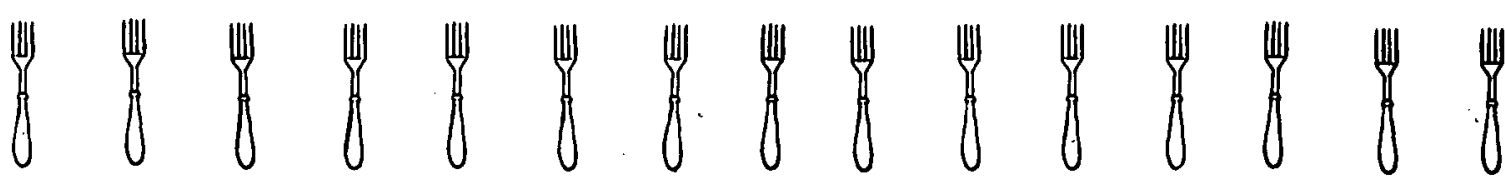

涪

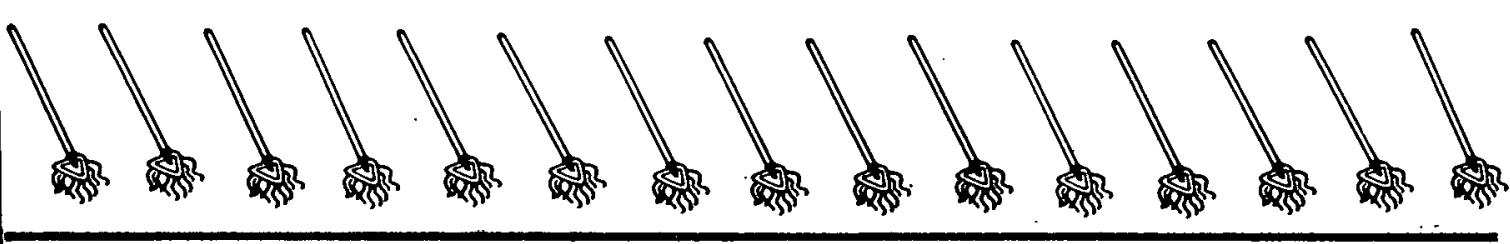

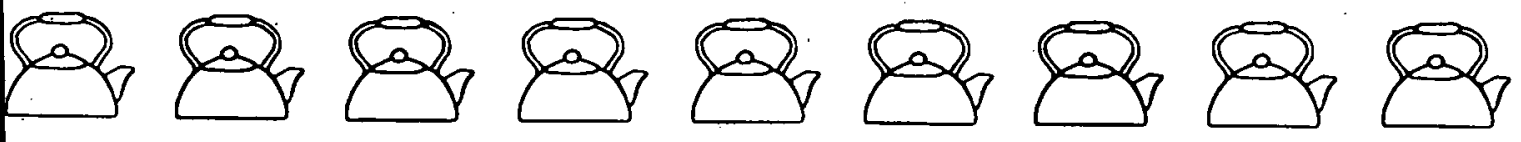

S.

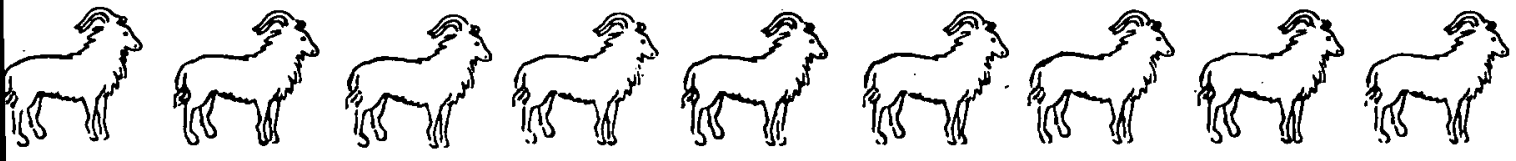

舀

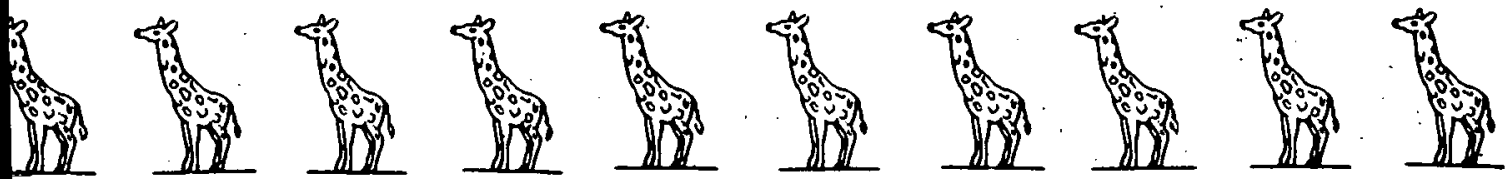




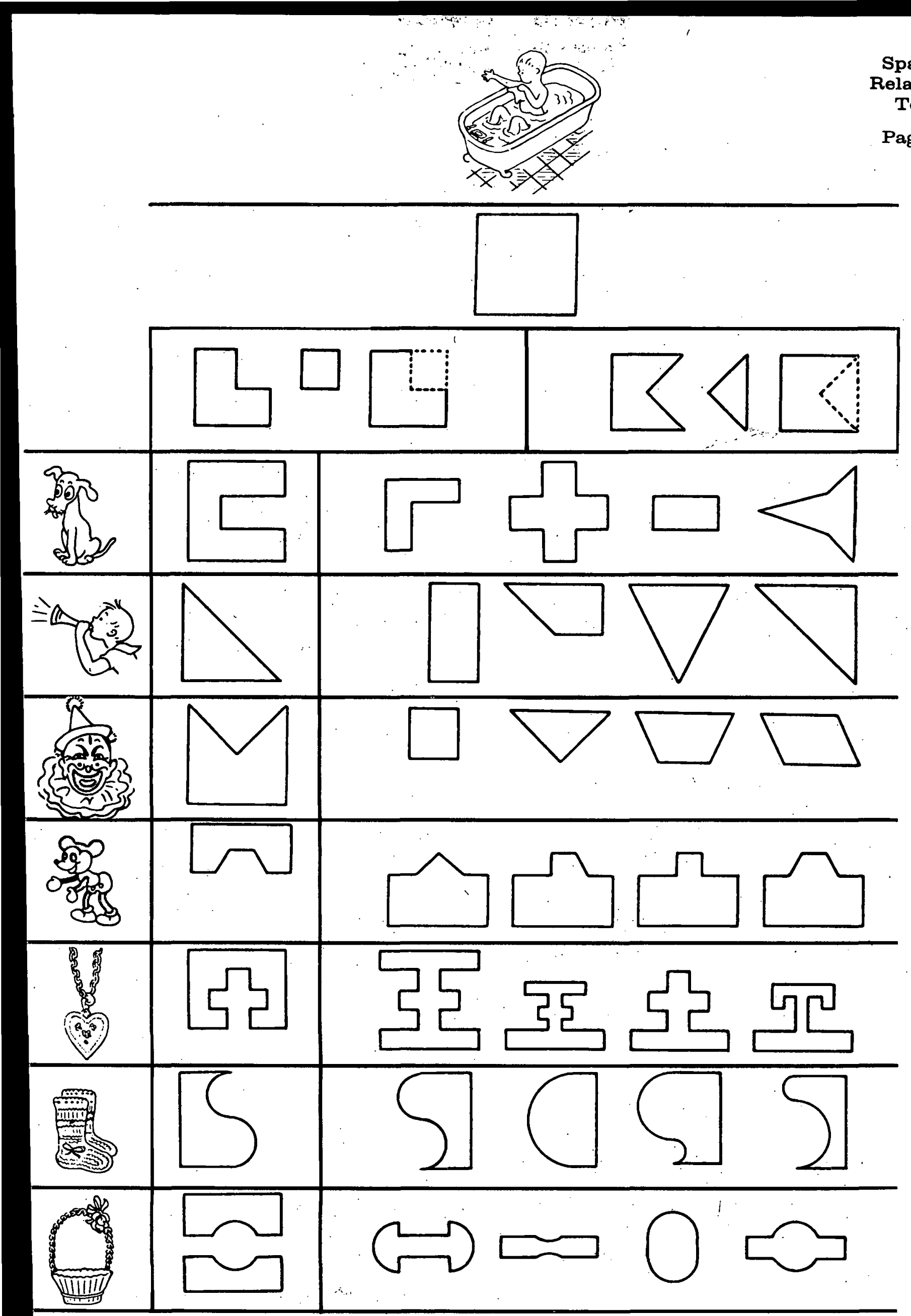

Spatial

elations

Test

Page 19 


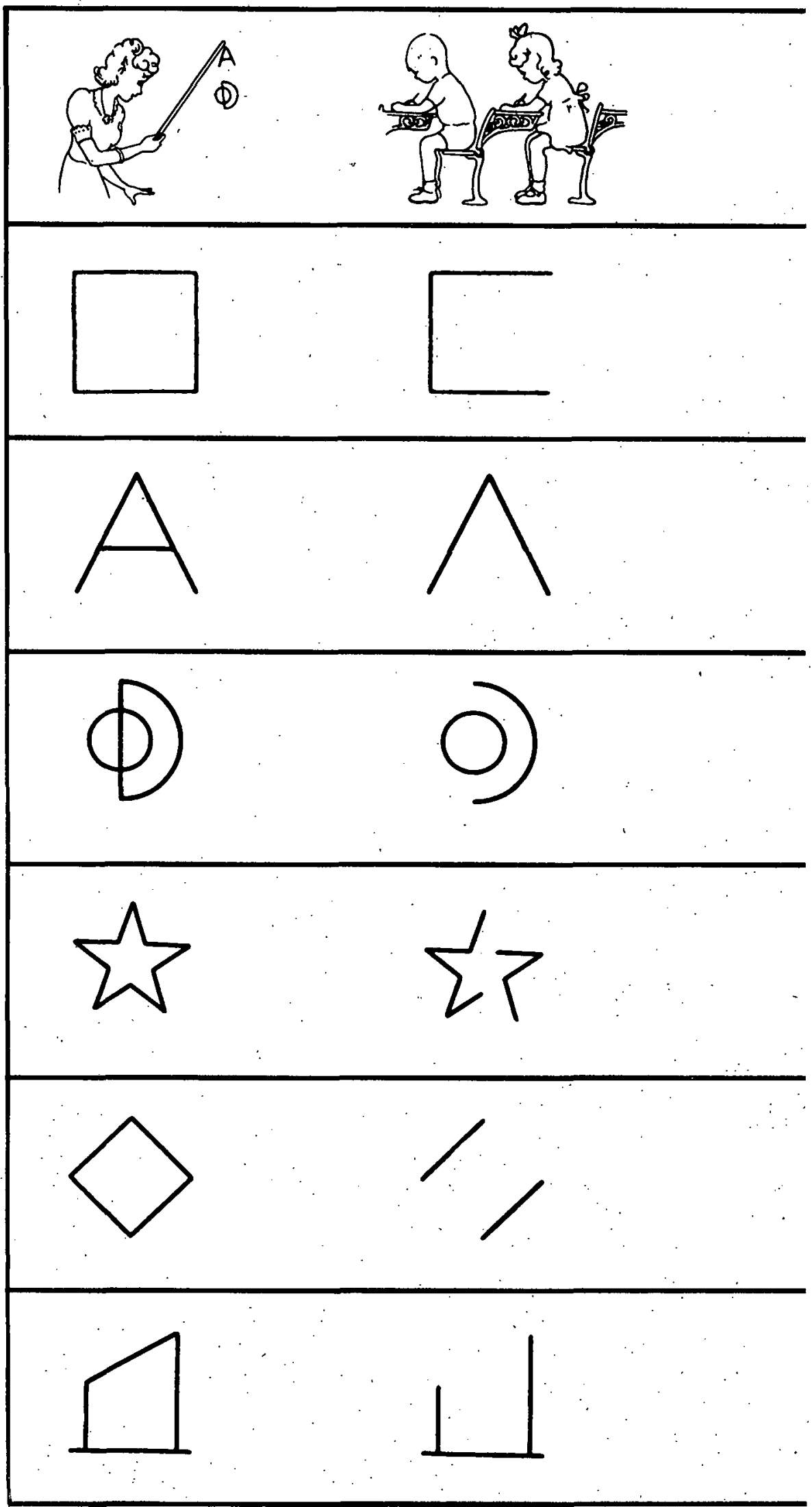




$$
\text { 周商 }
$$

Spatial

Relations

Test

Page 23
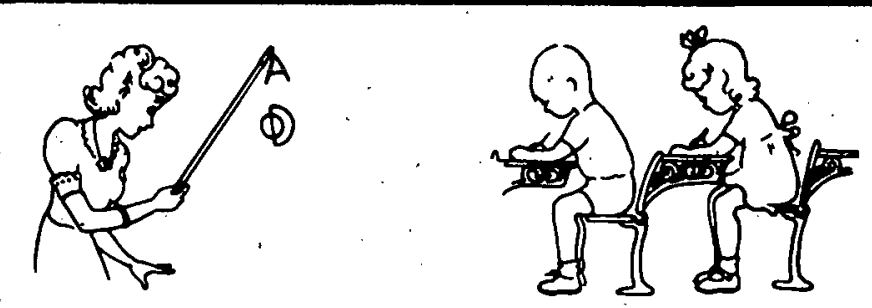

(4)
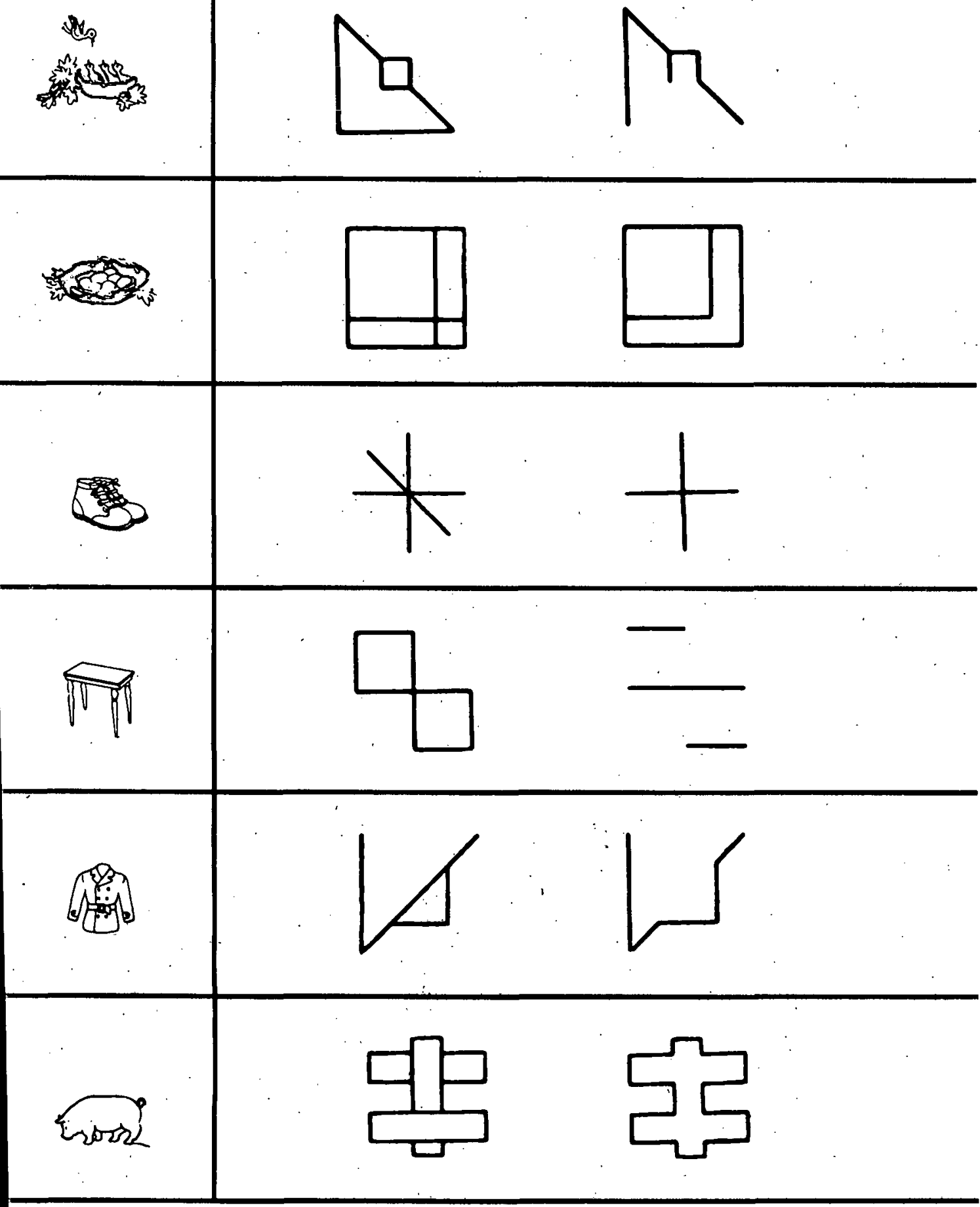
SRA PRIMARY MENTAL ABILITIES K- 1

FIRST GRADE - 1971-72

TOTAL SCORES

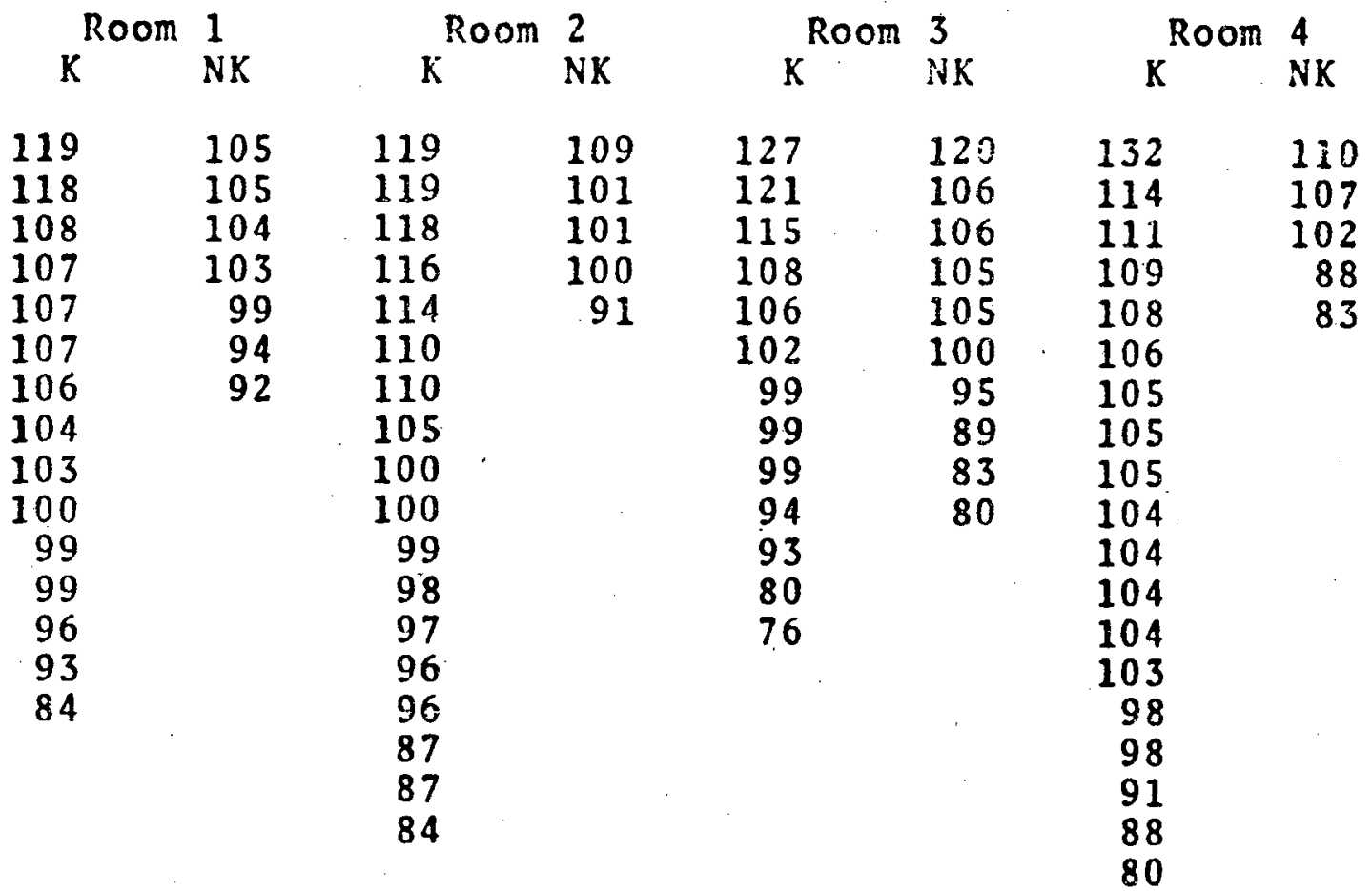

FIRST GRADE - 1967-68

TOTAL SCORES

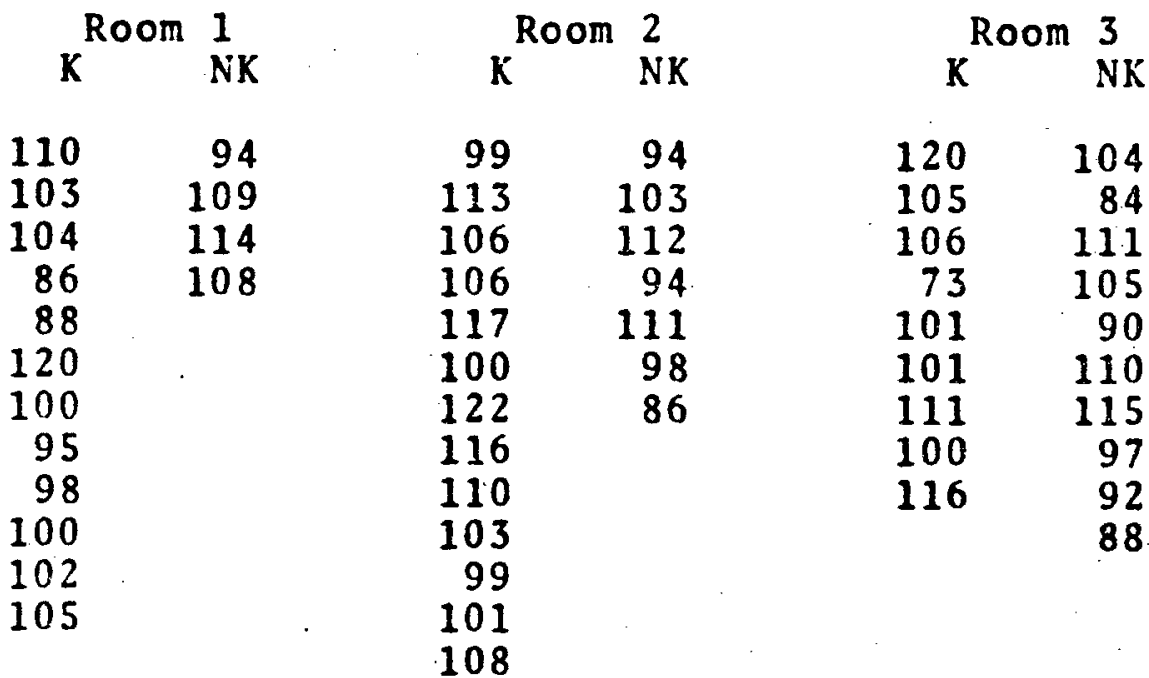


APPENDIX C

TABULATION OF INDIVIDUAL RESPONSES TO CHOICES

First Grades

Fourth Grades

SOCIOGRAMS

First Grades

Fourth Grades 


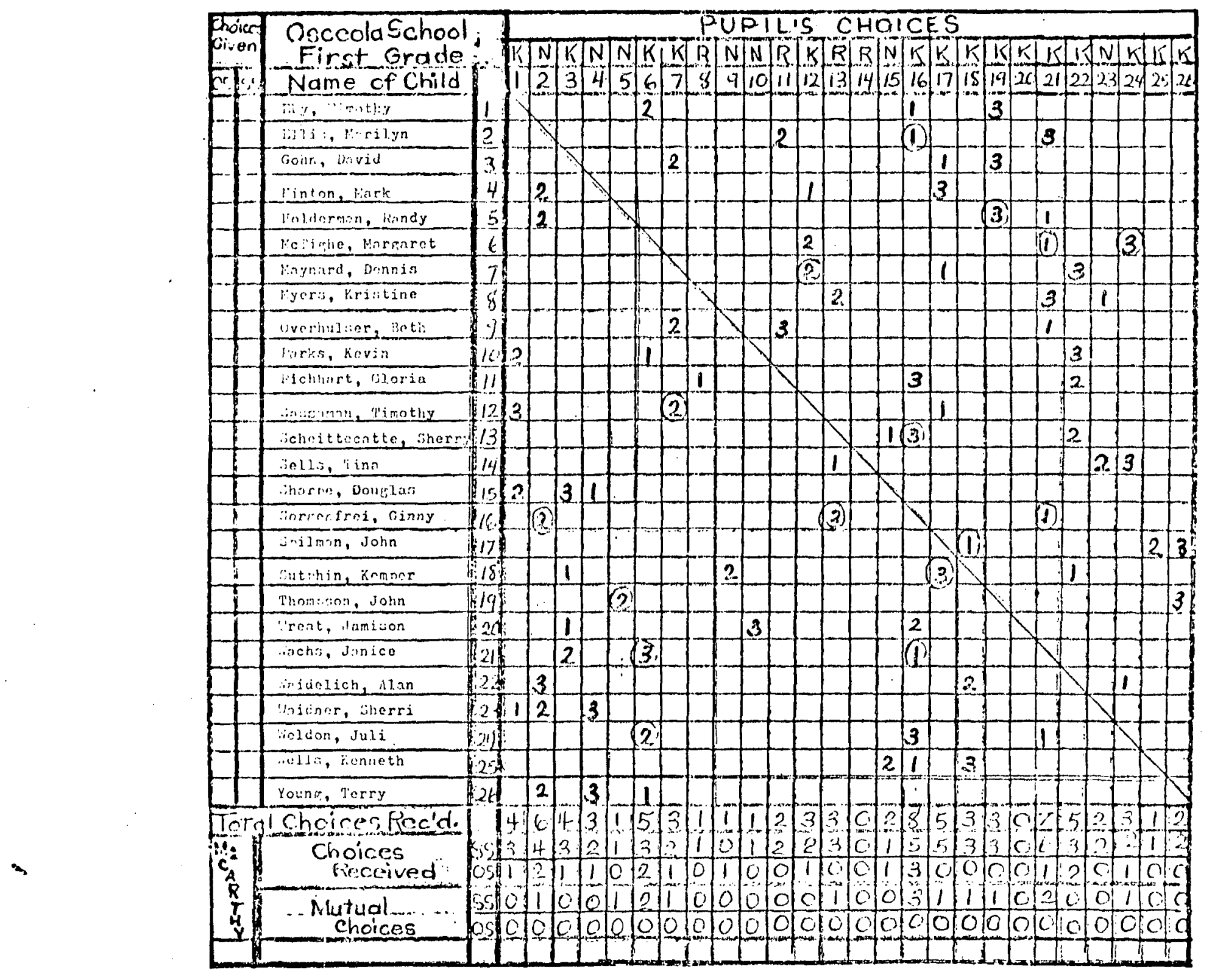




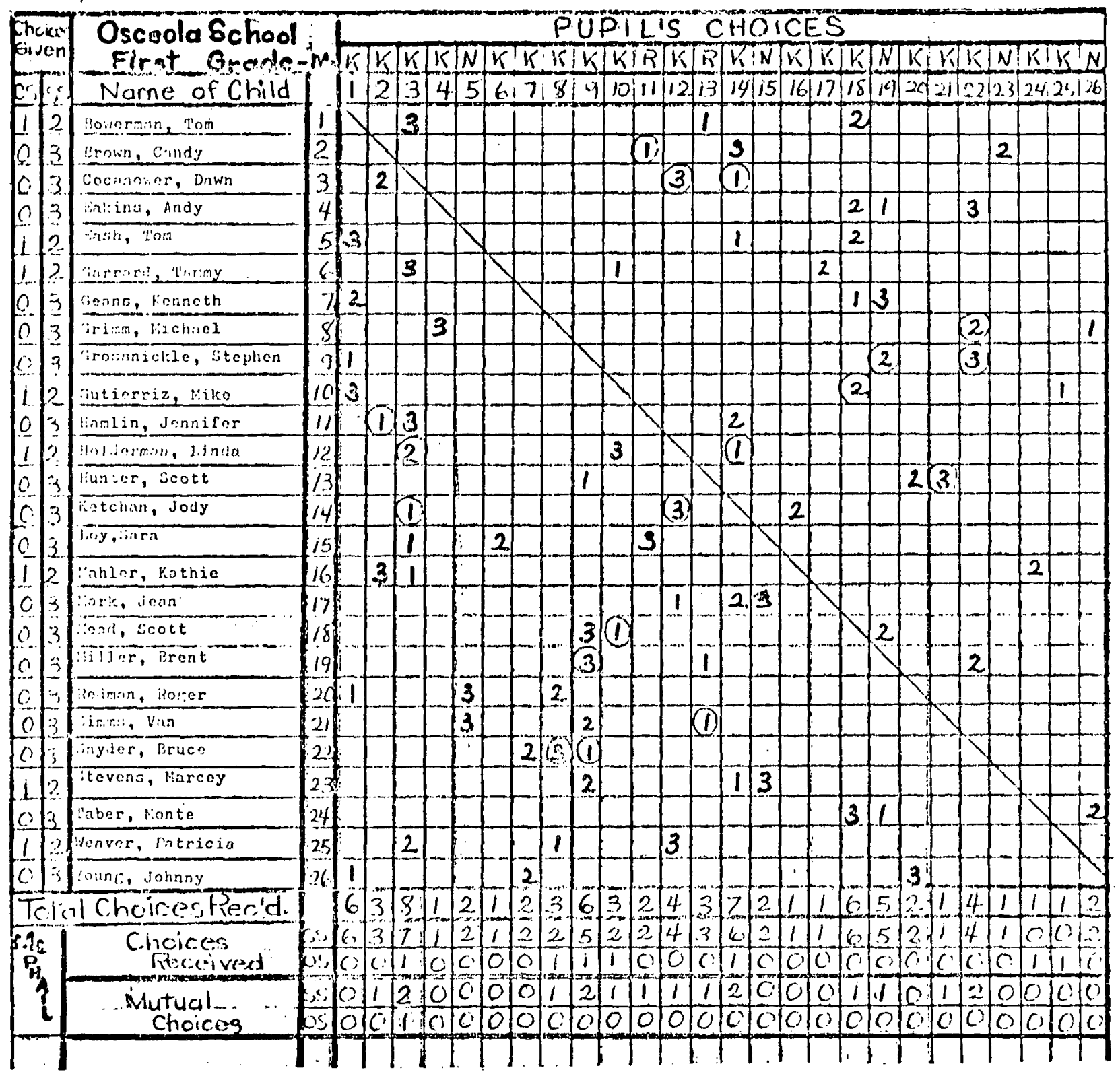




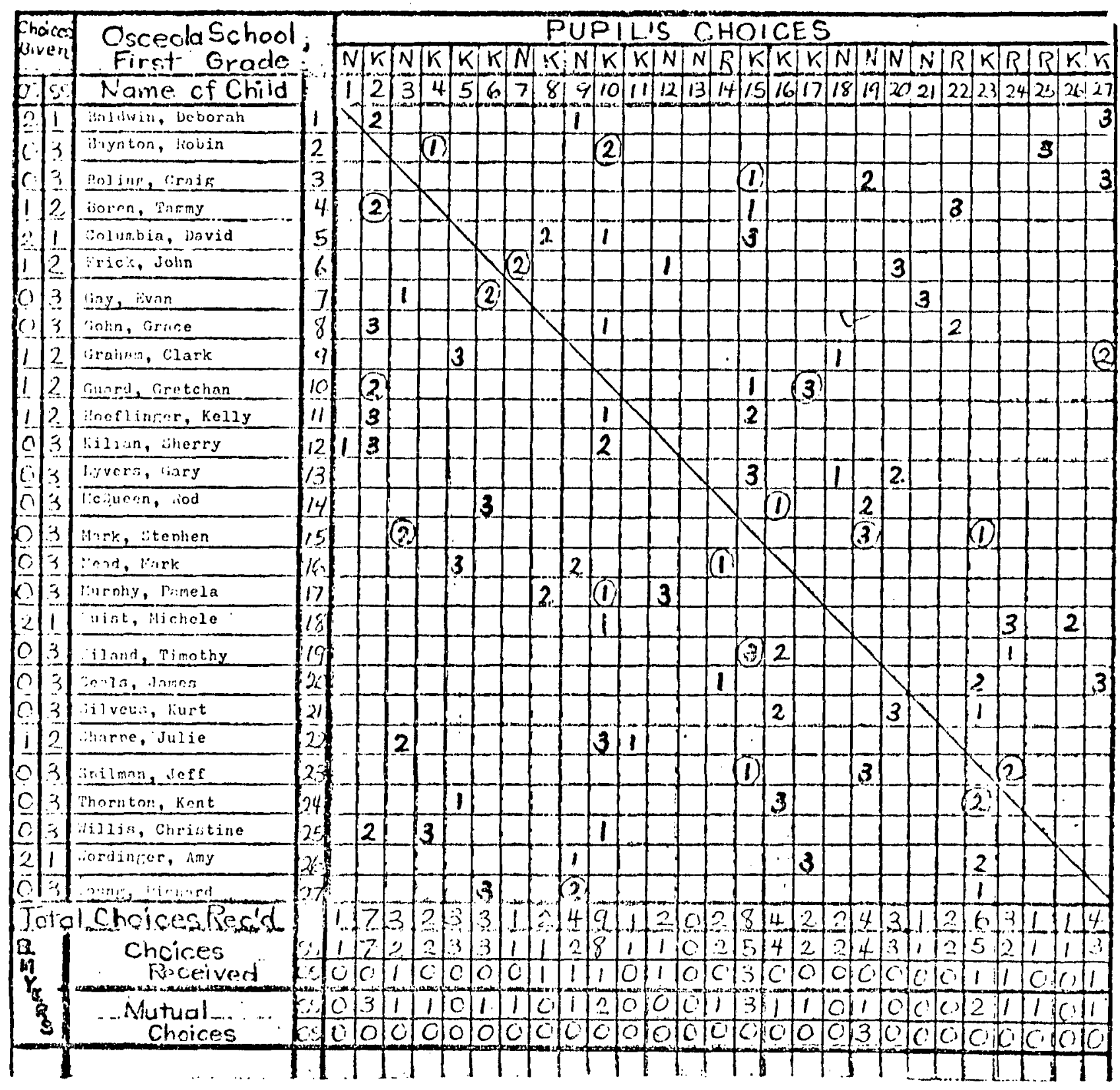




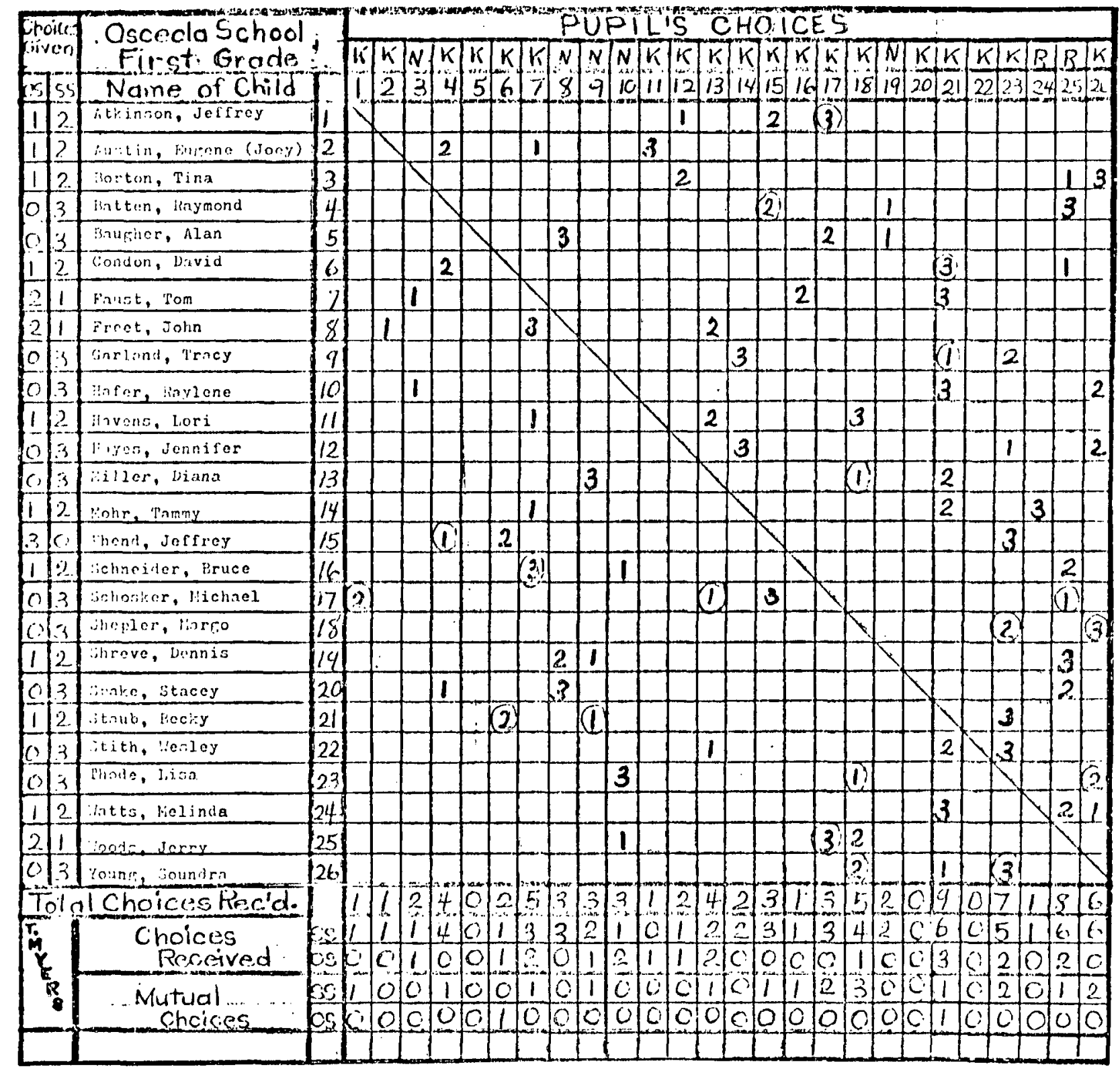




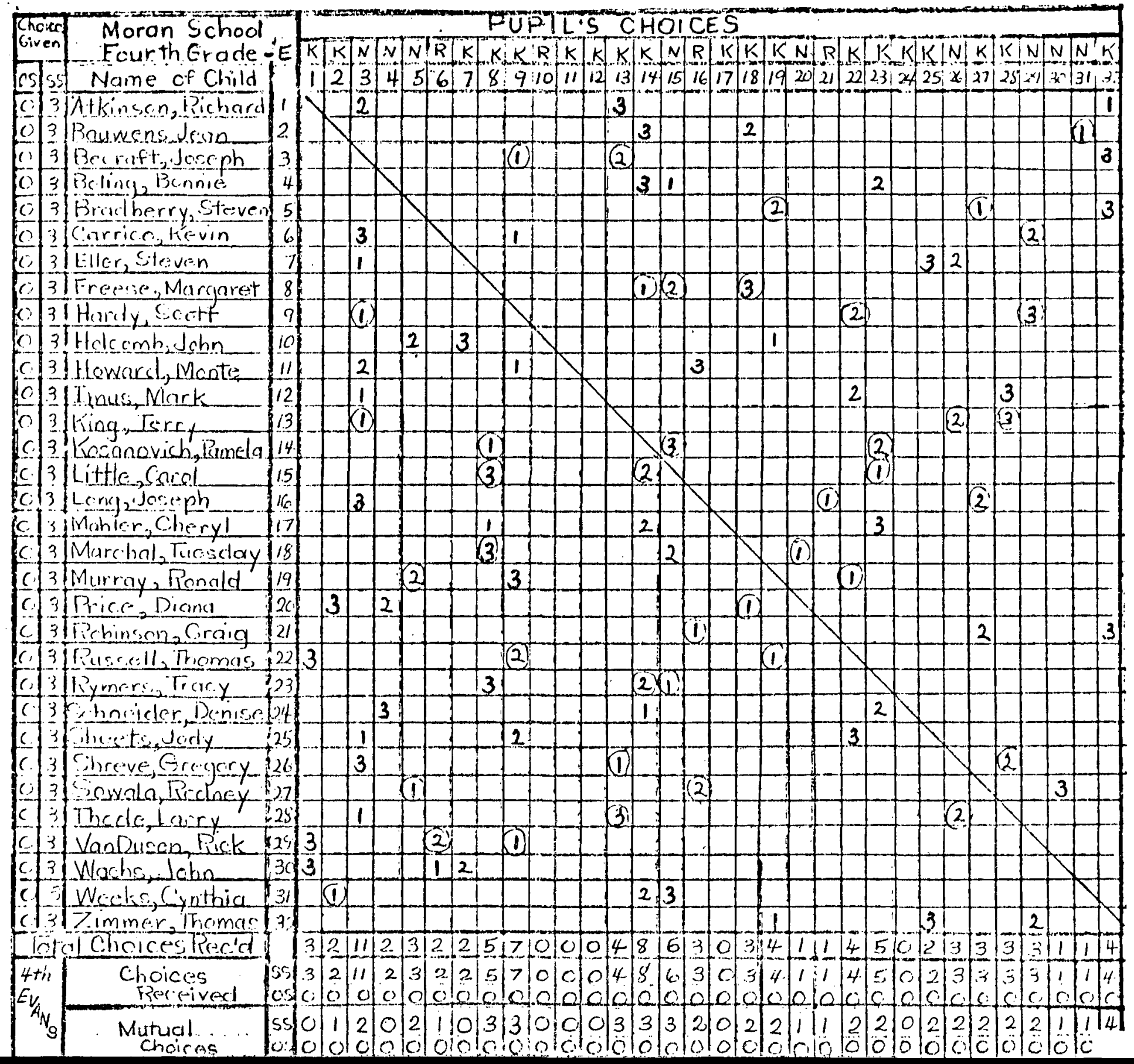




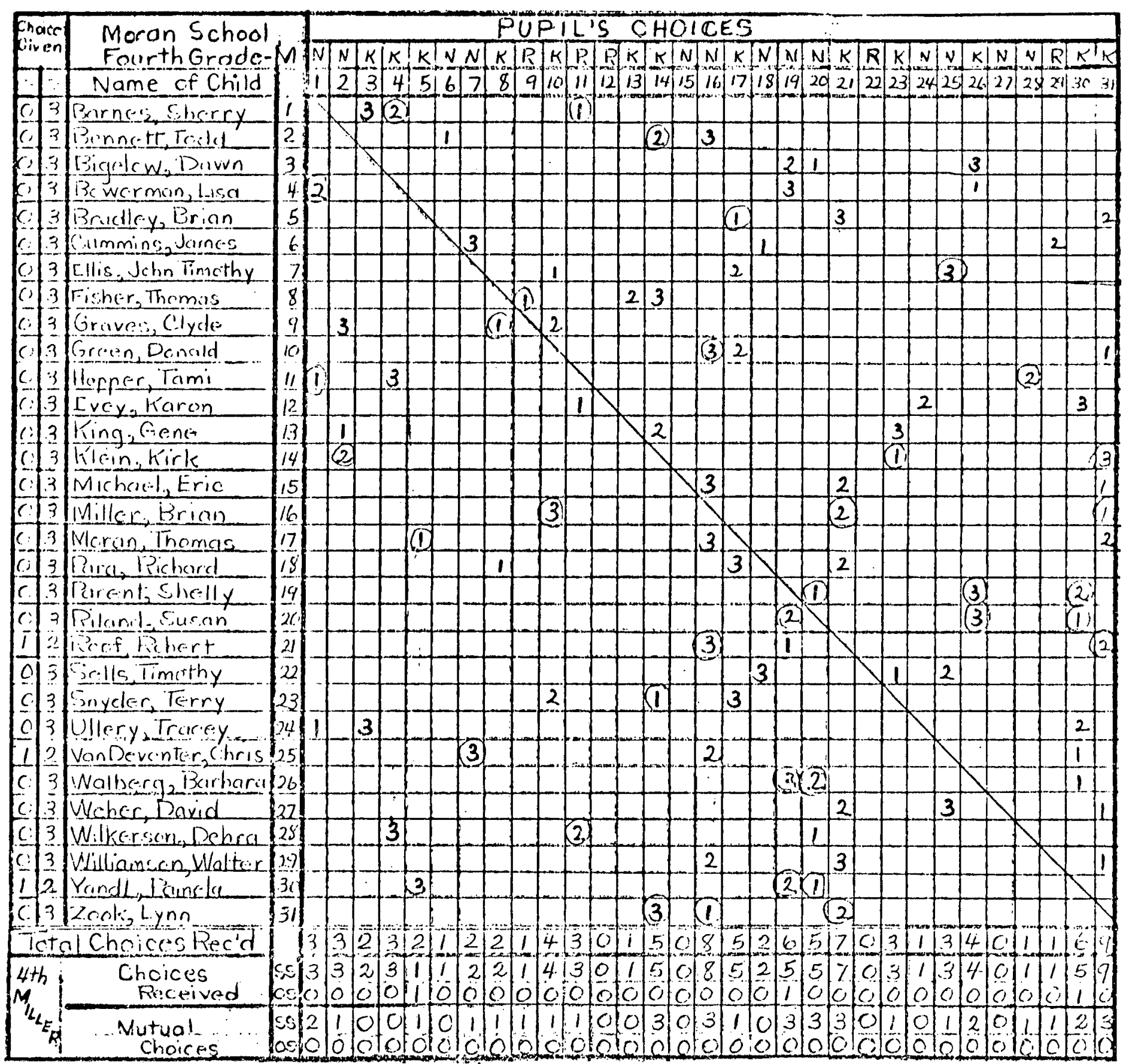




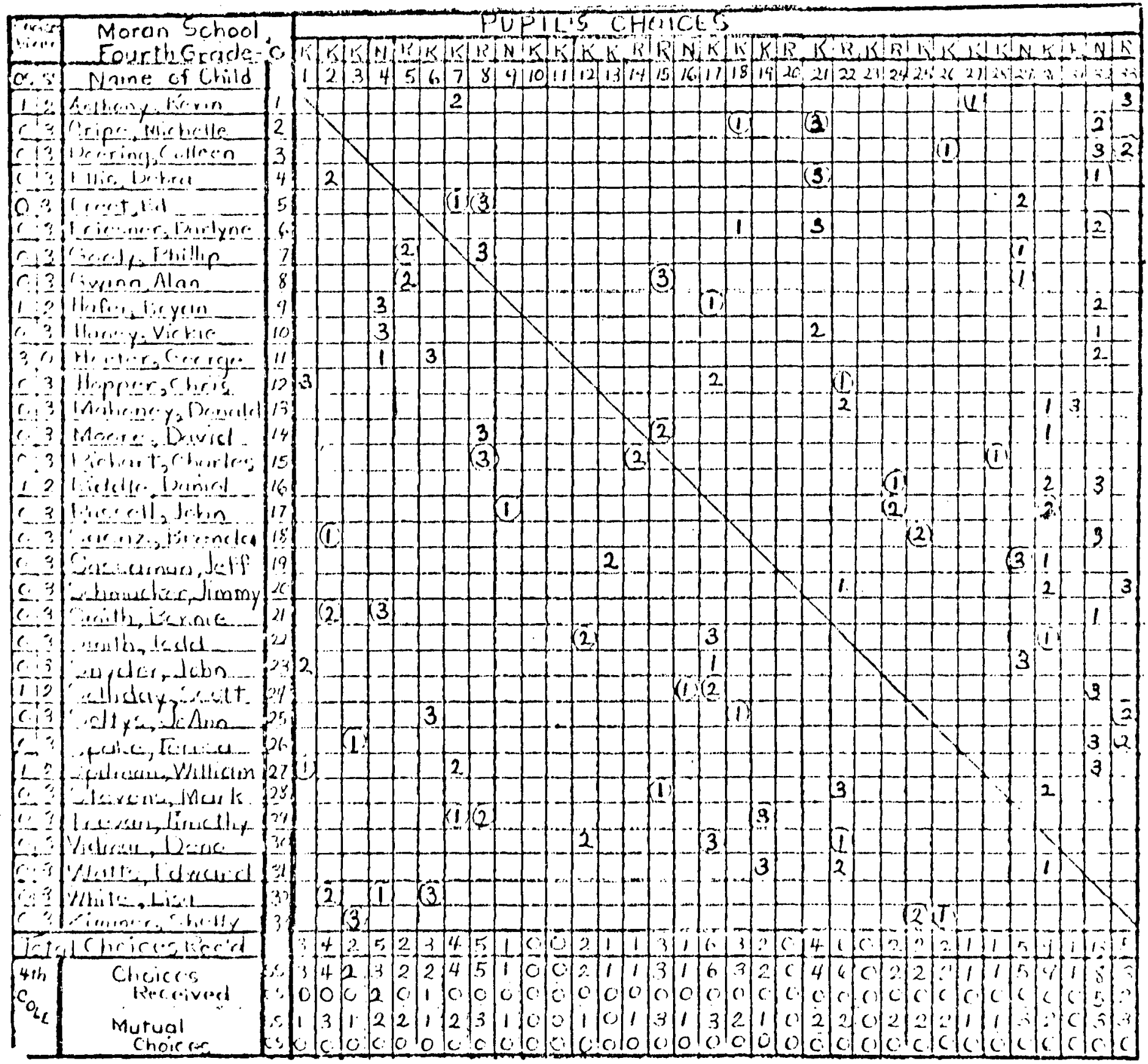




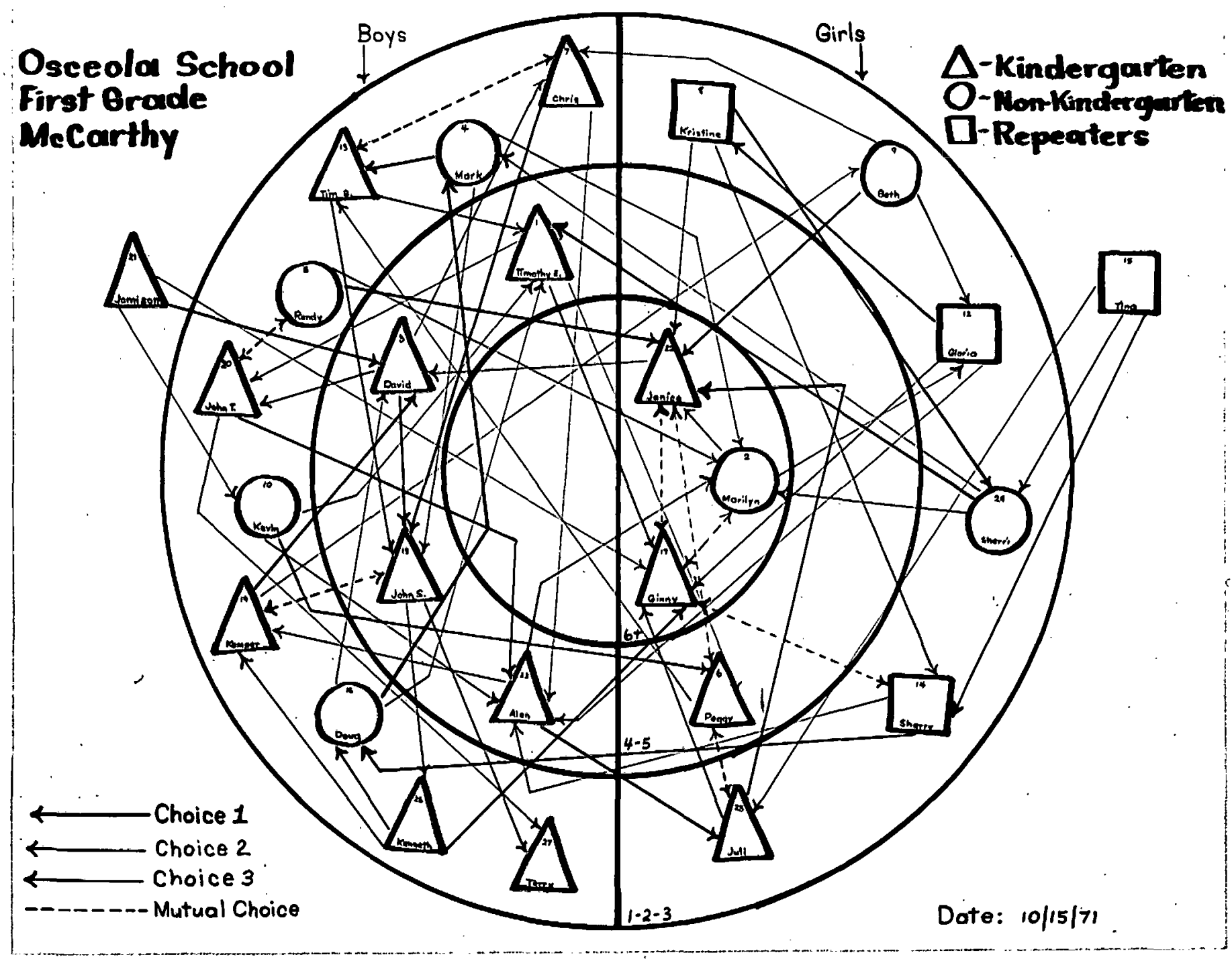




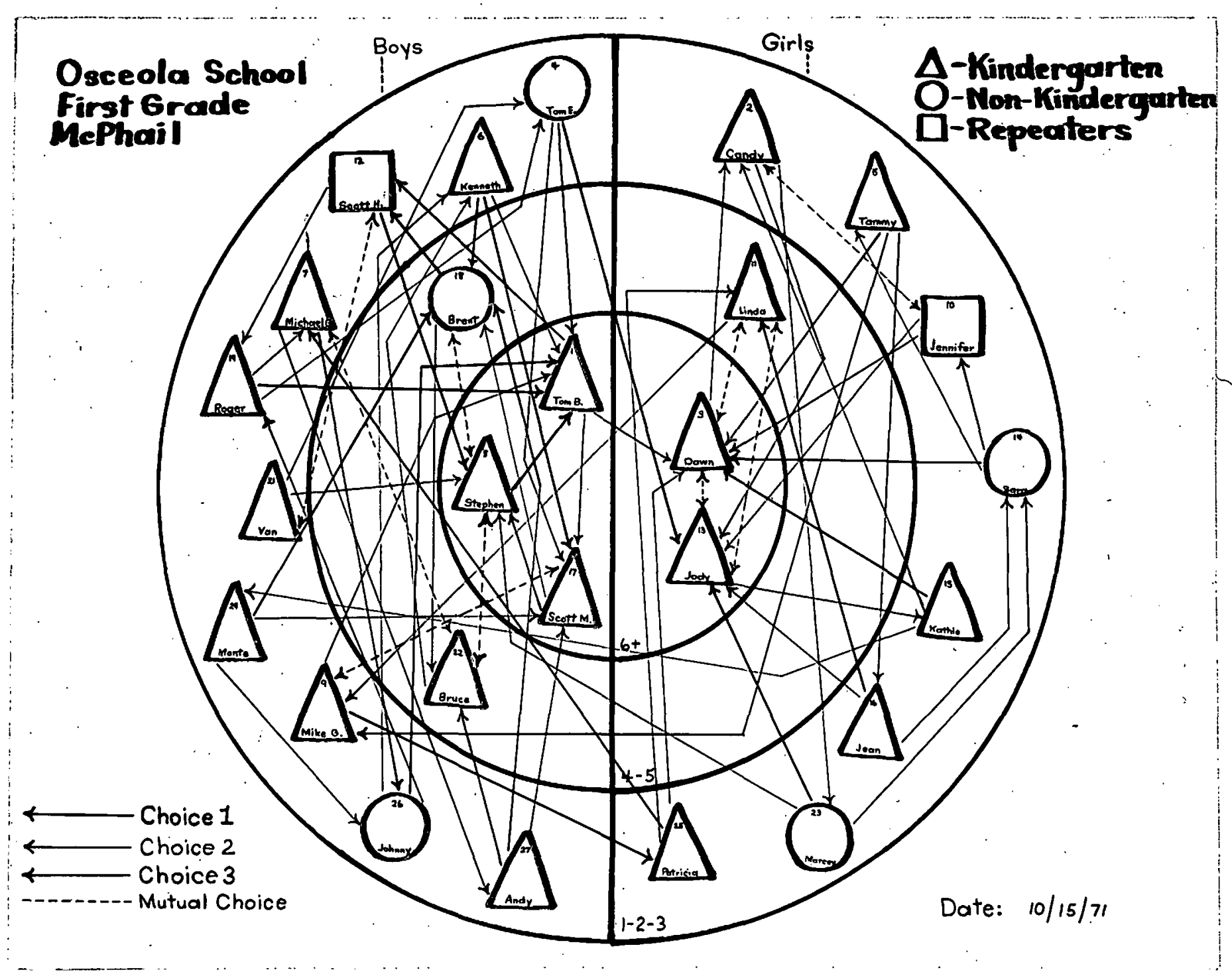




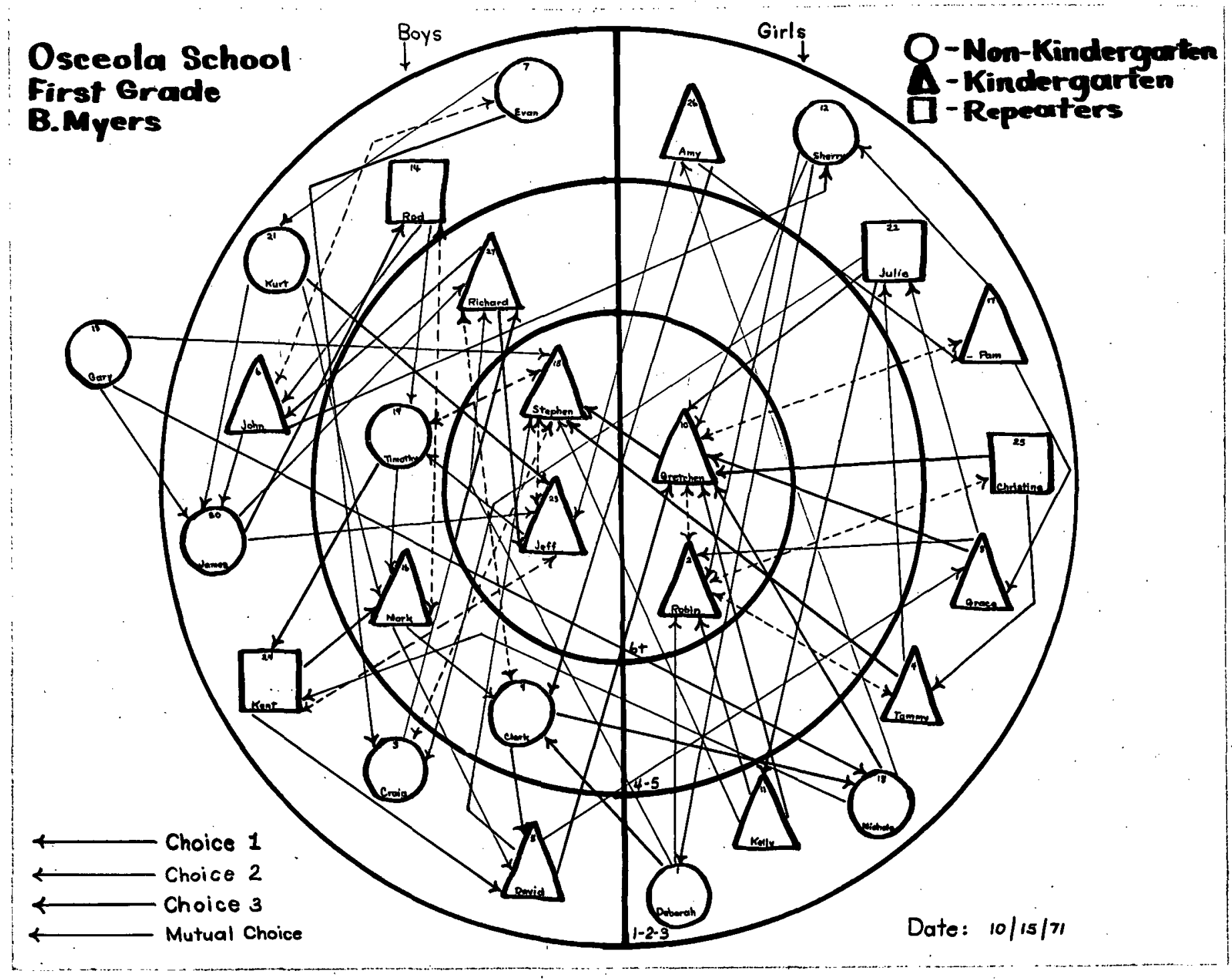




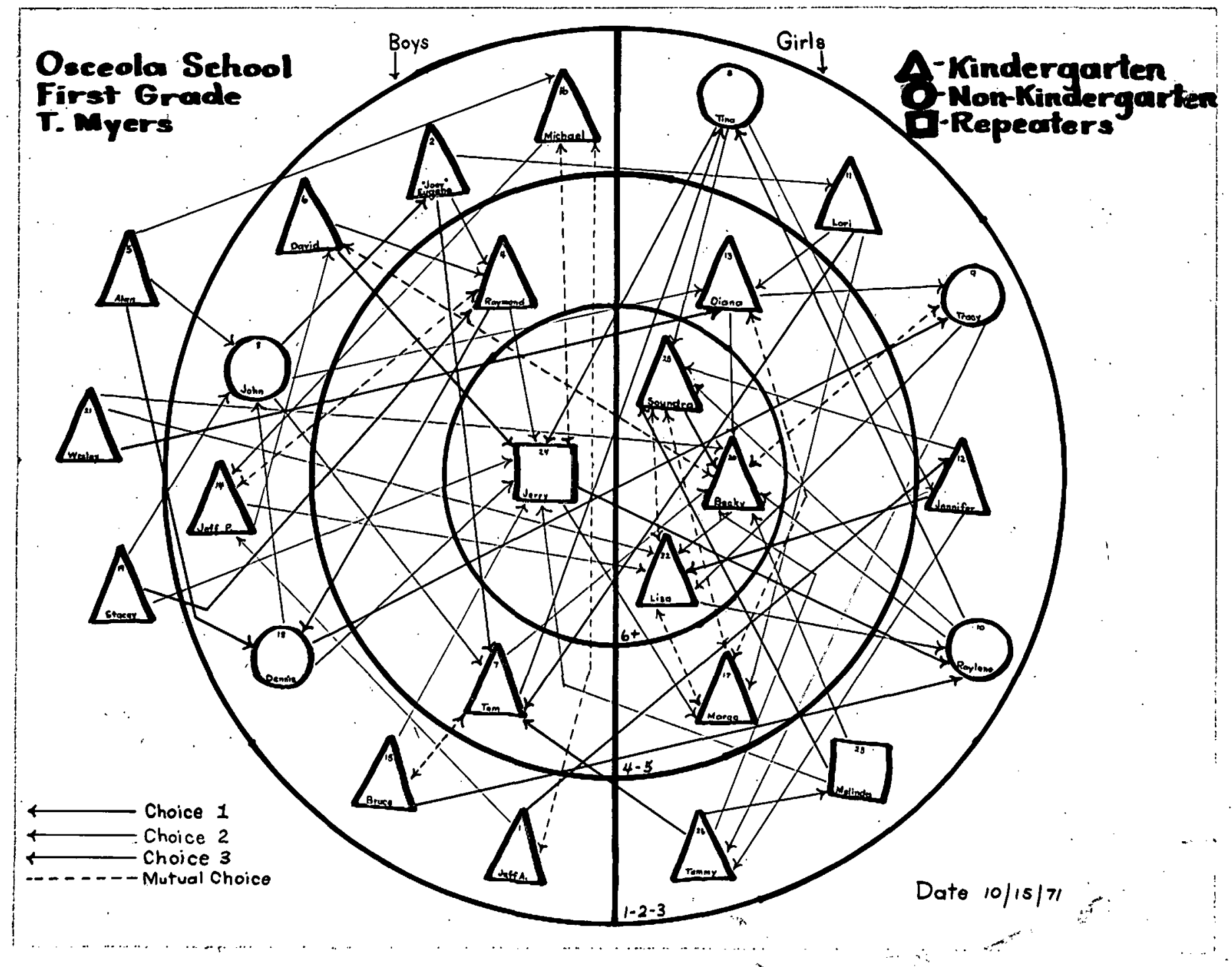




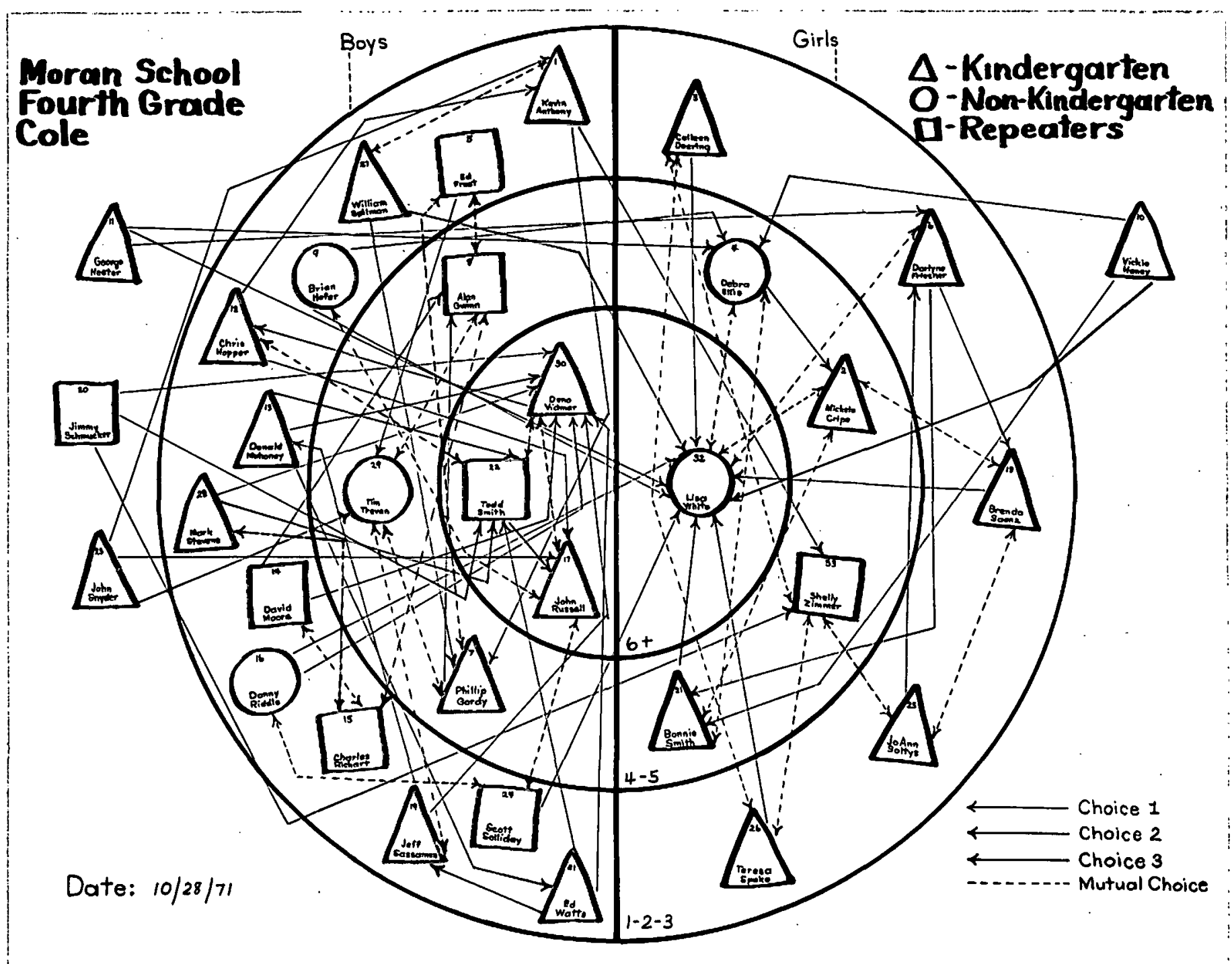




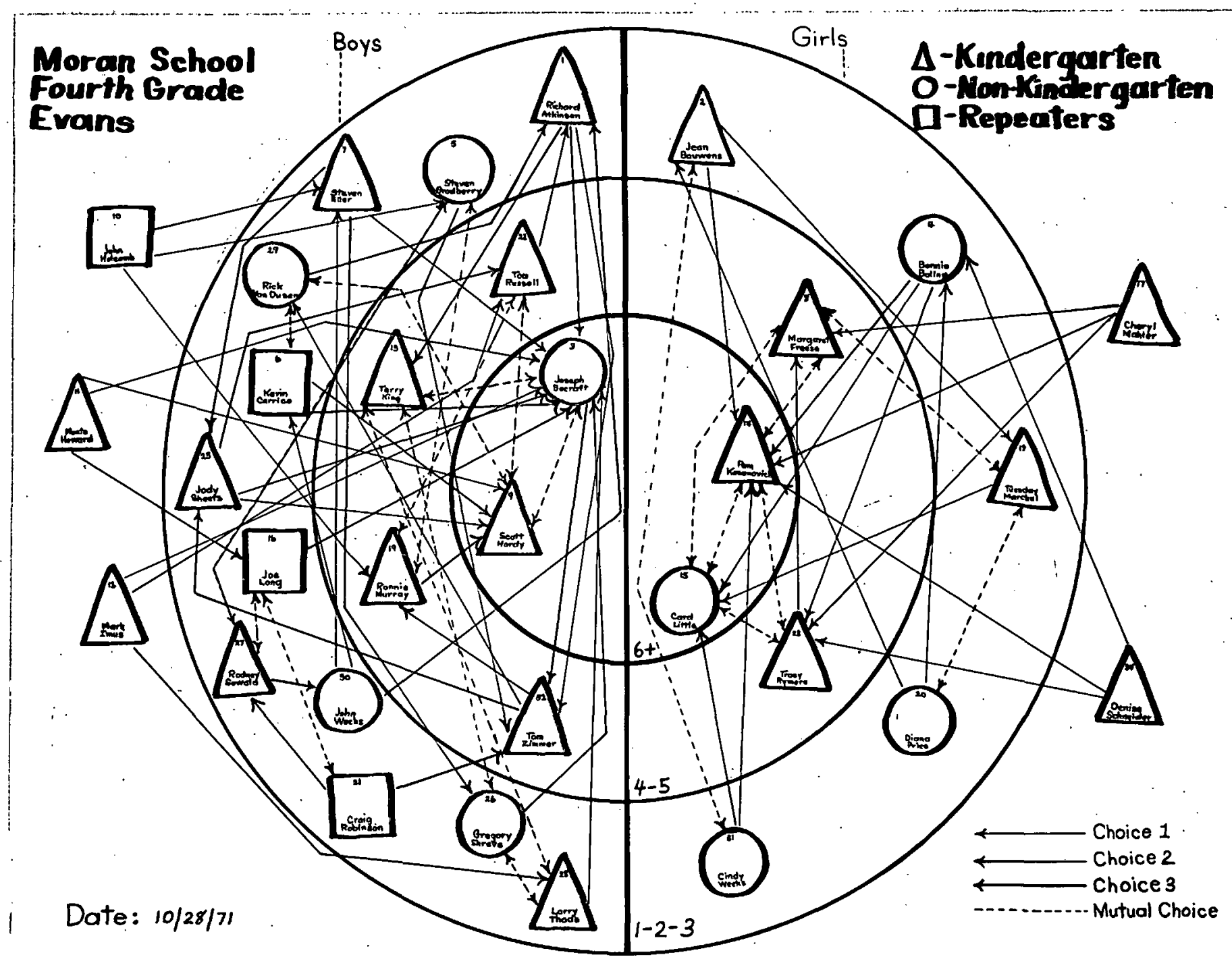

点 


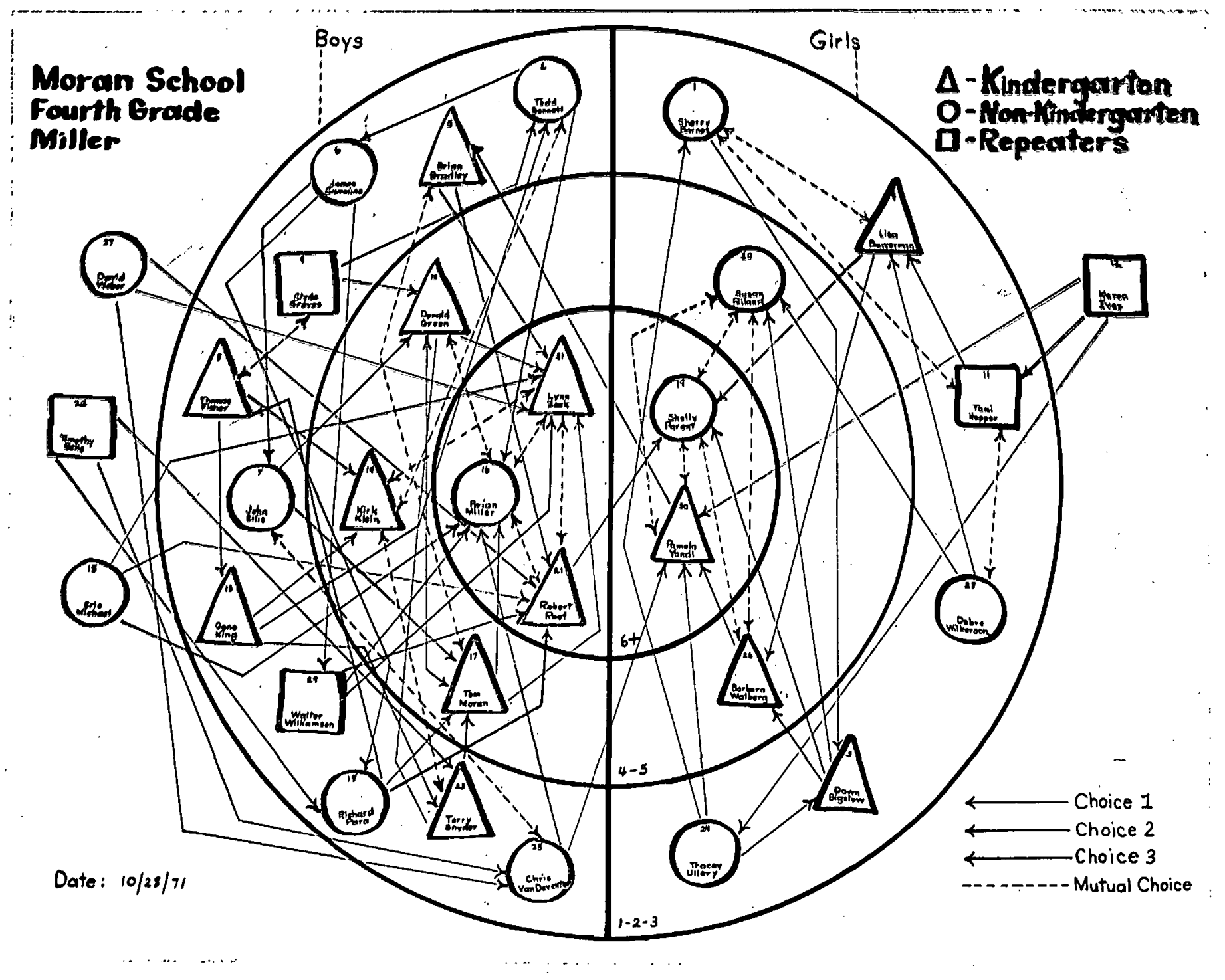


APPENDIX D

INDIVIDUAL CHARACTER TRAIT RATINGS

First Grade

Fourth Grade 
CHARACTER TRAIT JUDGEVENT

FIRST GRADE

Self-Confidence
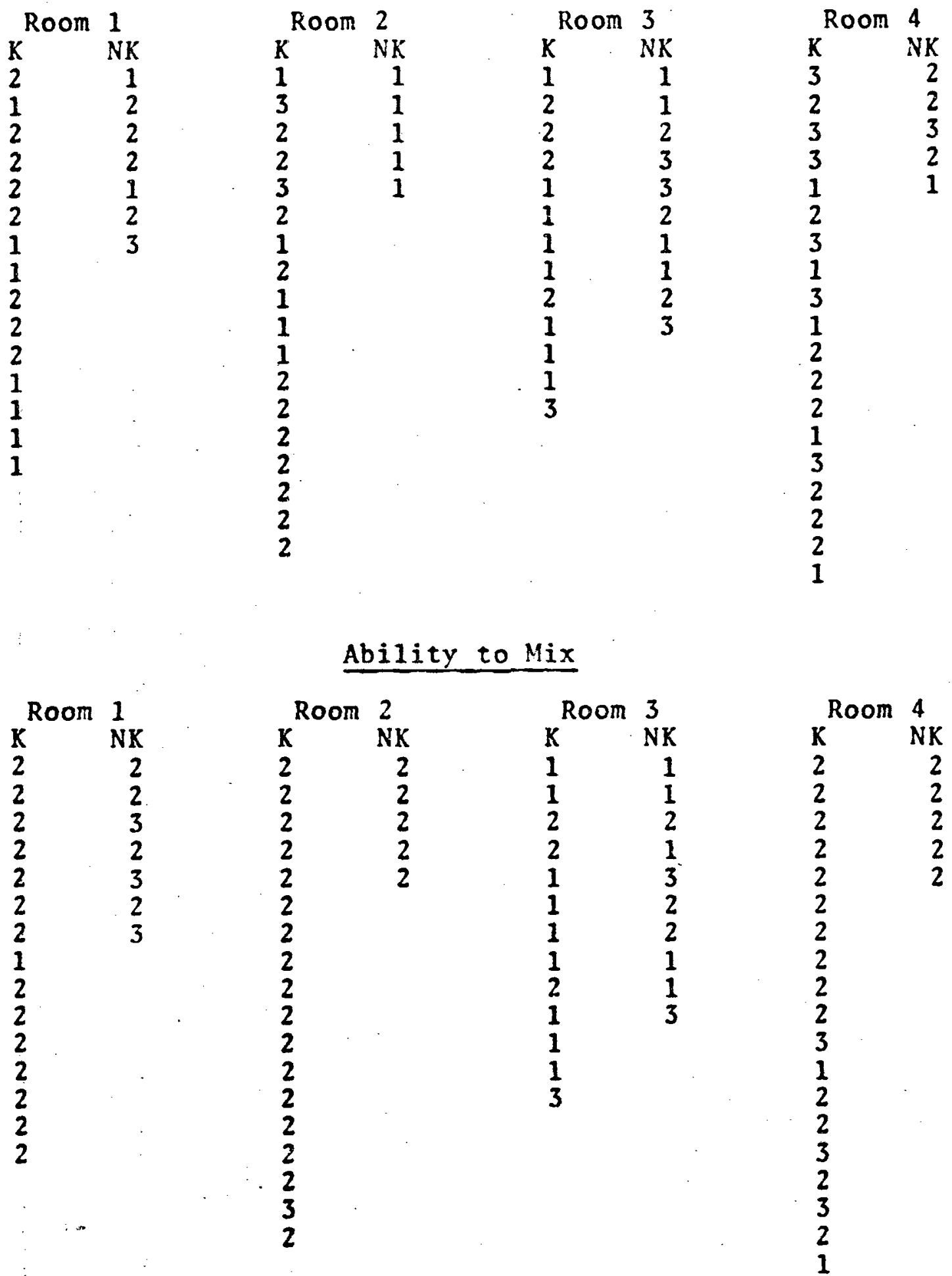
CHARACTER TRAIT JUDGEMENT

\section{FIRST GRADE}

Friendliness
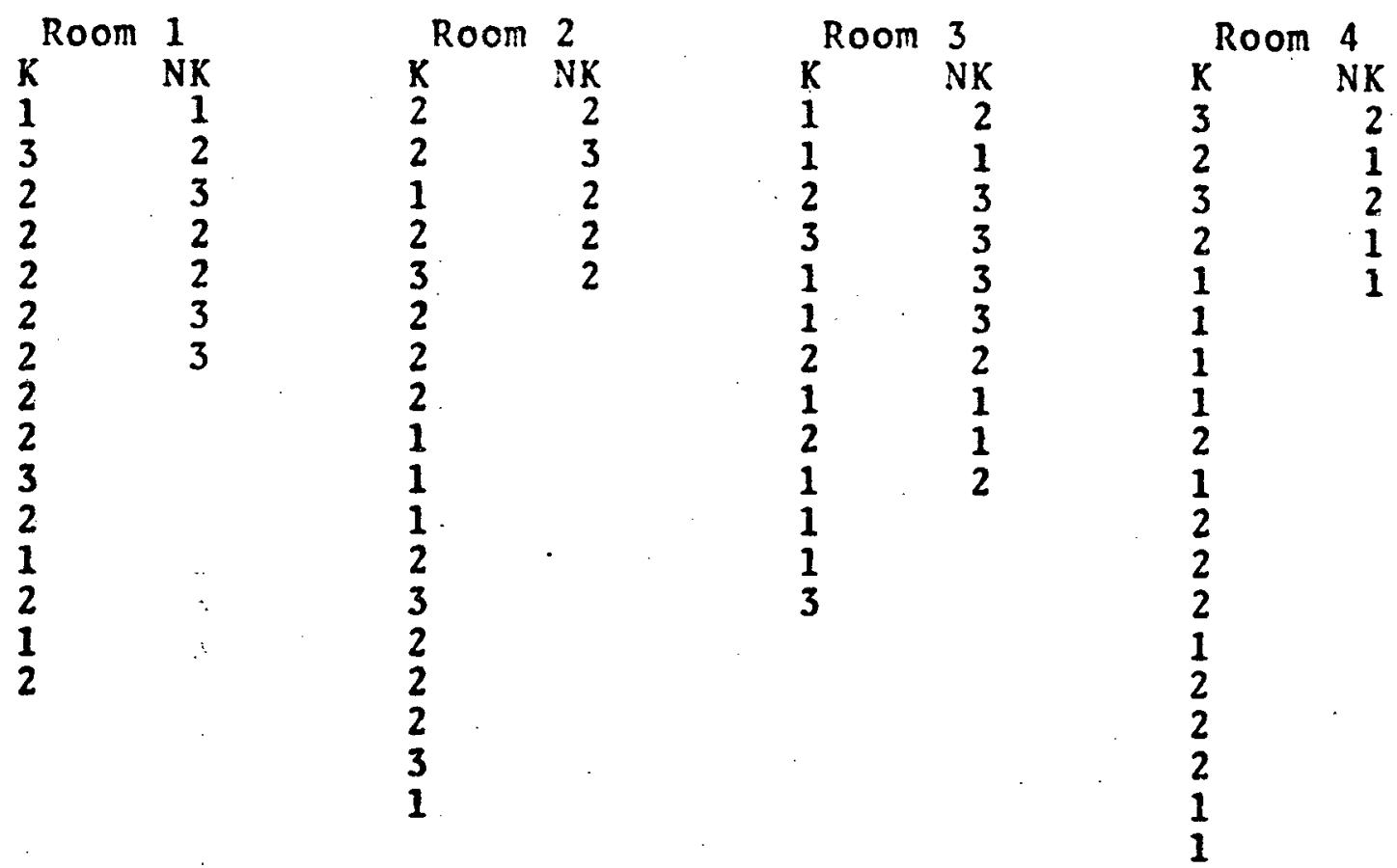

\section{Interest}

Room 1

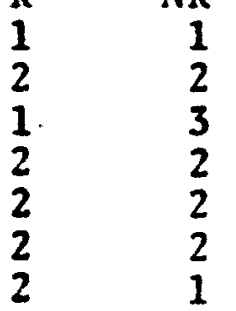

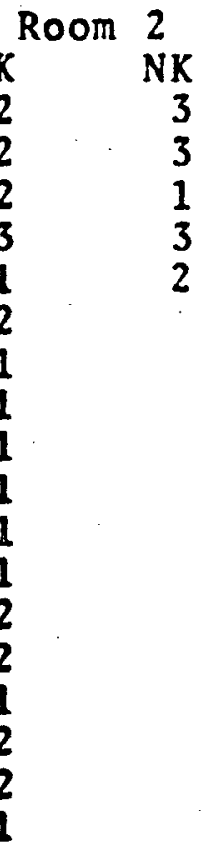
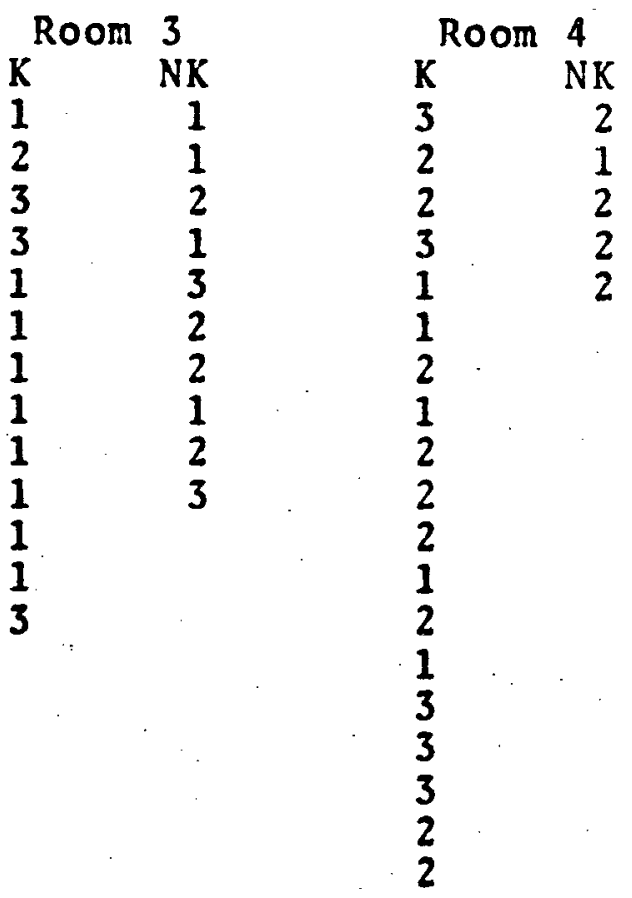
CHARACTER TRAIT JUDGEMENT

FIRST GRADE

\section{Attention}
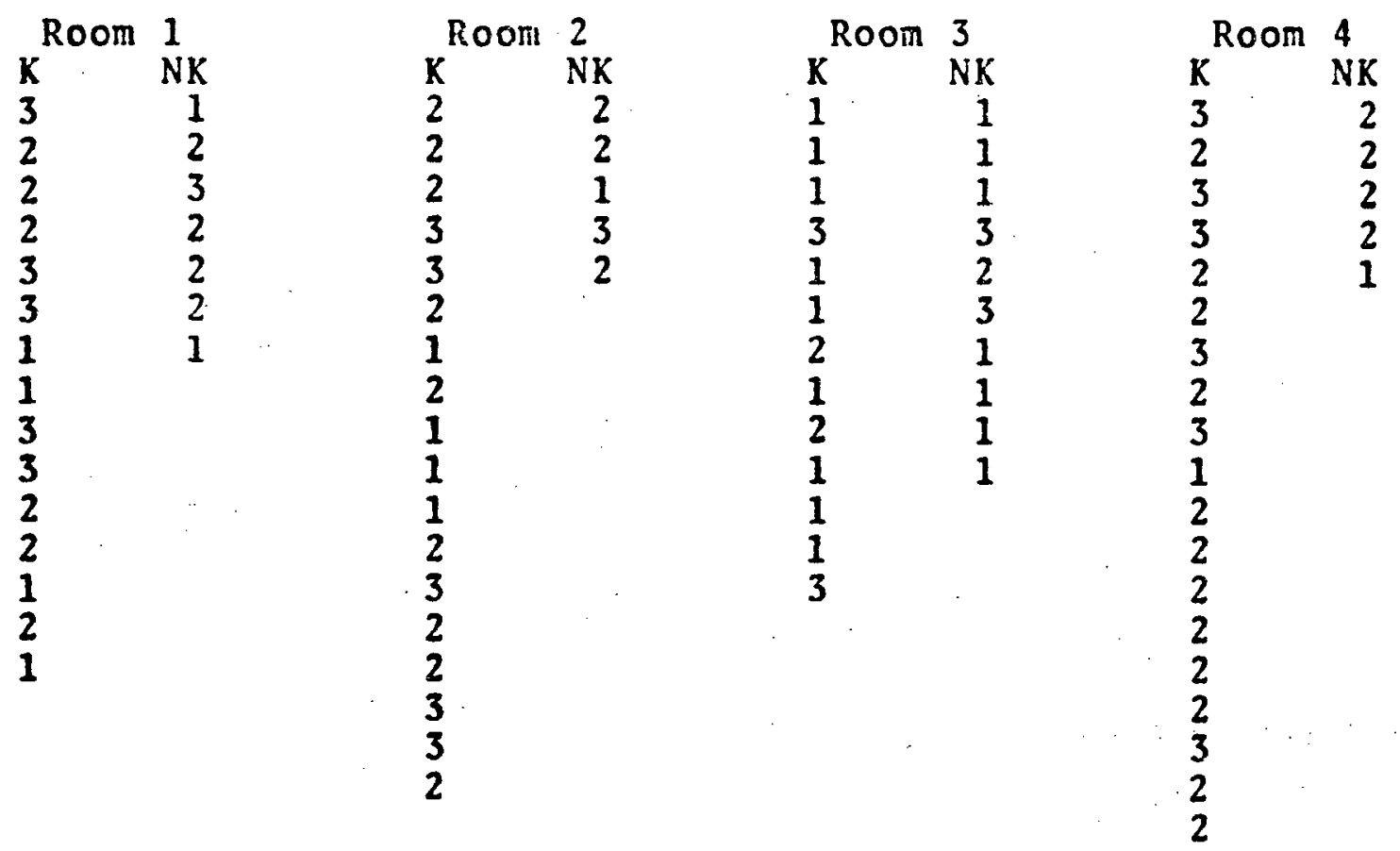

Ability to Think
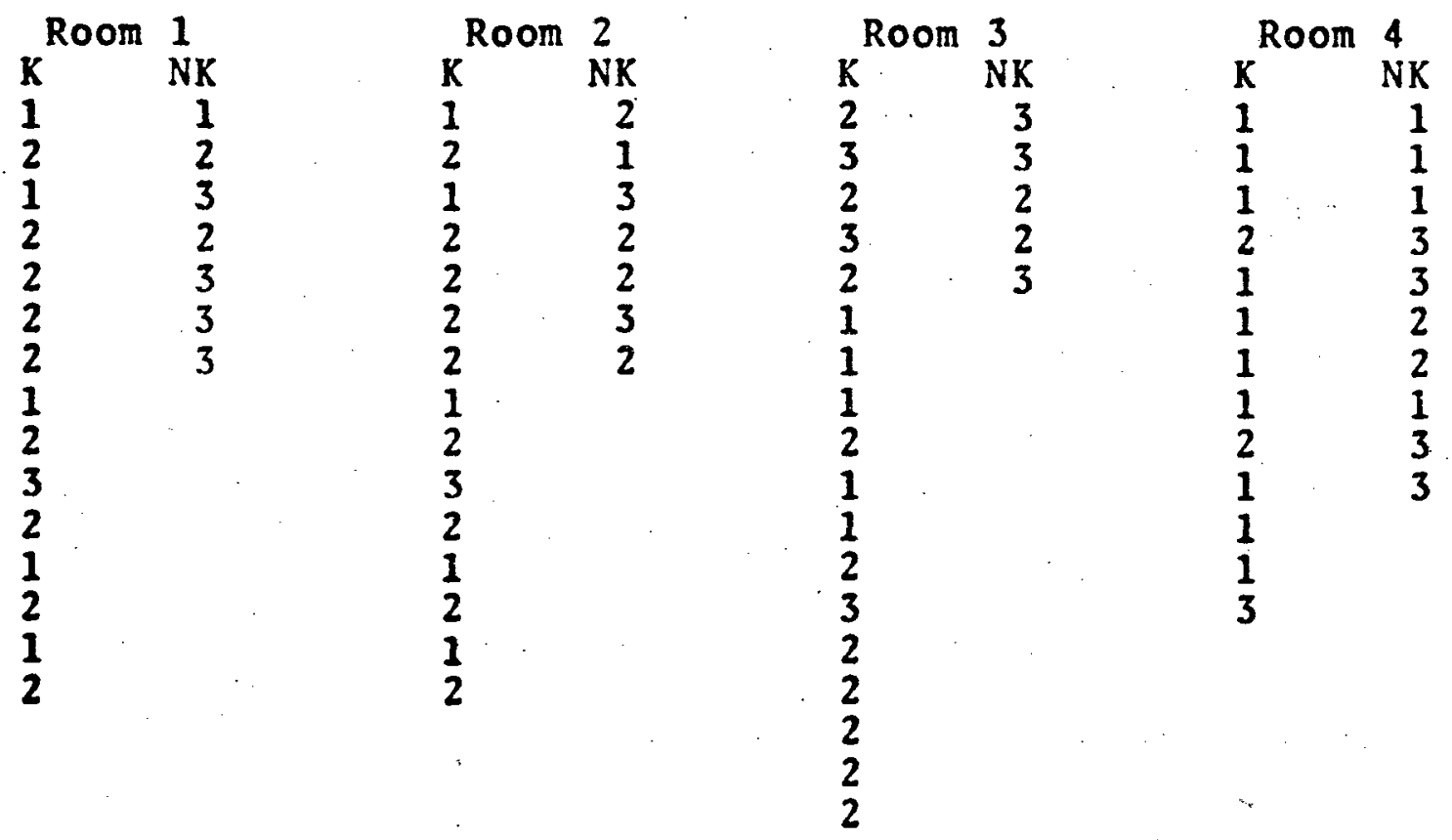


\section{CHARACTER TRAIT JUDGEMENT}

FIRST GRADE

\section{Origina1ity}
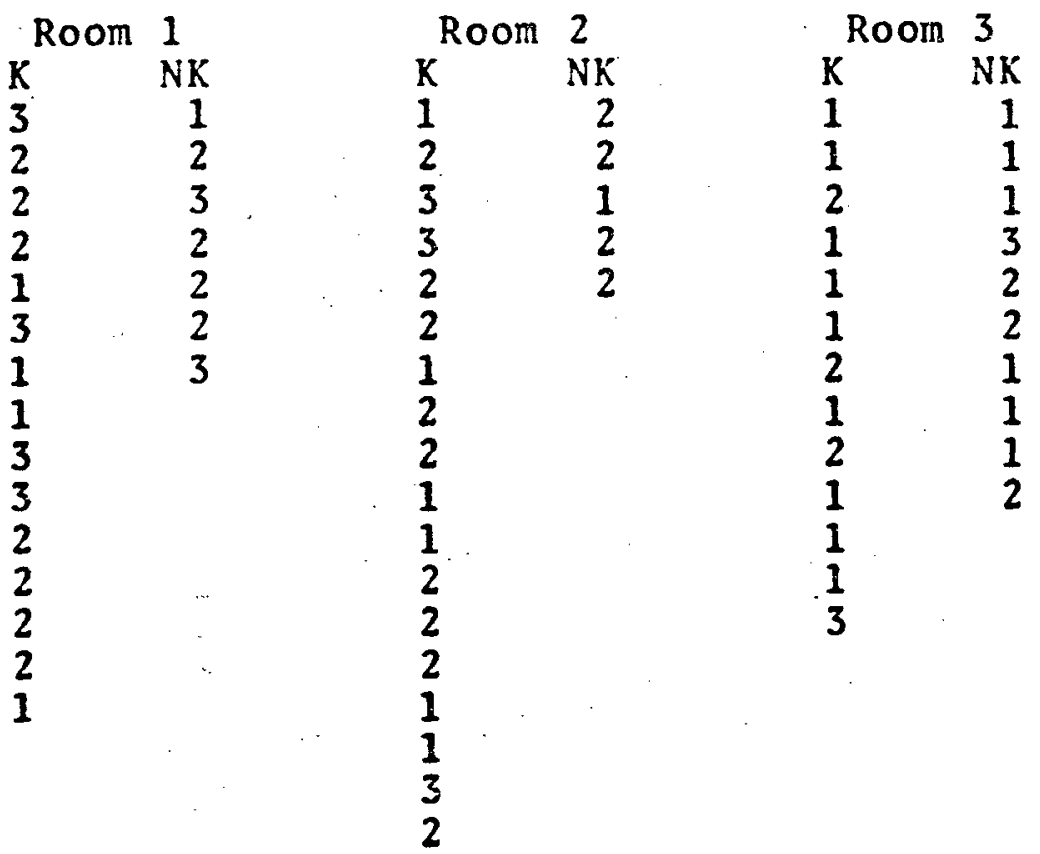

\section{Response to Directions}

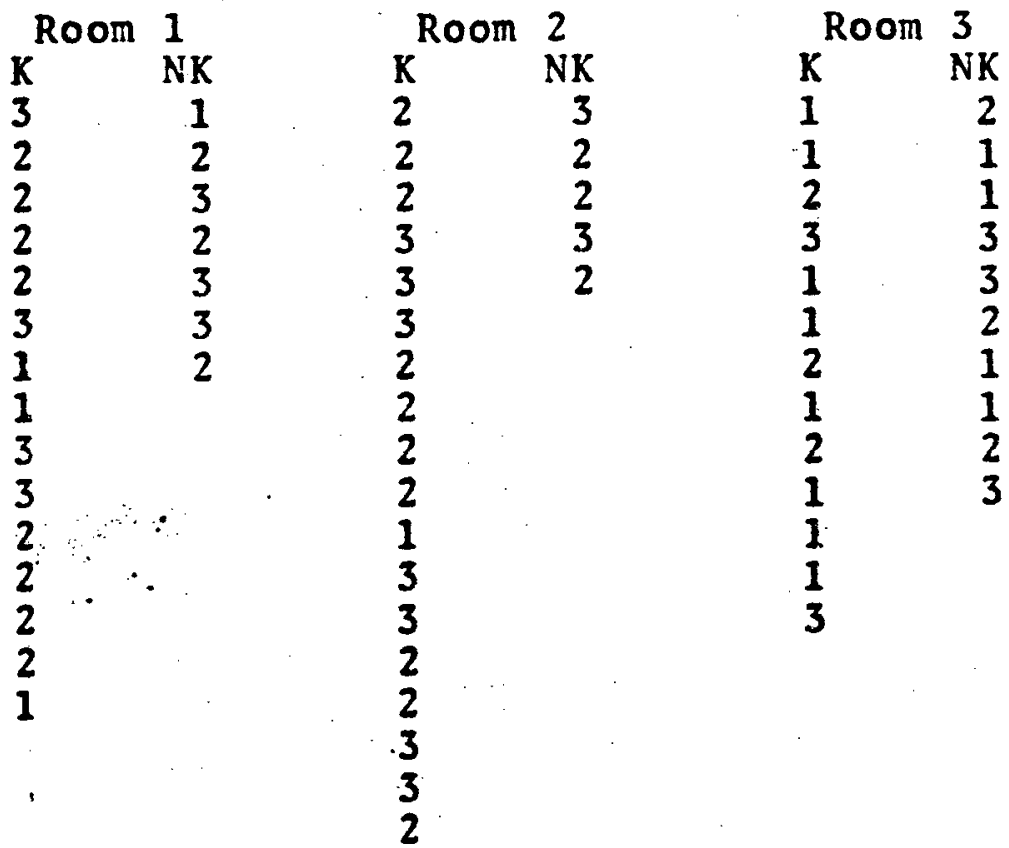

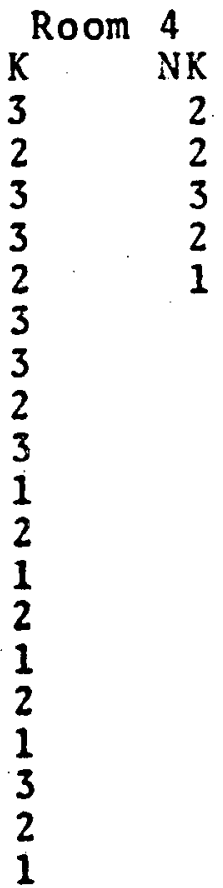


CHARACTER TRAIT JUDGEMENT

FIRST GRADE

Oral Expression

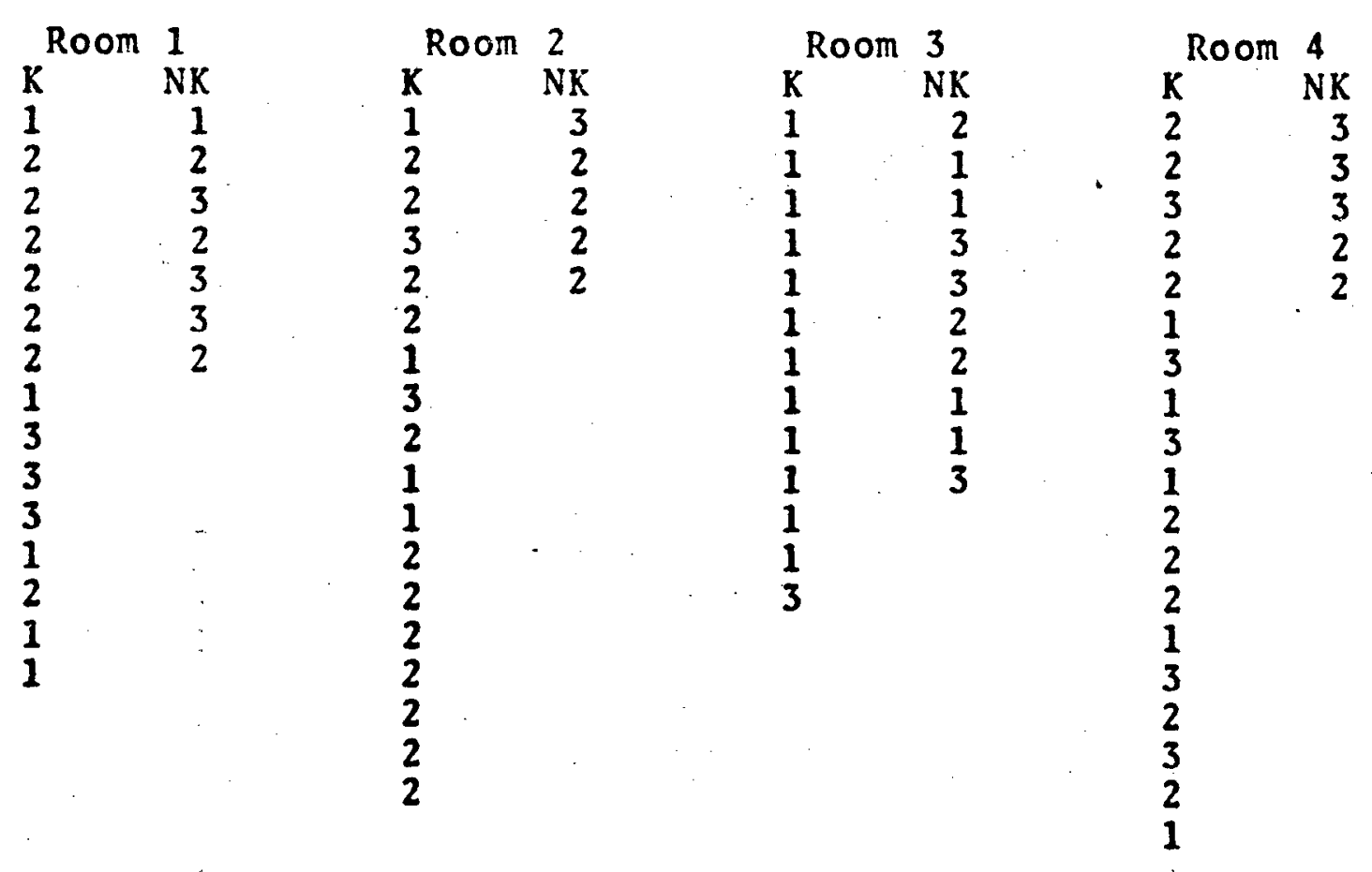

Ability to Play

$\mathrm{K}^{\text {Room }} \underset{\mathrm{NK}}{1}$

$\begin{array}{ll}1 & 2 \\ 2 & 2\end{array}$

$2 \quad 2$

22

22

32

$2 \quad 2$

2

Room 3

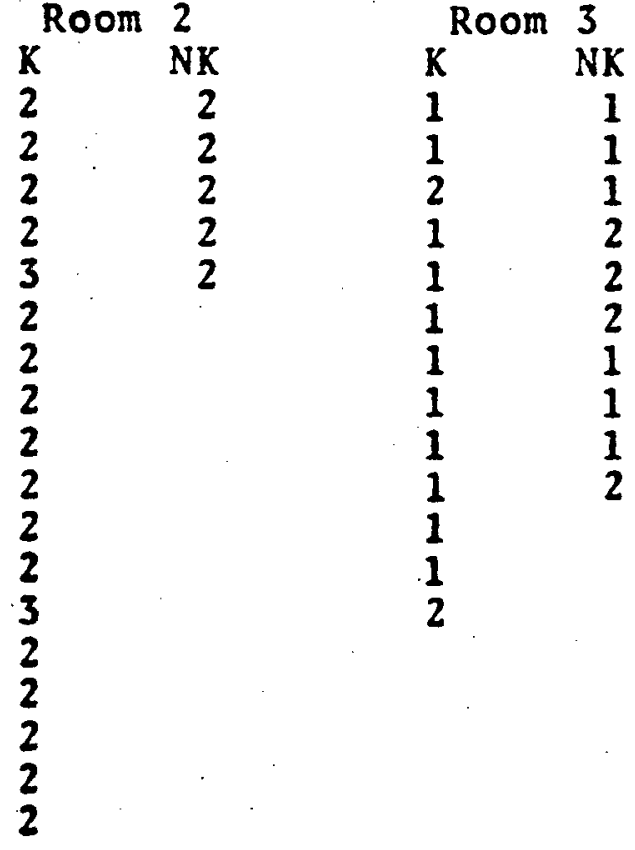

Room 4

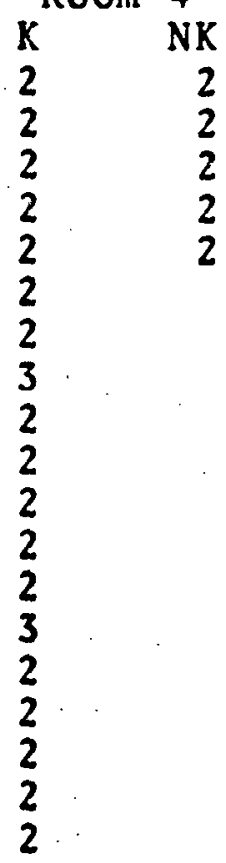


CHARACTER TRAIT JUDGEMENT

FOURTH GRADE

Self-Confidence
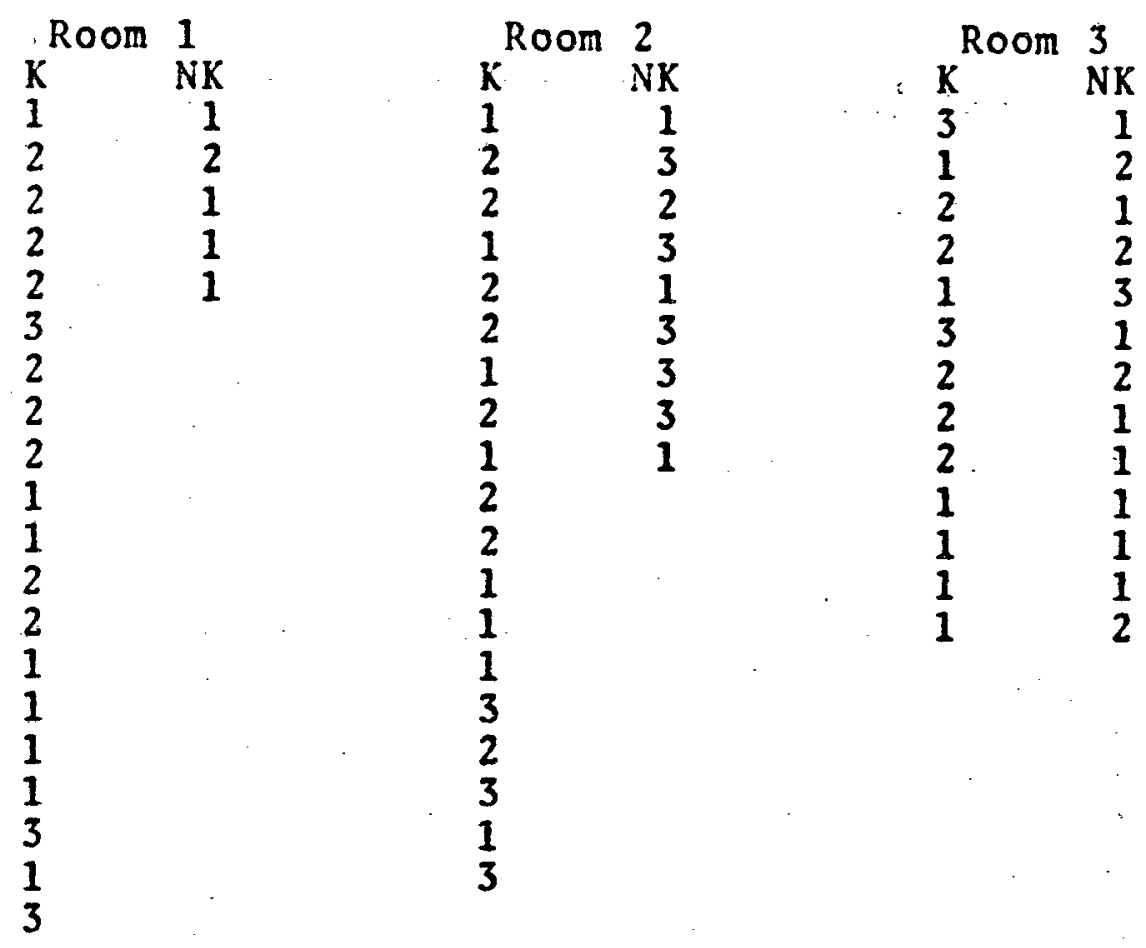

Ability to Mix
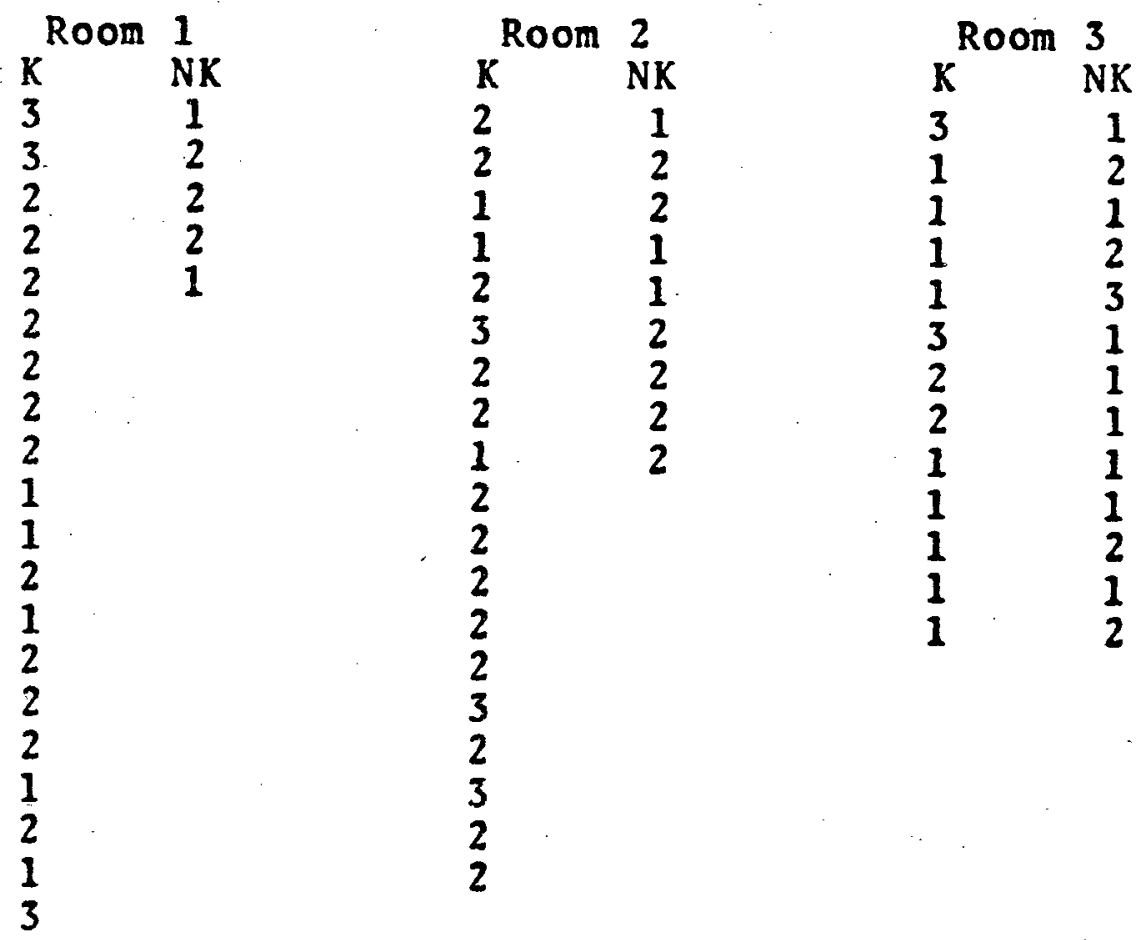


\section{CHARACTER TRAIT JUDGERENT}

FOURTH GRADE

\section{Friendliness}

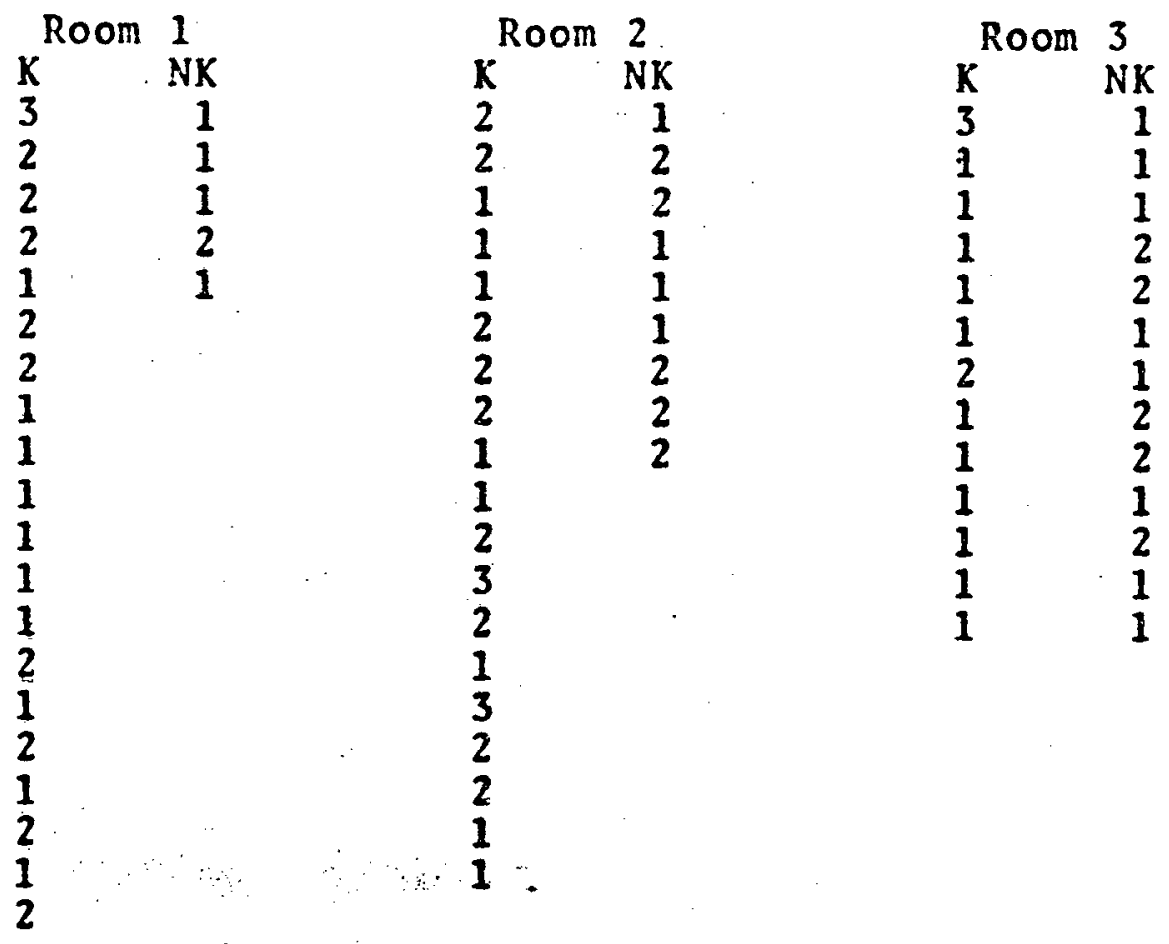

Interest
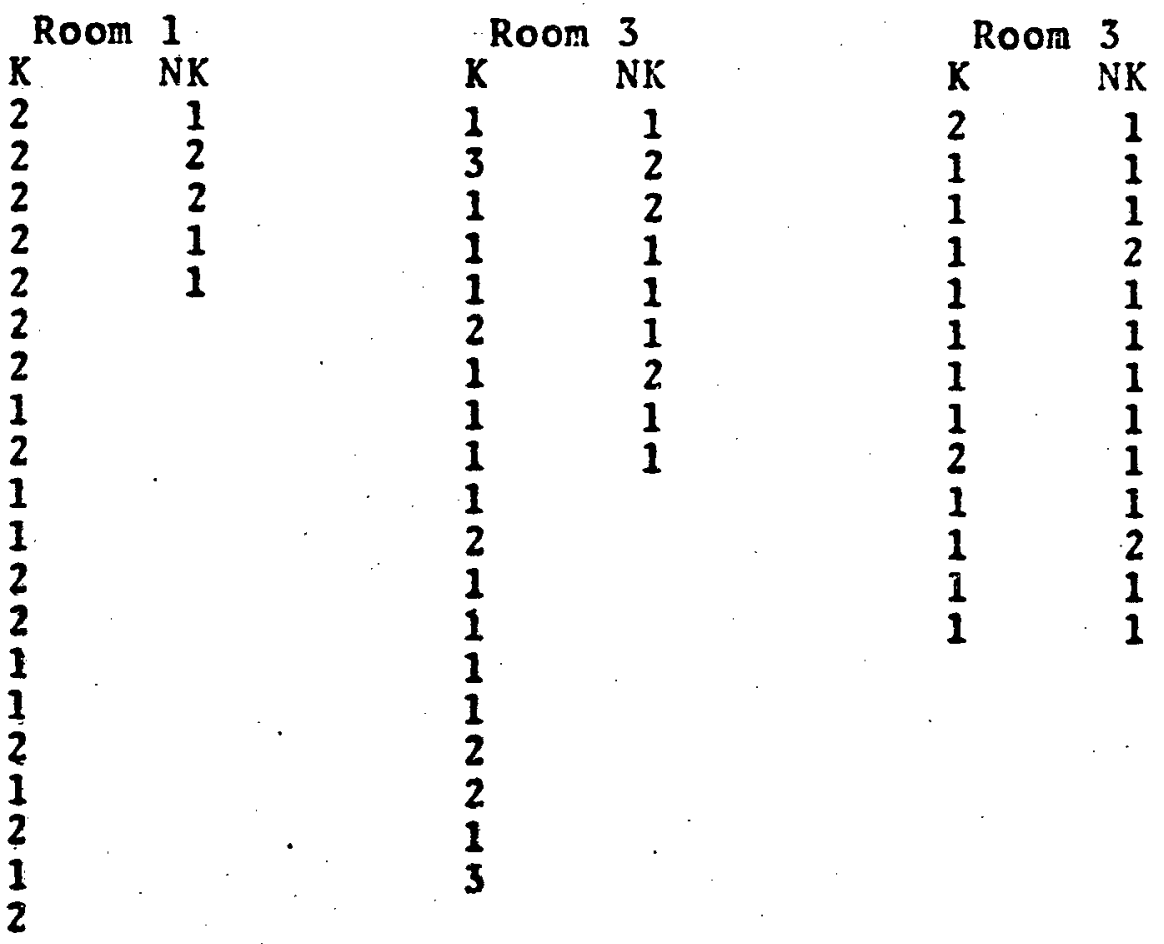
Character tRAIT JUDGEMENT

FOURTH GRADE

Attention
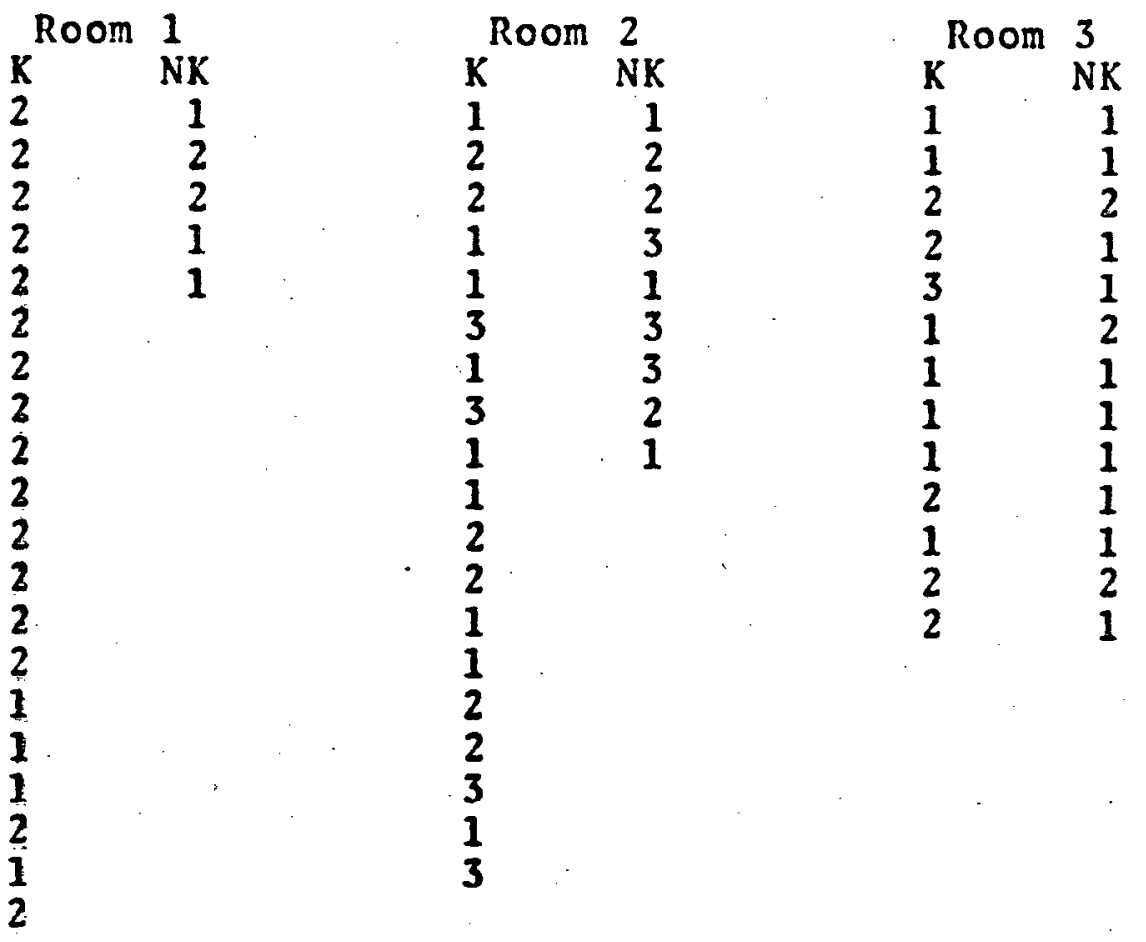

Ability to Think
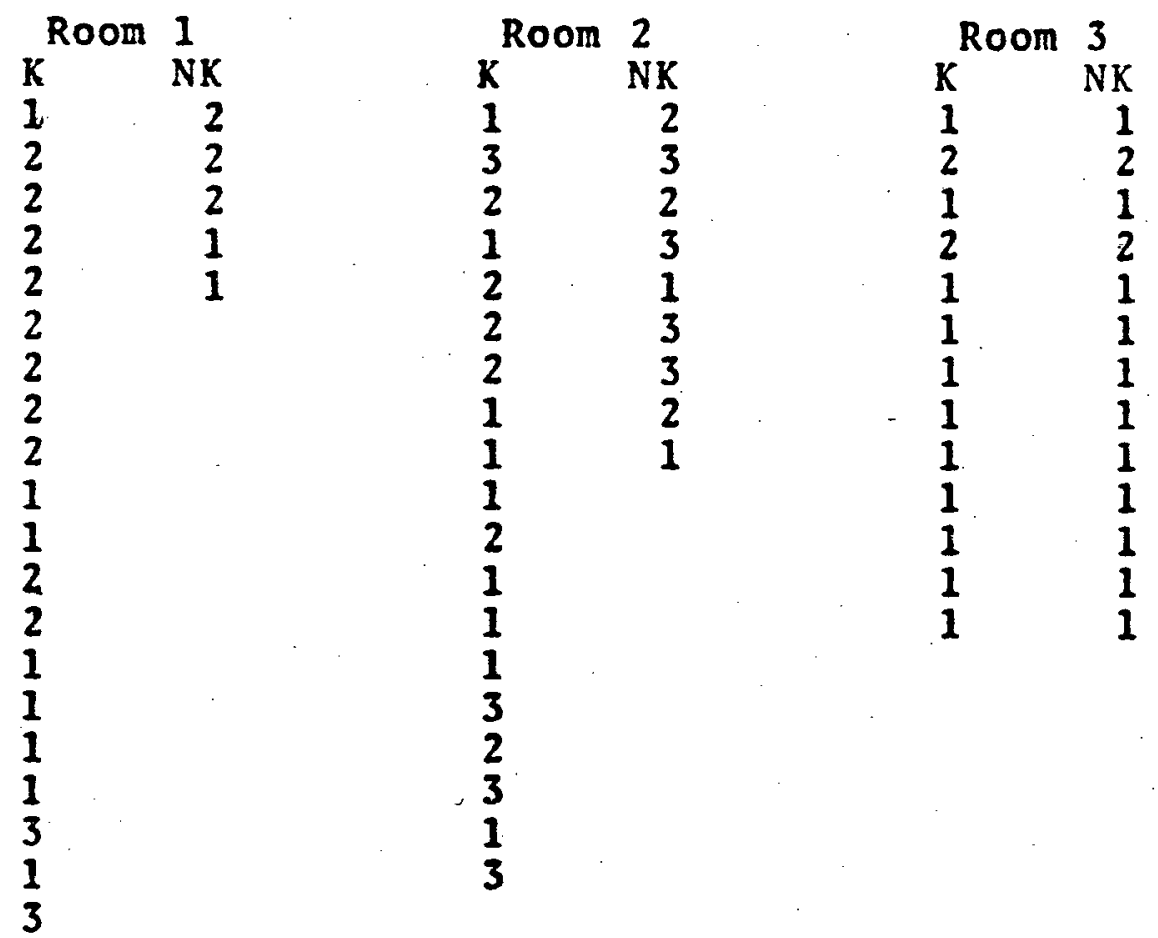
CHARACTER TRAIT JUDGEMENT

FOURTH GRADE

Originality
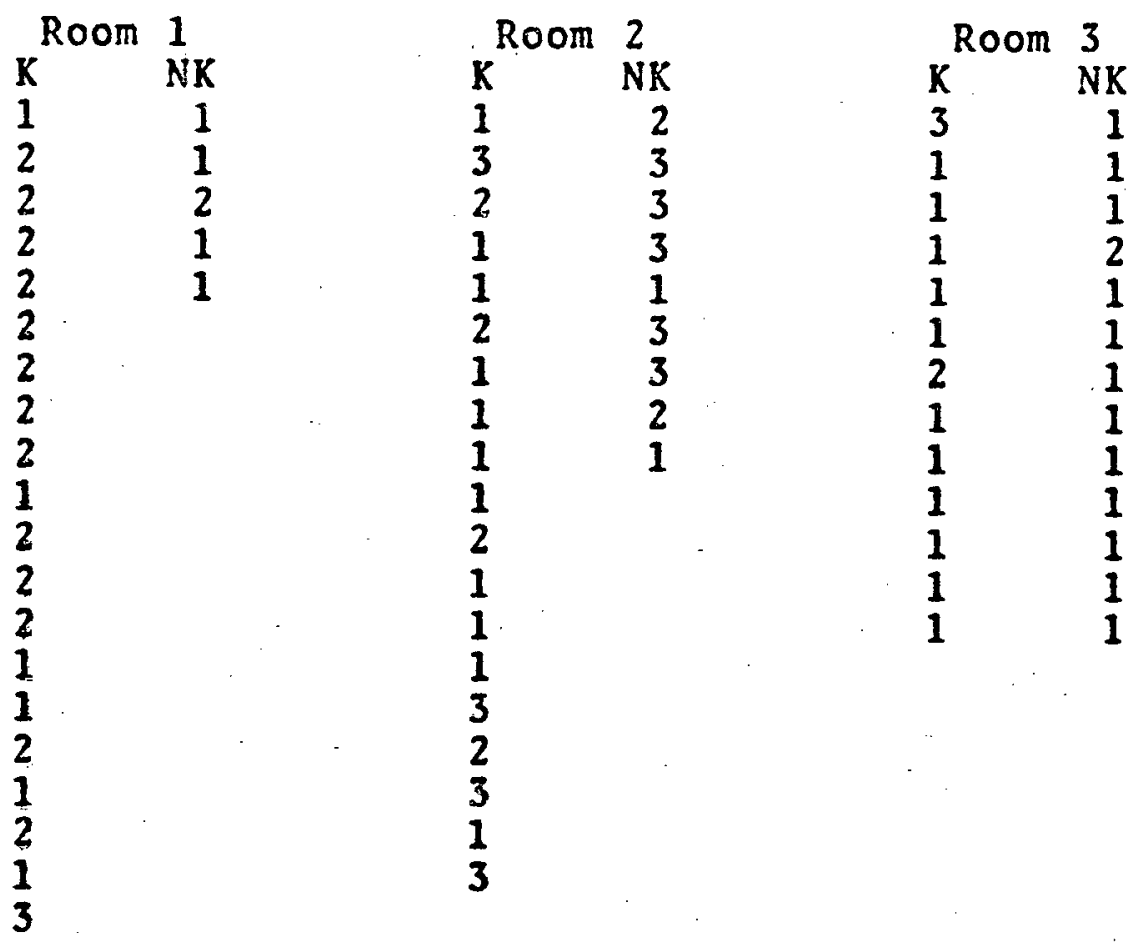

Response to Directions
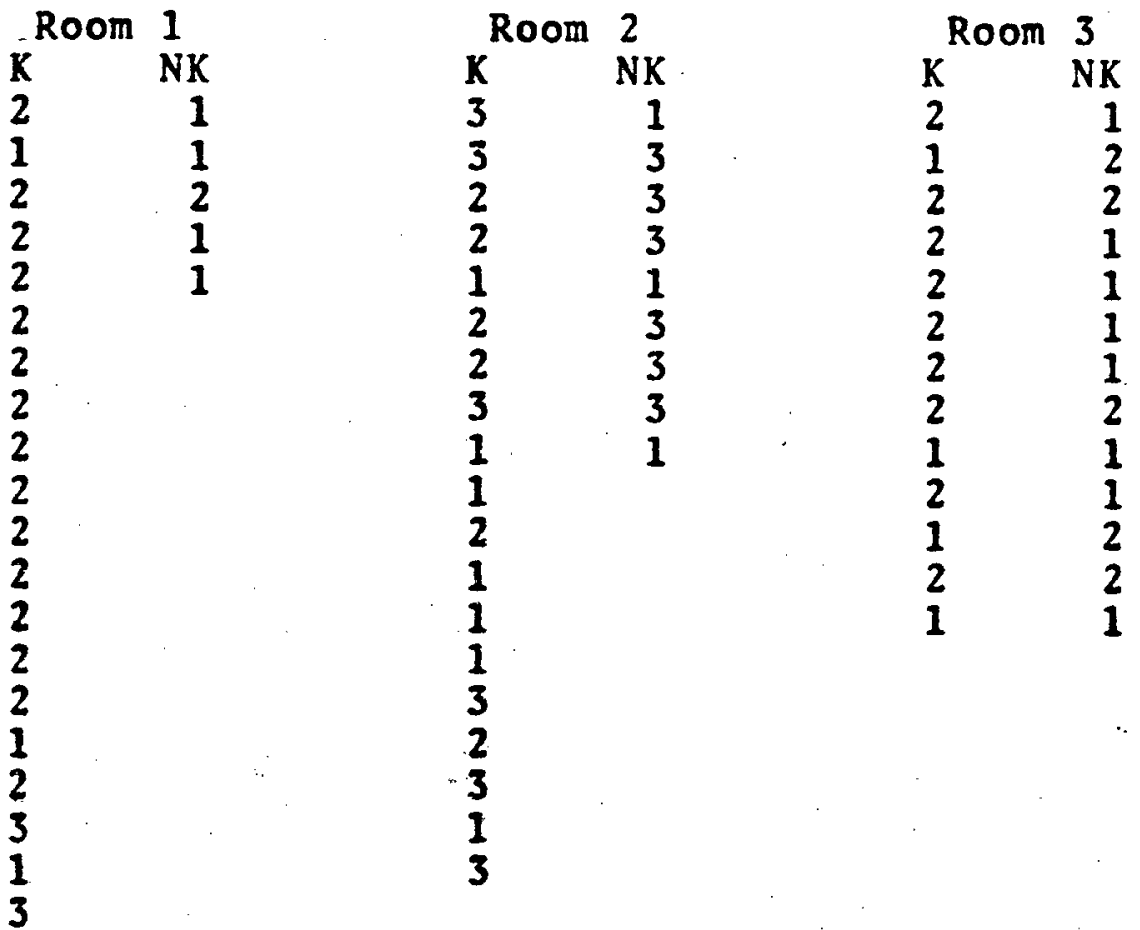
CHARACTER TRAIT JUDGEMENT

FOURTH GRADE

\section{Oral Expression}
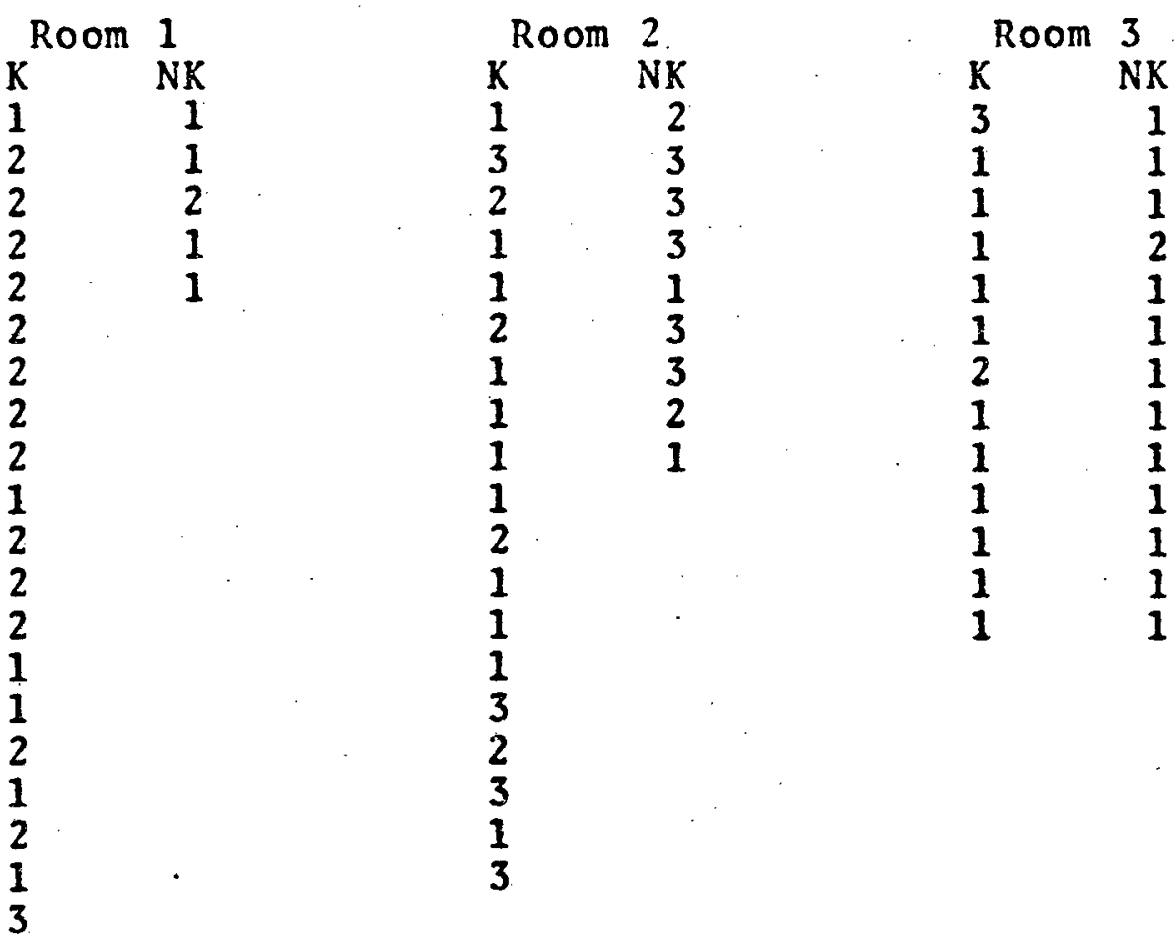

Ability to Play

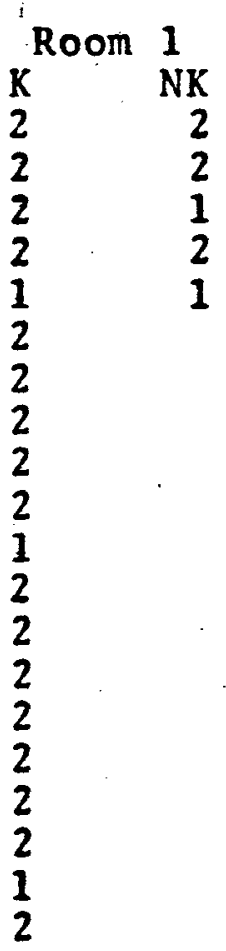

\begin{tabular}{lrrr} 
Room & 2 & \multicolumn{2}{c}{ Room } \\
K & NK & K & NK \\
1 & 1 & 3 & 2 \\
2 & 2 & 1 & 1 \\
1 & 2 & 1 & 1 \\
1 & 1 & 1 & 1 \\
1 & 1 & 1 & 2 \\
3 & 2 & 2 & 1 \\
1 & 2 & 1 & 1 \\
1 & 2 & 1 & 1 \\
1 & 1 & 1 & 1 \\
1 & & 1 & 1 \\
2 & & 1 & 2 \\
1 & & 1 & 2 \\
1 & & 1 & 2
\end{tabular}


APPENDIX E

NINE WEEKS ACHIEVEMENT RATINGS

First Grade

Fourth Grade 
NINE WEEKS ACHIEVEMENT RATINGS

FIRST GRADE

READ ING

$K^{\text {Room }} \underset{\text { NK }}{1}$

$K^{\text {Room }} \underset{\text { NK }}{2}$

$\begin{array}{ll}\text { Room } & 3 \\ \text { NK }\end{array}$

$\begin{array}{ll}\text { Room } & 4 \\ & \text { NK }\end{array}$

$\begin{array}{llll}2 & 3 & 2 & 1 \\ 3 & 1 & 2 & 2 \\ 3 & 2 & 2 & 2 \\ 2 & 2 & 1 & 2 \\ 2 & 2 & 2 & 2\end{array}$

$\begin{array}{ll}2 & 1 \\ 2 & 2\end{array}$

4

1

2

1

3

3
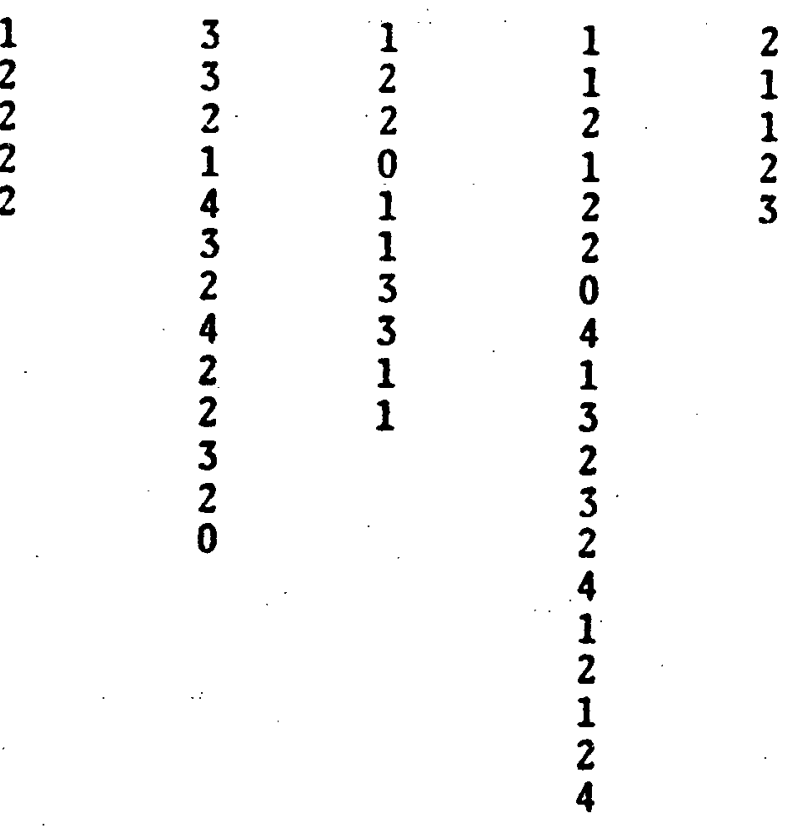

WRITING

$\mathrm{K}^{\text {Room }} \underset{\mathrm{NK}}{1}$<smiles>[R]O[R]([Y])=[W]</smiles>

$K^{\text {Room }} \underset{\mathrm{NK}}{3}$
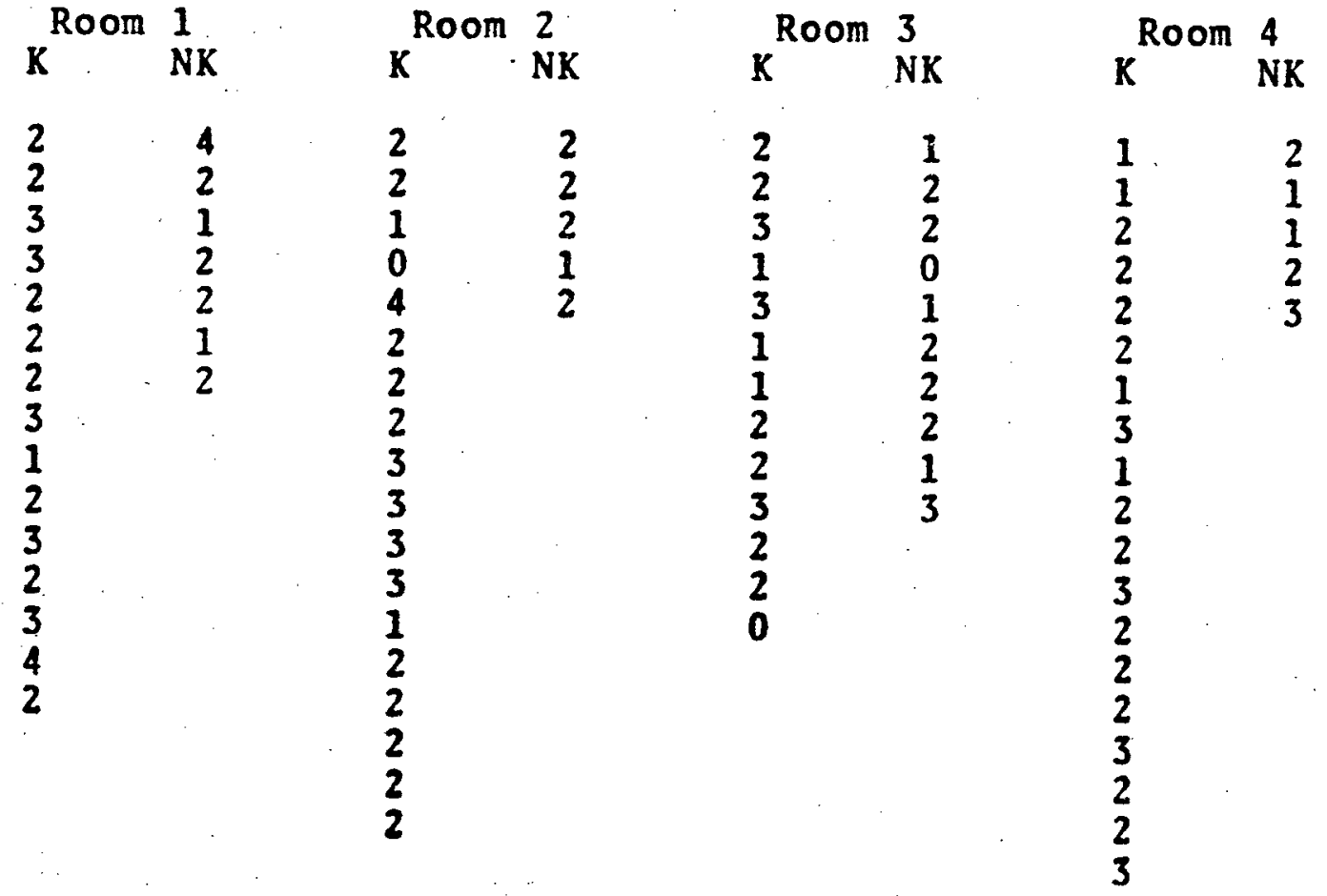
NINE WEEKS ACHIEVEMENT RATINGS

FIRST GRADE

MATHEMATICS

\begin{tabular}{llll} 
K $^{\text {Room }}$ & NK & \multicolumn{2}{c}{ Room 2} \\
3 & 4 & 3 & NK \\
4 & 1 & 2 & 2 \\
4 & 2 & 2 & 2 \\
3 & 3 & 1 & 2 \\
3 & 3 & 2 & 2 \\
2 & 3 & 2 & \\
3 & 2 & 2 & \\
3 & & 2 & \\
1 & & 2 & \\
2 & & 2 & \\
3 & & 3 & \\
4 & & 2 & \\
3 & & 2 & \\
3 & & 2 & \\
3 & & 2 & \\
& & 2 &
\end{tabular}

$\mathrm{K}^{\text {Room } 3} \underset{\mathrm{NK}}{3}$

1
3
3

0

0

2

3

1

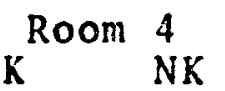

$\begin{array}{ll}2 & 3 \\ 1 & 0 \\ 2 & 1 \\ 1 & 3 \\ 3 & 4\end{array}$

4

2

0

3

3

3

3

2

3 
NINE WEFKS ACHIEVEMENT RATINGS

FOURTH GRADE

READING

$\mathrm{K}^{\text {Room }} \underset{\text { NK }}{1}$

$\mathrm{K}^{\text {Room }} \underset{\text { NK }}{2}$

${ }_{K}^{\text {Room } 3}$ NK

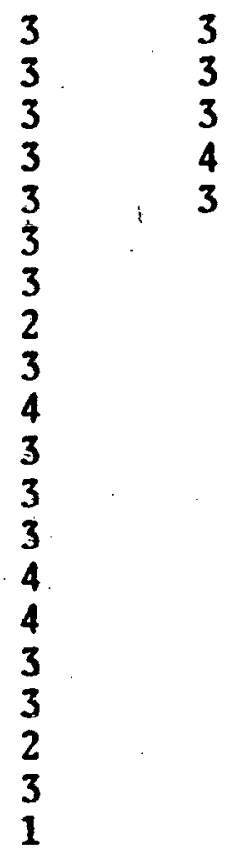

$\begin{array}{llll}2 & 3 & 4 & 3 \\ 2 & 2 & 3 & 2 \\ 2 & 4 & 3 & 2 \\ 4 & 2 & 3 & 2 \\ 3 & 4 & 2 & 4 \\ 3 & 2 & 4 & 3 \\ 2 & 2 & 2 & 2 \\ 3 & 3 & 2 & 3 \\ 4 & 4 & 4 & 3 \\ 4 & & 3 & 3 \\ 3 & & 4 & 3 \\ 4 & & 3 & 2 \\ 4 & & 4 & 3\end{array}$

WR IT ING

$\mathrm{K}^{\text {Room }} \mathbf{1}$

$\mathrm{x}^{\text {Room }} \underset{\text { NK }}{2}$

$\mathrm{K}^{\text {Room }} \stackrel{3}{\text { NK }}$

$\begin{array}{ll}3 & 4 \\ 4 & 3 \\ 3 & 3 \\ 4 & 4 \\ 3 & 4\end{array}$

$\begin{array}{ll}2 & 3 \\ 2 & 4 \\ 3 & 2 \\ 3 & 2 \\ 4 & 3 \\ 3 & 3 \\ 4 & 3 \\ 2 & 4 \\ 3 & 4\end{array}$

$\begin{array}{ll}2 & 3 \\ 4 & 2 \\ 2 & 3 \\ 3 & 2\end{array}$

1.3

3

3

3

3

4

3

3

3

4

4

3

4

3 
NINE WEEKS ACHIEVEMENT RATINGS

FOURTH GRADE

\section{MATHEMATICS}

$\mathrm{K}^{\text {Room }} \underset{\mathrm{NK}}{1}$

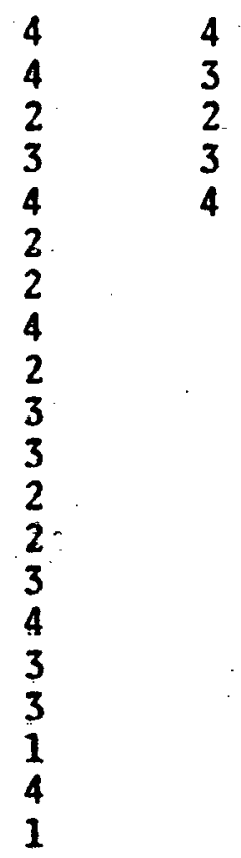

$K^{\text {Room }} \underset{\text { NK }}{2}$

$\begin{array}{ll}3 & 4 \\ 2 & 2 \\ 2 & 2 \\ 4 & 3 \\ 3 & 4\end{array}$

3

4

3

4

4

3

4

4

2

2

3

4
Room 3
NK

$\begin{array}{ll}3 & 4 \\ 3 & 3 \\ 4 & 3 \\ 2 & 3 \\ 2 & 4 \\ 3 & 3 \\ 4 & 2 \\ 4 & 4 \\ 3 & 3 \\ 3 & 4 \\ 4 & 1 \\ 2 & 2 \\ 3 & 4\end{array}$


APPENDIX F

CALIFORNIA TEST OF PERSONALITY

PRIMARY - Grades Kgn. to 3

ELEMENTARY - Grades 4-5-6-7-8

INDIVIDUAL TEST SCORES

Grade One

Grade Four 


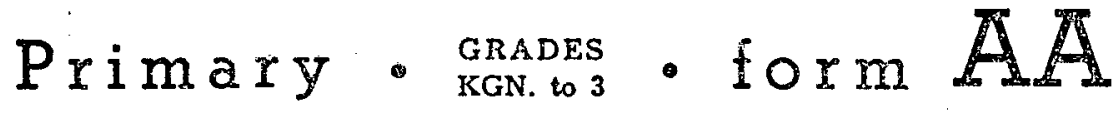 \\ California Test of Personality \\ 1953 Revision \\ Devised by \\ LOUIS P. THORPE, WILIIS W. CLARK, AND ERNEST W. TIEGS}

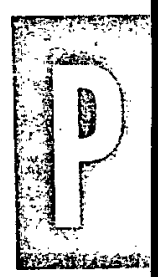

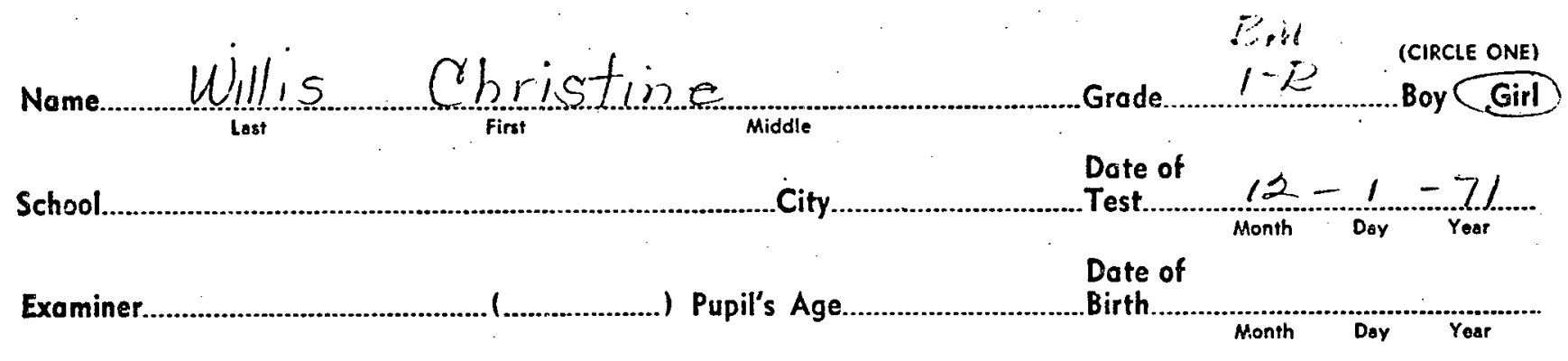

\section{TO BOYS AND GIRLS:}

This booklet has some questions which can be answered YES or NO. Your answers will show what you usually think, how you usually feel, or what you usually do about things. Work as fast as you can without making mistakes. DO NOT TURN THIS PAGE UNTIL TOLD TO DO SO. 


\section{PRACTICE QUESTIONS}

A. Do you have a dog at home? YES NO

B. Did you walk all the way to school today? YES NO 
1. Is it easy for you to play by yourself when you have to?

(YES NO

2. Is it easy for you to talk to your class?

YES NO $\checkmark$

3. Do you feel like crying when you are hurt a little?

(YES) NO $V$

4. Do you feel bad when you are blamed for things?

YES NO $\checkmark$

5. Do you usually finish the games you start?

YES NO $\checkmark$

6. Does someone usually help you dress? YES NO

7. Can you get the children to bring back your things?

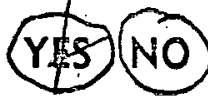

8. Do you need help to eat your meals? YES NO

1. Do the children think you can do things well?

(YES NO

2. Do the other children often do nice things for you?

YES NO

3. Do you have fewer friends than other children?

4. Do most of the boys and girls like you?

YES NO

5. Do your folks think that you are bright?

YES NO

6. Can you do things as well as other children?

7. Do people think that other children are better than you?

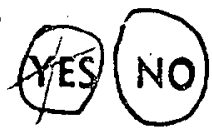

YES

8. Are most of the children smarter than you?

YES NO 
1. Do your folks sometimes let you buy things?

(YES) NO

2. Do you have to tell some people to let you alone?

(YES) NO $\checkmark$

3. Do you go to enough new places?

YES NO

4. Do your folks keep you from playing with the children you like?

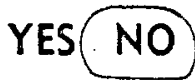

5. Are you allowed to play the games you like?

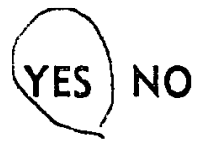

6. Are you punished for many things you do?

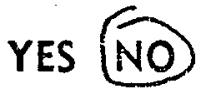

7. May you do most of the things you like?

(YES NO

8. Do you have to stay at home too much?

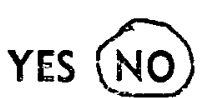

1. Do you need to have more friends? YES NO $\checkmark$ SECTION 1 D

2. Do you feel that people don't like you?

\section{YES NO}

3. Do you have good times with the children at school?

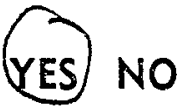

4. Are the children glad to have you in school?

YES; NO

5. Are you lonesome even when you are with people?

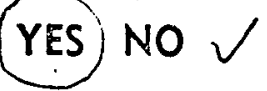

6. Do people like to have you around them?

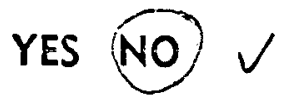

7. Do most of the people you know like you?

YES NO

8. Do lots of children have more fun at home than you do?

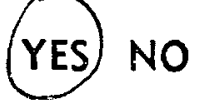


1. Do the boys and girls often try to cheat you?

(YES) NO $\checkmark$

2. Do you feel very bad when people talk about you?

YES NO $V$

3. Are most of the boys and girls mean to you?

YES NO $v$

4. Do you feel bad because people are mean to you?

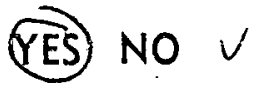

5: Do many children say things that hurt your feelings?

(YES NO $V$

6. Are many older people so mean that you hate them?

(YES NO $\checkmark$

7. Do you often feel so.bad that you do not know what to do?

YES NO $v$

8. Would you rather watch others play than play with them?

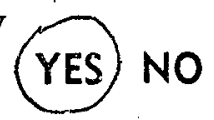

Section I E

(number right)

0

1. Do you often wake up because of
bad dreams?

2. Is it hard for you to go to sleep at night?

'YÉS: (NO)

3. Do things often make you cry?

(YES) NO $\checkmark$

4. Do you catch colds easily?

YES NO $\checkmark$

5. Are you often tired even in the morning?

6. Are you sick much of the time?

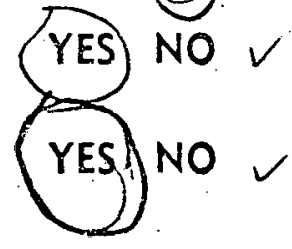

7. Do your eyes hurt often?

8. Are you often mad at people without knowing why? 
1. Do the boys and girls often try to cheat you?

YES NO $\checkmark$

2. Do you feel very bad when people talk about you?

YES NO $V$

3. Are most of the boys and girls mean to you?

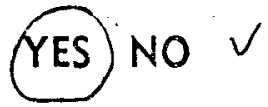

4. Do you feel bad because people are mean to you?

(YES) NO $V$

5. Do many children say things that hurt your feelings?

YES No $V$

6. Are many older people so mean that you hate them?

(YES) NO $\checkmark$

7. Do you often feel so bad that you do not know what to do?

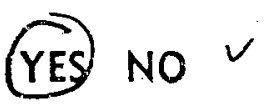

8. Would you rather watch others play than play with them?

1. Do you often wake up because of bad dreams?

2. Is it hard for you to go to sleep at night?

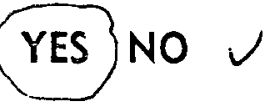

'YES (NO)

3. Do things often make you cry?

(YES) NO $\checkmark$

4. Do you catch colds easily?

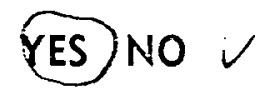

5. Are you often tired even in the morning?

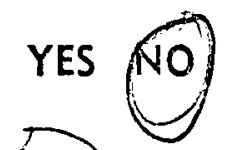

6. Are you sick much of the time?

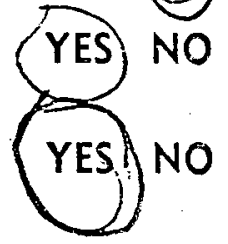

8. Are you often mad at people without knowing why?

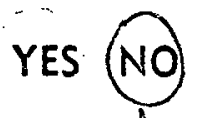


1. Do you often do nice things for the other children in your school?

2. Are there many bad children in your school?

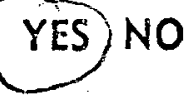

(YES NO $\checkmark$

3. Do the boys and girls seem to think that you are nice to them?

YES NO

4. Do you think that some teachers do not like the children?

5. Would you rather stay home from school if you could?

YES NO $V$

6. Is it hard to like the children in your school?

YES NO

7. Do the other boys and girls say that you don't play fair in games?

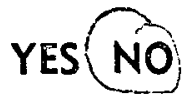

8. Do the children at school ask you to play games with them?

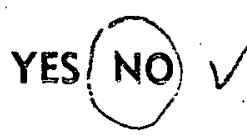

Section $2 \varepsilon$

(number right)

1. Do you play with some of the children living near your home?

2. Do the people near your home seem to like you?

3. Are the people near your home often mean?

4. Are there people near your home who are not nice?

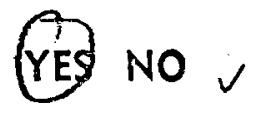

5. Do you have good times with people who live near you?

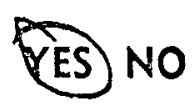

6. Are there some mean boys and girls who live near you?

7. Are you asked to play in other people's yards?

8. Do you have more fun near your home than other children do near theirs?

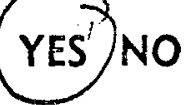

YES
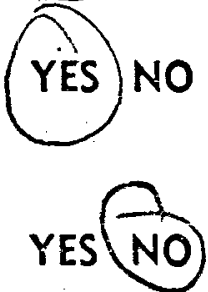
1. Do you often do nice things for the other children in your school?

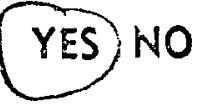

SECTION 2 E

2. Are there many bad children in your school?

YES NO $\checkmark$

3. Do the boys and girls seem to think that you are nice to them?

YES NO

4. Do you think that some teachers do not like the children?

YES NO)

5. Would you rather stay home from school if you could?

YES NO $V$

6. Is it hard to like the children in your school?

YES NO

7. Do the other boys and girls say that you don't play fair in games?

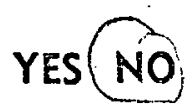

8. Do the children at school ask you to play games with them?

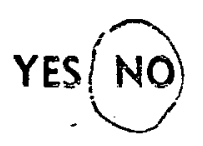

Section 2 E

(number right) ...

1. Do you play with some of the children living near your home?

(YES NO

SECTION 2 F

2. Do the people near your home seem to like you?

3. Are the people near your home often mean?

YES NO $\checkmark$

4. Are there people near your home who are not nice?

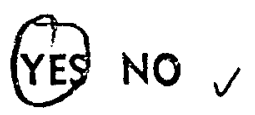

5. Do you have good times with people who live near you?

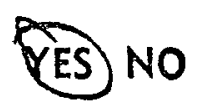

6. Are there some mean boys and girls who live near you?

7. Are you asked to play in other people's yards?

8. Do you have more fun near your home than other children do near theirs?

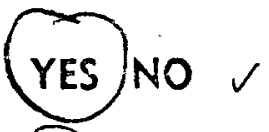




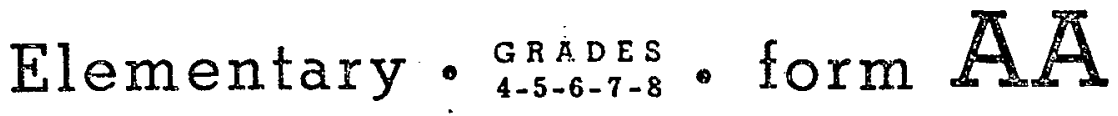 \\ California Test of Personality \\ 1953 Revision \\ Devised by \\ LOUIS P. THORPE, WILLIS W. CLARK, AND ERNEST W. TIEGS}

Do not write or mark on this booklet unless told to do so by the examiner.

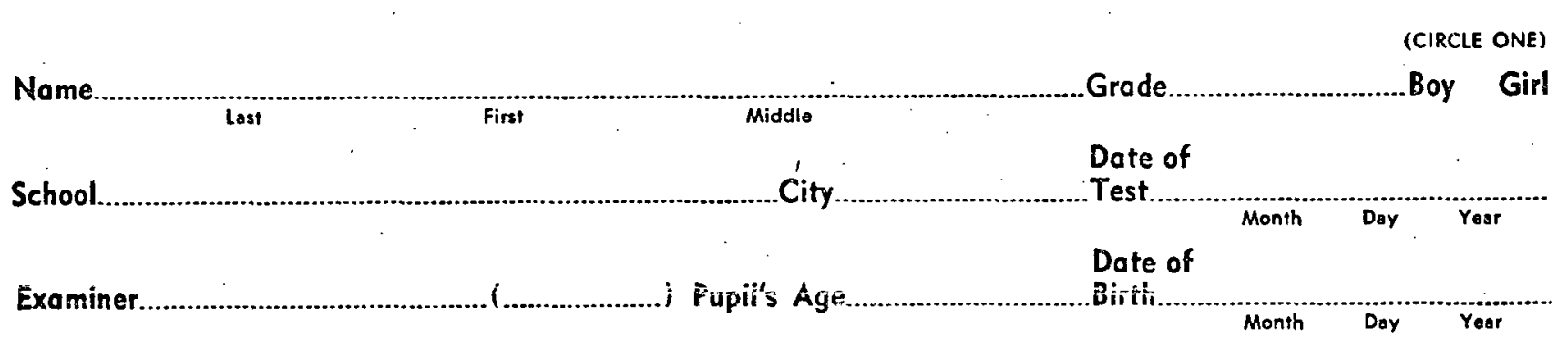

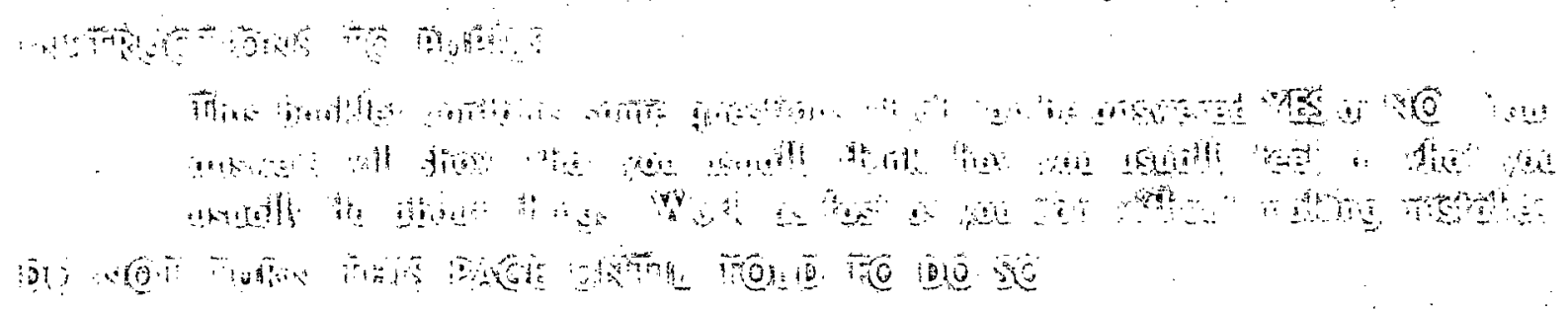

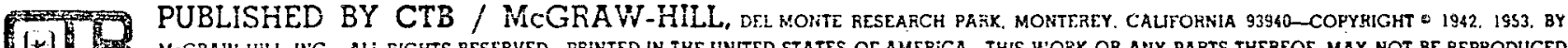 [W] WEGRA-HILL INC - ALL RIGHTS RESERVED -PEINTED IN THE UNITED STATES OF AMERICA-THIS WOPK. OR ANY PARTS THEREOF, MAY NOT BE REPRODUCED $8>6$ T ANY TORM WTHC




\section{INSTRUCTIONS TO PUPILS}

DO NOT WRITE OR MARK ON THIS TEST BOOKLET UNLESS TOLD TO DO SO BY THE EXAMINER.

You are to decide for each question whether the answer is YES or NO and mark it as you are told. The following are two sample questions:

\section{SAMPLES}

A. Do you have a dog at home? YES NO

B. Can you ride a bicycle? YES NO

\section{DIRECTIONS FOR MARKING ANSWERS}

\section{ON ANSWER SHEETS}

Woke o heavy biuck mark under the word YES or NO to show your answer. If you have a dog at home, you would mark under the YES for question $A$ as shown below. If you cannot ride a bicycle, you would mark under the NO for question $B$ as shown below.

$$
\mathrm{A}
$$

Remember, you mork under the word that shows your answer. Now find Samples $A$ and $B$ on your answer sheet and show your answer for each by marking YES or NO. Do it now. Find onswer row number 1 on your answer sheet. Now wait until the examiner tells you to begin.

\section{ON TEST BOOKLETS}

Draw a circle around the word YES or NO, whichever shows your answer. If you have a dog of home, draw a circle around the word YES in Sample A above; if not, draw a circle around the word NO. Do it now.

If you can ride a bicycle, draw a circle around the word YES in Sample B obove; if not, draw a circle around the word NO. Do it now.

Now woit until the exominer tells you to begin.

After the examiner tells you to begin, go right on from one page to another until you have finished the test or are told to stop. Work as fast as you can without making mistakes. Now look at item 1 on page 3. Ready, begin. 
1. Do you usually keep at your work until it is done?

2. Do you usually apologize when you are wrong?

3. Do you help other boys and girls have a good time at parties?

YES NO

4. Do you usually believe what other boys or girls tell you?

YES NO

5. Is it easy for you to recite or talk in class?

YES NO

6. When you have some free time, do you usually ask your parents or teacher what to do?

YES NO

7. Do you usually go to bed on time, even when you wish to stay up?

8. Is it hard to do your work when someone blames you for something?

9. Can you often get boys and girls to do what you want them to?

10. Do your parents or teachers usually need to tell you to do your work?

YES , NO

11. If you are a boy, do you talk to new girls? If you are a girl, do you talk to new boys ?

YES NO

12. Would you rather plan your own work than to have someone else plan it for you?

YES NO
13. Do your friends generally think that your ideas are good?

YES NO

14. Do people often do nice things for you?

YES NO

15. Do you wish that your father (or mother) had a better job?

YES NO

16. Are your friends and classmates usually interested in the things you do?

YES NO

17. Do your classmates seem to think that you are not a good friend?

YES NO

18. Do your friends and classmates often want to help you?

YES NO

19. Are you sometimes cheated when you trade things?

YES NO

20. Do your classmates and friends usually feel that they know more than you do?

YES NO

21. Do your folks seem to think that you are doing well?

YES NO

22. Can you do most of the things you try?

YES NO

23. Do people often think that you cannot do things very well?

YES NO

24. Do most of your friends and classmates think you are bright? YES NO

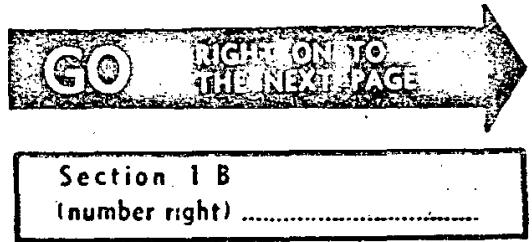

Inumber righ
Page 3

CTP-E.AA
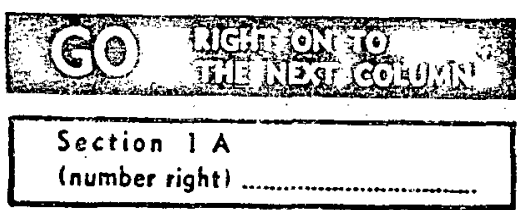
SECTION $1 \mathrm{C}$

25. Do you feel that your folks boss you too much?

YES

26. Are you allowed enough time to play?

YES NO

27. May you usually bring your friends home when you want to?

28. Do others usually decide to which parties you may go?

YES NO

40. Are you as well and strong as most boys and girls?

YES NO

41. Are your cousins, aunts, uncles, or grandparents as nice as those of most of your friends?

YES NO want to during your spare time? YES NO

30. Are you prevented from doing most of the things you want to?

YES NO

31. Do your folks often stop you from going around with your friends? YES NO

32. Do you have a chance to see many new things?

YES NO

33. Are you given some spending money?

YES NO

34. Do your folks stop you from taking short walks with your friends?

35. Are you punished for lots of little things?

36. Do some people try to rule you so much that you don't like it? YES NO

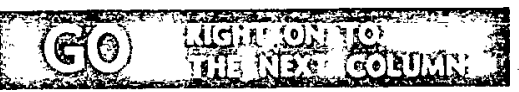

Poge 4

CTP-E - AA

Section $1 \mathrm{C}$

Section $1 \mathrm{D}$

(number right)
48. Do the boys and girls usually invite you to their parties?

YES NO 
49. Have people often been so unfair that you gave up?

YES NO

50. Would you rather stay away from most parties?

YES NO

51. Does it make you shy to have everyone look at you when you enter a room?

YES NO

52. Are you often greatly discouraged about many things that are important to you?

YES NO

53. Do your friends or your work often make you worry?

YES NO

54. Is your work often so hard that you stop trying?

55. Are people often so unkind or unfair that it makes you feel bad? YES NO

56. Do your friends or classmates often say or do things that hurt your feelings?

YES NO

57. Do people often try to che'at you or do mean things to you?

YES NO

58. Are you often with people who have so little interest in you that you feel lonesome?

YES NO

59. Are your studies or your life so dull that you often think about many other things?

YES NO

60. Are people often mean or unfair to you?

YES NO
61. Do you often have dizzy spells? YES NO

62. Do you often have bad dreams? YES NO

63. Do you often bite your fingernails?

YES NO

64. Do you seem to have more headaches than most children?

YES NO

65. Is it hard for you to keep from being restless much of the time? YES NO

66. Do you often find you are not hungry at meal time?

YES NO

67. Do you catch cold easily?

YES NO

68. Do you often feel tired before noon?

YES NO

69. Do you believe that you have more bad dreams than most of the boys and girls?

YES NO

70. Do you often feel sick to your stomach?

YES NO

71. Do you often have sneezing spells?

YES NO

72. Do your eyes hurt often?

YES NO
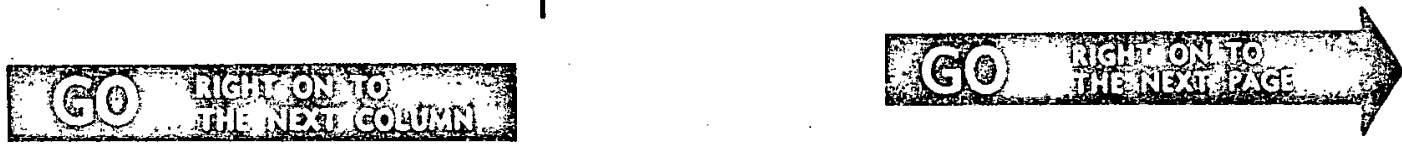

Page 5

CTP.E.AA

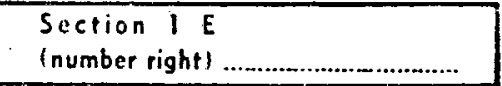

Section I F

inumber right 
73. Is it all right to cheat in a game when the umpire is not looking? YES NO

74. Is it all right to disobey teachers if you think they are not fair to you?

YES NO

75. Should one return things to people who won't return things they borrow?

76. Is it all right to take things you need if you have no money?

YES NO

77. Is it necessary to thank those who have helped you?

YES NO

78. Do children need to obey their fathers or mothers even when their friends tell them not to?

79. If a person finds something, does he have a right to keep it or sell it?

YES NO

80. Do boys and girls need to do what their teachers say is right?

81. Should boys and girls ask their parents for permission to do things?

YES NO

82. Should children be nice to people they don't like?

YES NO

83. Is it all right for children to cry or whine when their parents keep them home from a show?

YES NO

84. When people get sick or are in trouble, is it usually their own fault?

YES NO
85. Do you let people know you are right no matter what they say?

YES NO

86. Do you try games at parties even if you haven't played them before?

YES NO

87. Do you help new pupils to talk to other children?

YES NO

88. Does it make you feel angry when you lose in games at parties?

YES NO

89. Do you usually help other boys and girls have a good time?

YES NO

90. Is it hard for you to talk to people as soon as you meet them?

YES NO

91. Do you usually act friendly to people you do not like?

YES NO

92. Do you often change your plans in order to help people?

YES NO

93. Do you usually forget the names of people you meet?

YES NO

94. Do the boys and girls seem to think you are nice to them?

YES NO

95. Do you usually keep from showing your temper when you are angry?

YES NO

96. Do you talk to new children at school?

YES NO

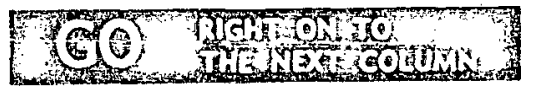

Section 2 A

CTP -E : AA

(number right)

Section 2

(number right) 
97. Do you like to scare or push smaller boys and girls?

98. Have unfair people often said that you made trouble for them? YES NO

99. Do you often make friends or classmates do things they don't want to?

YES NO

100. Is it hard to make people remember how well you can do things?

YES NO

101. Do people often act so mean that you have to be nasty to them?

YES NO

102. Do you often have to make a "fuss" or "act up" to get what you deserve?

YES NO

10j. is anyone at school so mean that you tear, or cut, or break things?

YES NO

104. Are people often so unfair that you lose your temper?

105. Is someone at home so mean that you often have to quarrel?

YES NO

106. Do you sometimes need something so much that it is all right to take it?

107. Do classmates often quarrel with you?

YES NO

108. Do people often ask you to do such hard or foolish things that you won't do them?

YES NO
109. Do your folks seem to think that you are just as good as they are?

YES NO

110. Do you have a hard time becalise it seems that your folks hardly ever have enough money? YES NO

111. Are you unhappy because your folks do not care about the things you like?

YES NO

112. When your folks make you mind are they usually nice to you about it?

YES NO

113. Do your folks often claim that you are not as nice to them as you should be?

YES NO

114. Do you like both of your parents about the same?

YES NO

115. Do you feel that your folks fuss at you instead of helping you?

YES NO

116. Do you sometimes feel like running away from home?

YES NO

117. Do you try to keep boys and girls away from your home because it isn't as nice as theirs?

YES NO

118. Does it seem to you that your folks at home often treat you mean?

YES NO

119. Do you feel that no one at home loves you?

YES NO

120. Do you feel that too many people at home try to boss you? YES NO

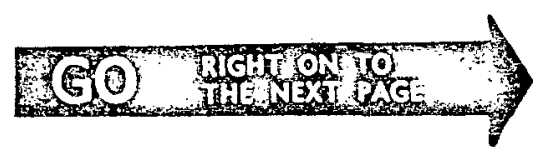

Section 20

(number right).
Page 7

CTP-E-AA

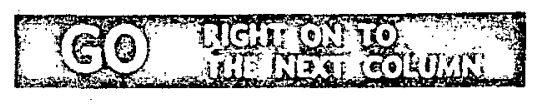

Section $2 \mathrm{C}$

(number right) 


\section{SECTION 2 E}

121. Do you think that the boys and girls at school like you as well as they should?

122. Do you think that the children would be happier if the teacher were not so strict?

123. Is it fun to do nice things for some of the other boys or girls?

124. Is school work so hard that you are afraid you will fail?

125. Do your schoolmates seem to think that you are nice to them?

YES NO

126. Does it seem to you that some of the teachers "have it in for" pupils?

127. Do many of the children get along with the teacher much better than you do?

YES NO

128. Would you like to stay home from school a lot if it were right to do so?

YES NO

129. Are most of the boys and girls at school so bad that you try to stay away from them?

130. Have you found that some of the teachers do not like to be with the boys and girls?

YES NO

131. Do many of the other boys or girls claim that they play games more fairly than you do?

YES NO

132. Are the boys and girls at school usually nice to you?

YES NO
133. Do you visit many of the interesting places near where you live?

YES NO

134. Do you think there are too few interesting places near your home?

YES NO

135. Do you sometimes do things to make the place in which you live look nicer?

YES NO

136. Do you ever help clean up things near your home?

YES NO

137. Do you take good care of your own pets or help with other people's pets?

YES NO

138. Do you sometimes help other people?

YES NO

139. Do you try to get your friends to obey the laws?

YES NO

140. Do you help children keep away from places where they might get sick?

YES NO

141. Do you dislike many of the people who live near your home?

YES NO

142. Is it all right to do what you please if the police are not around?

YES NO

143. Does it make you glad to see the people living near you get along fine?

YES NO

144. Would you like to have things look better around your home? YES NO

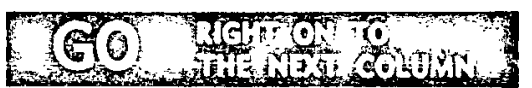

Page 8

Section $2 E$

CTP-E - AA

(number right)

Section $2 F$

(number right) 
CALIFORNIA TEST OF PERSONALITY

FIRST GRADE

PERSONAL WORTH
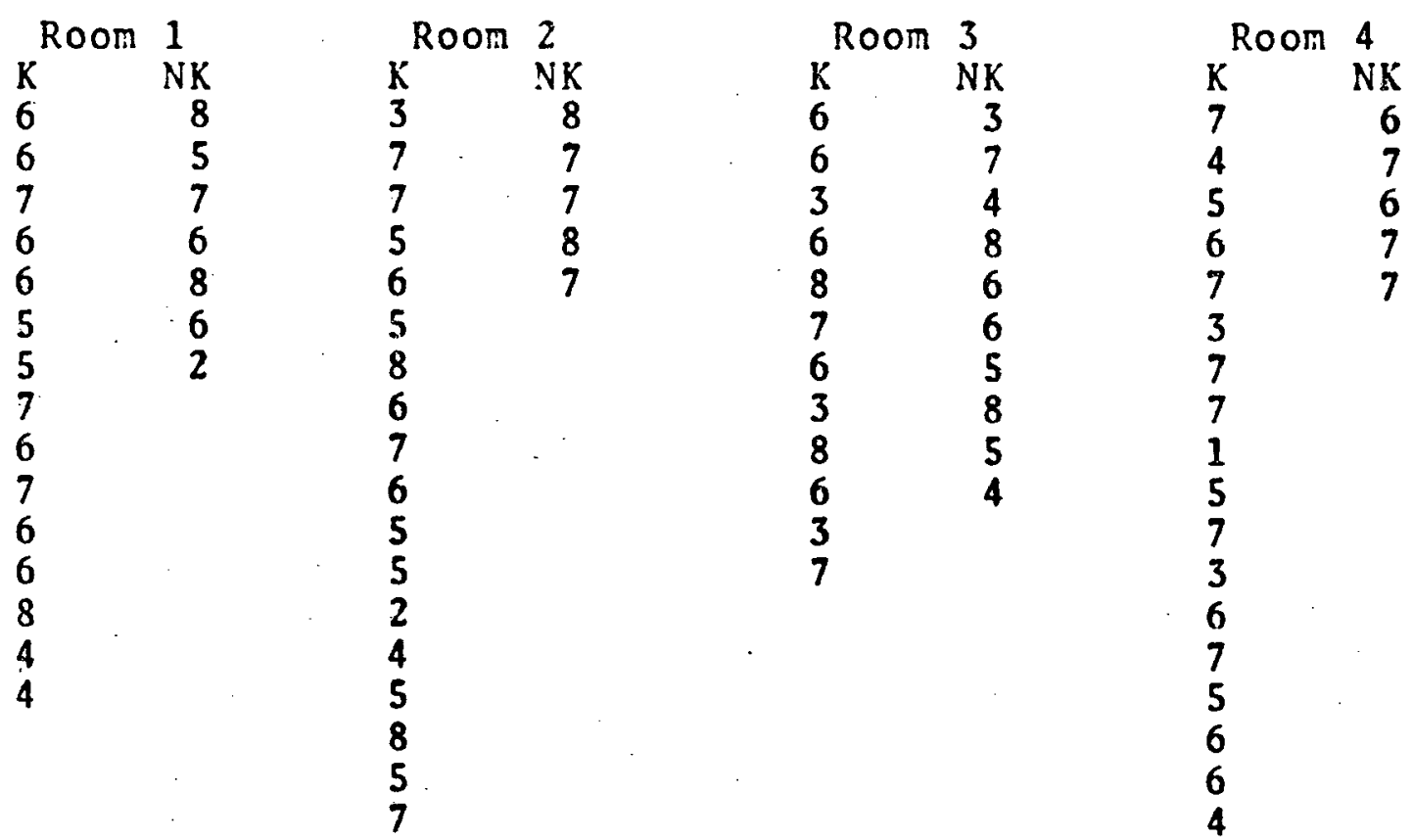

TOTAL PERSONAL ADJUSTMENT

\begin{tabular}{llllll}
\multicolumn{1}{c}{ Room } & 1 & Room 2 & \multicolumn{2}{c}{ Room } \\
K & NK & $K$ & NK & K & NK \\
30 & 36 & 20 & 31 & 36 & 31 \\
32 & 25 & 30 & 24 & 27 & 30 \\
29 & 32 & 26 & 30 & 33 & 36 \\
34 & 31 & 26 & 33 & 25 & 33 \\
27 & 32 & 23 & 34 & 28 & 30 \\
26 & 23 & 32 & & 27 & \\
29 & 20 & 36 & & 33 & \\
28 & & 33 & & 30 & \\
26 & & 31 & & 17 & \\
31 & & 32 & & 23 & \\
20 & & 26 & & 39 & \\
30 & & 30 & & 24 & \\
32 & & 21 & & 37 & \\
16 & & 20 & & 23 & \\
15 & & 27 & & 34 & \\
& & 30 & & 31 & \\
& & 27 & & 29 &
\end{tabular}

Room 4 K NK $29 \quad 22$ $30 \quad 38$ $22 \quad 25$ $26 \quad 27$ $38 \quad 18$ $30 \quad 37$ $34 \quad 25$ $24 \quad 39$ $35 \quad 27$ $33 \quad 33$ 31 


\section{CALIFORNIA TEST OF PERSONALITY}

\section{FIRST GRADE}

SCHOOL RELATIONS
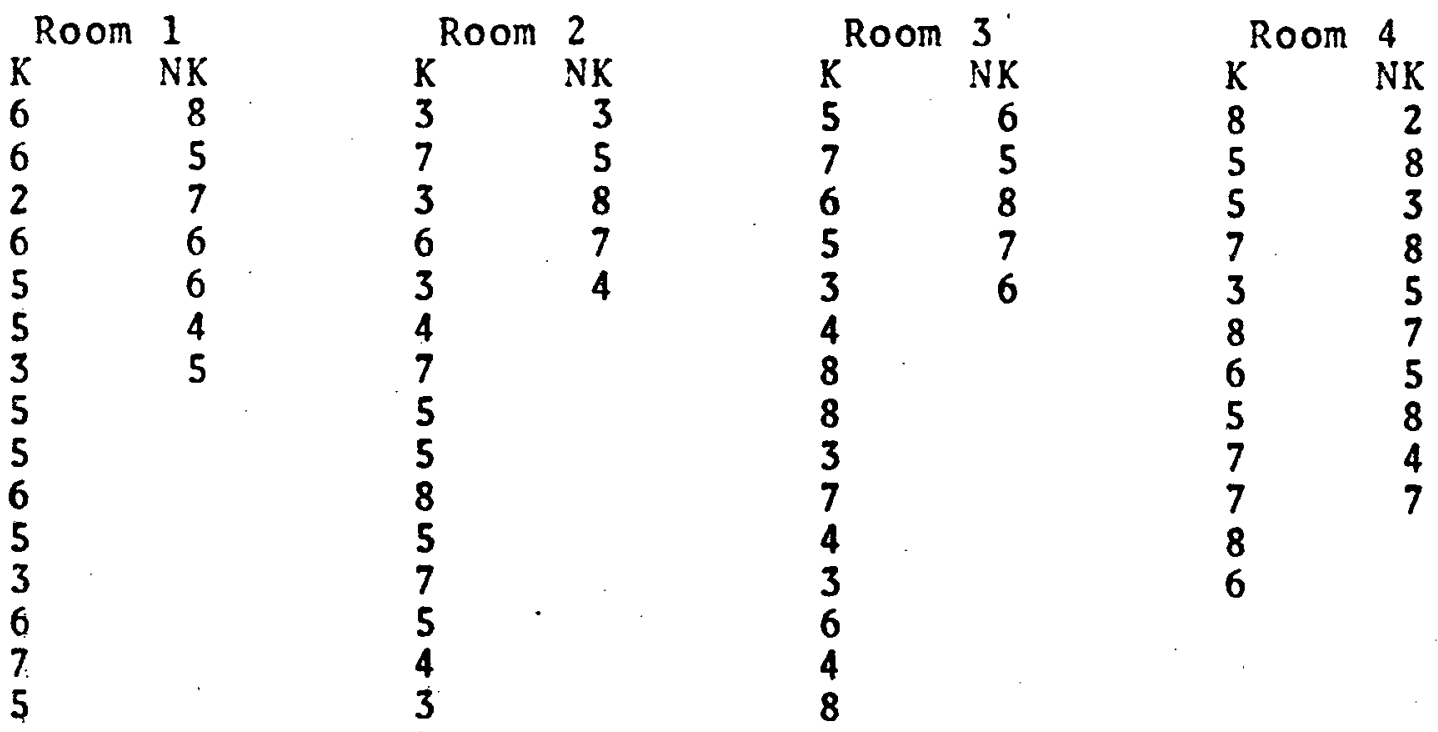

Room 1

$37 \quad 45$

$33 \quad 29$

$34 \quad 37$

$45 \quad 34$

$34 \quad 33$

$25 \quad 32$

$21 \quad 33$

32

26

35

26

25

37

34

27

2
NK
3
5
8
7
4

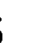
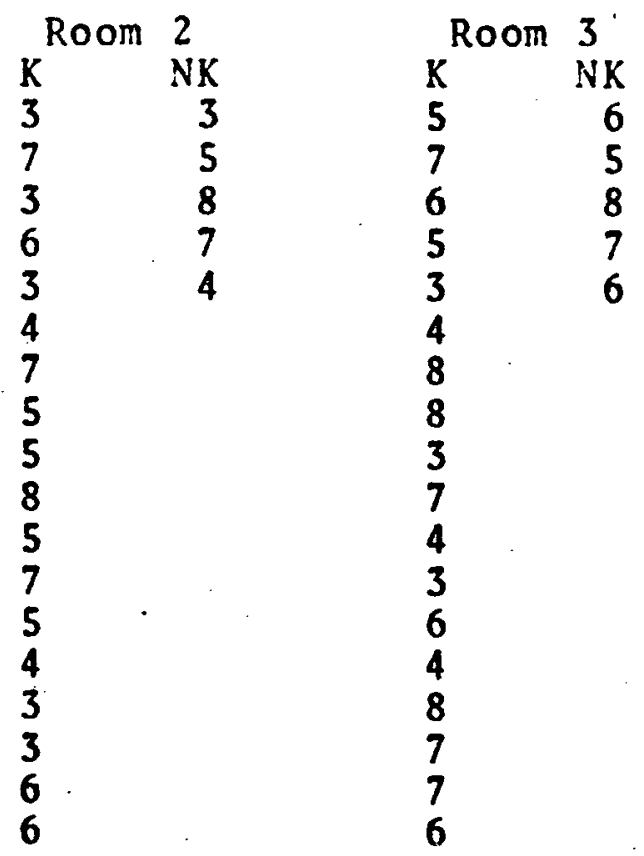

TOTAL SOCIAL ADJUSTMENT

\begin{tabular}{llll} 
Room 2 & \multicolumn{2}{c}{ Room 3} \\
$K$ & NK & $K$ & NK \\
25 & 23 & 36 & 28 \\
41 & 37 & 33 & 4 \\
19 & 42 & 25 & 3 \\
32 & 35 & 37 & 39 \\
24 & 37 & 29 & 27 \\
35 & & 41 & 4 \\
42 & & 44 & 3 \\
26 & & 32 & 4 \\
31 & & 40 & 2 \\
46 & & 35 & 4 \\
32 & & 44 & \\
33 & & 37 & \\
29 & & & \\
25 & & & \\
19 & & & \\
19 & & & \\
33 & & & \\
38 & & &
\end{tabular}

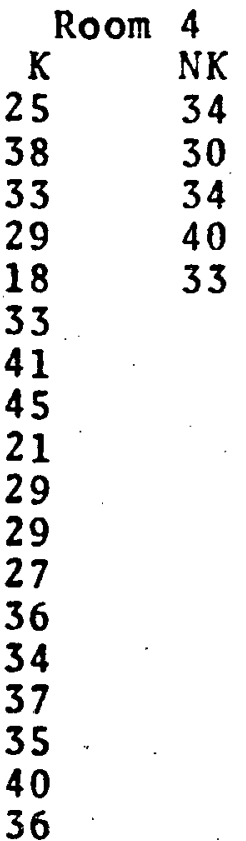




\section{CALIFORNIA TEST OF PERSONALITY}

FIRST GRADE

TOTAL ADJUSTMENT

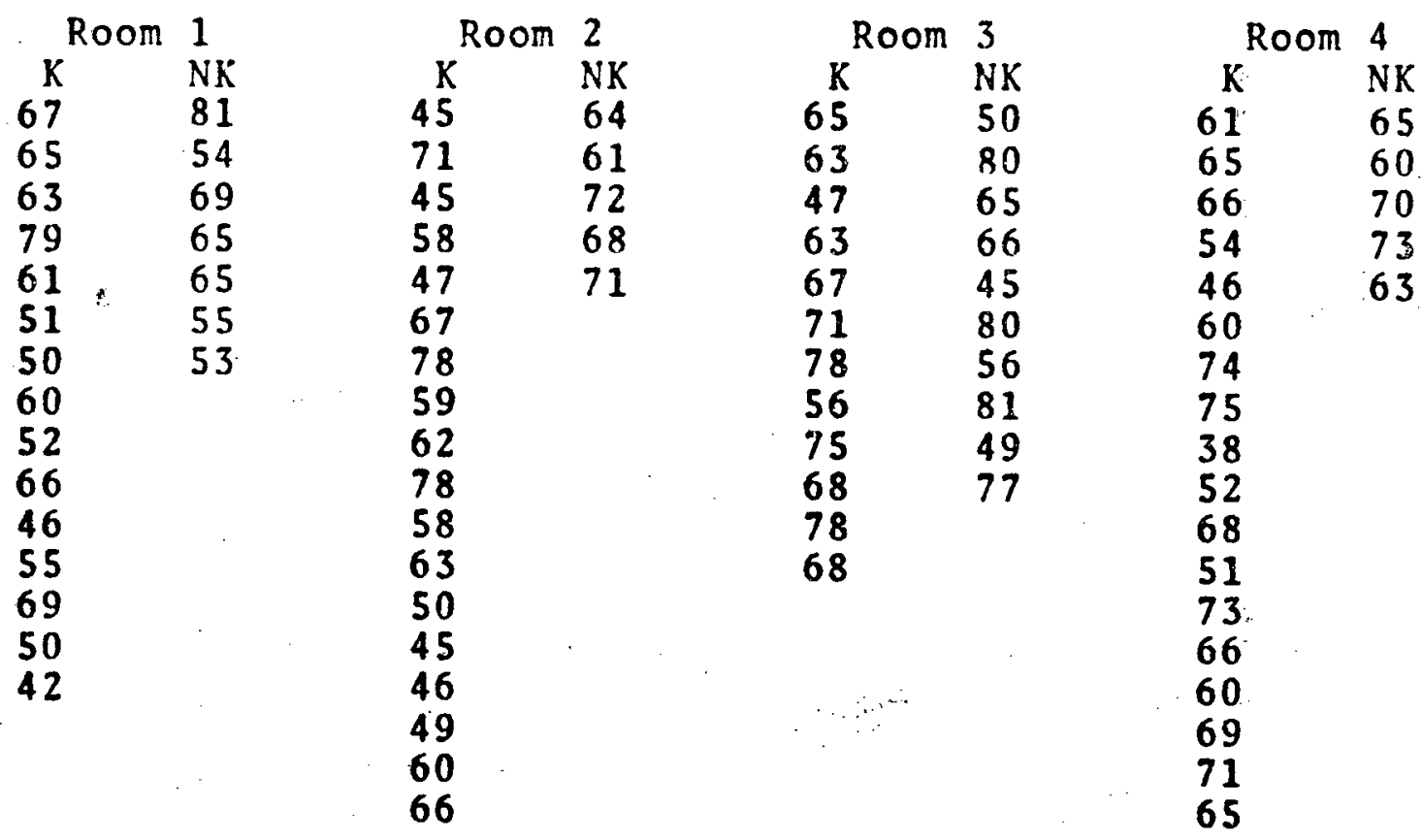


CALIFORNIA TEST OF PERSONALITY

FOURTH GRADE

PERSONAL WORTH

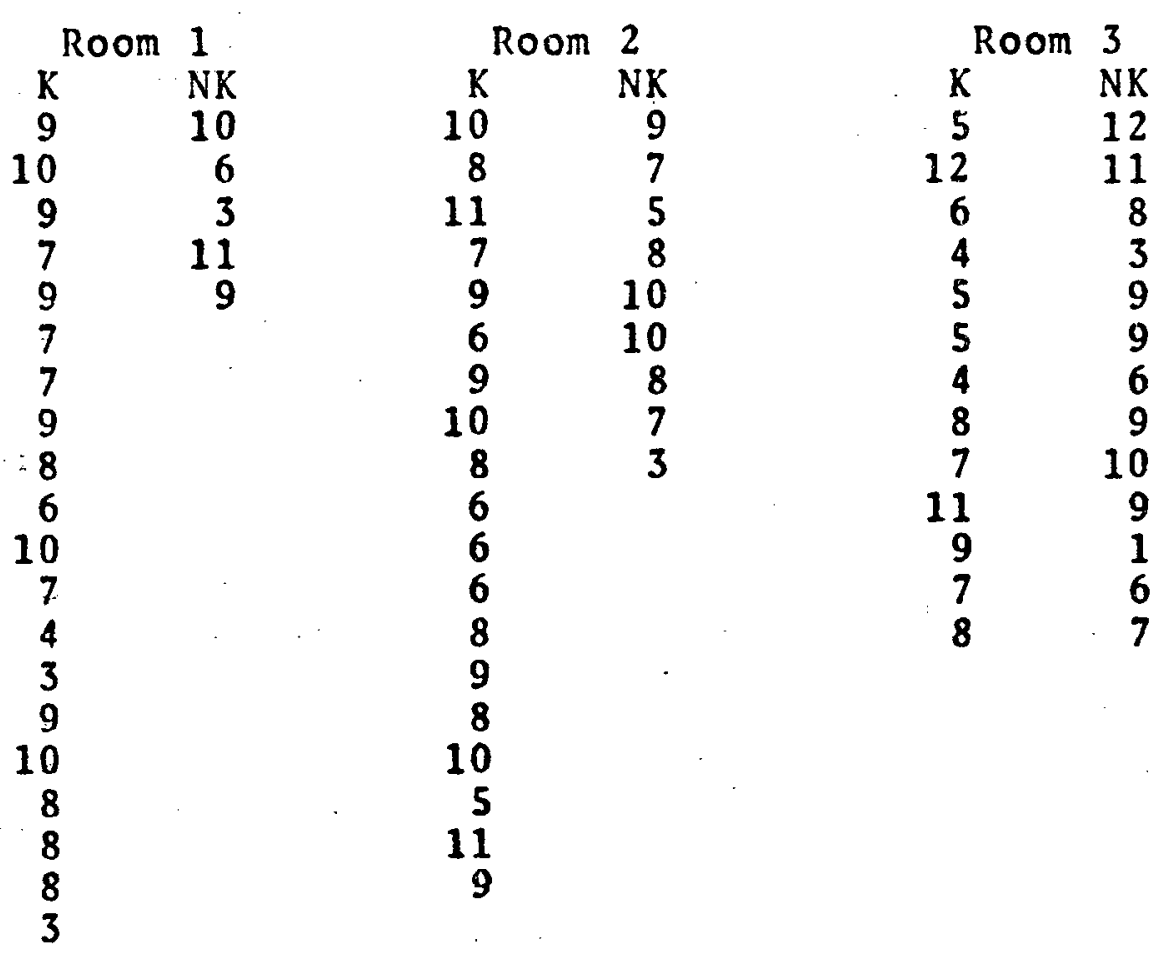

TOTAL PERSONAL ADJUSTMENT

\begin{tabular}{llllll}
\multicolumn{1}{c}{ Room 1} & \multicolumn{2}{c}{ Room 2} & \multicolumn{2}{r}{ Room 3} \\
K & NK & K & NK & K & NK \\
48 & 46 & 57 & 46 & 41 & 59 \\
46 & 56 & 22 & 37 & 40 & 47 \\
42 & 32 & 26 & 33 & 44 & 33 \\
43 & 51 & 55 & 35 & 34 & 37 \\
46 & 40 & 49 & 49 & 44 & 52 \\
34 & & 40 & 42 & 33 & 52 \\
41 & & 56 & 46 & 38 & 58 \\
58 & & 60 & 44 & 48 & 51 \\
43 & & 48 & 29 & 33 & 59 \\
35 & & 35 & & 55 & 41 \\
47 & & 29 & & 41 & 27 \\
26 & & 35 & & 33 & 33 \\
26 & & 40 & & 45 & 46 \\
50 & & 45 & & & \\
51 & & 45 & & & \\
49 & & 51 & & & \\
39 & & 43 & & & \\
46 & & 58 & & & \\
44 & & 35 & & & \\
43 & & & & &
\end{tabular}


CALIFORNIA TEST OF PERSONALITY

FOURTH GRADE

\section{SCHOOL RELATIONS}

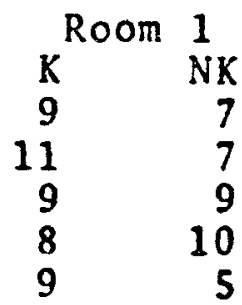

11

11

4

8

4

9

10

8

6.

7

\begin{tabular}{rr}
\multicolumn{2}{c}{ Room 2} \\
$K$ & NK \\
10 & 3 \\
4 & 3 \\
5 & 4 \\
9 & 8 \\
10 & 11 \\
7 & 9 \\
11 & 6 \\
11 & 5 \\
9 & 4 \\
5 & \\
7 & \\
4 & \\
8 & \\
10 & \\
7 & \\
8 & \\
6 & \\
4 & \\
6 & \\
& \\
&
\end{tabular}

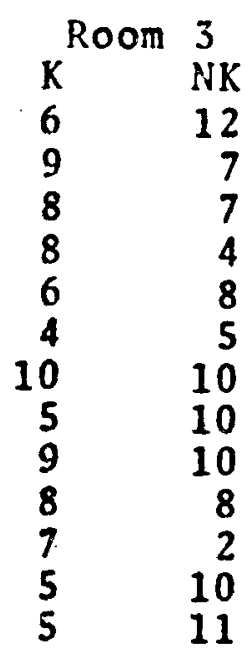

TOTAL SOCIAL ADJUSTMENT

$\begin{array}{ll}\text { Room } & 1 \\ K & \text { NK } \\ 55 & 50 \\ 59 & 53 \\ 53 & 43 \\ 56 & 67 \\ 61 & 47\end{array}$

60

34

64

45

40

53

40

42

58

63

51

41

46

50

33 .

$\begin{array}{cl}K^{\text {Room }} & 2 \\ 60 & \text { NK } \\ 36 & 42 \\ 40 & 50 \\ 57 & 25 \\ 54 & 52 \\ 48 & 65 \\ 64 & 52 \\ 62 & 48 \\ 52 & 46 \\ 42 & 32\end{array}$

42

53

40

33

52

47

48

37

46

44

\begin{tabular}{cc}
\multicolumn{2}{c}{ Room 3} \\
$K$ & NK \\
48 & 70 \\
49 & 49 \\
53 & 43 \\
54 & 40 \\
47 & 59 \\
34 & 45 \\
56 & 52 \\
47 & 47 \\
62 & 50 \\
56 & 48 \\
54 & 21 \\
28 & 37 \\
40 & 55
\end{tabular}


146

CALIFORNIA TEST OF PERSONALITY FOURTH GRADE

TOTAL ADJUSTMENT

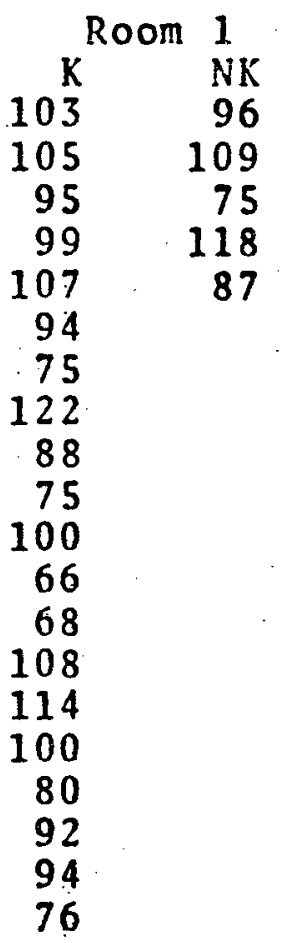

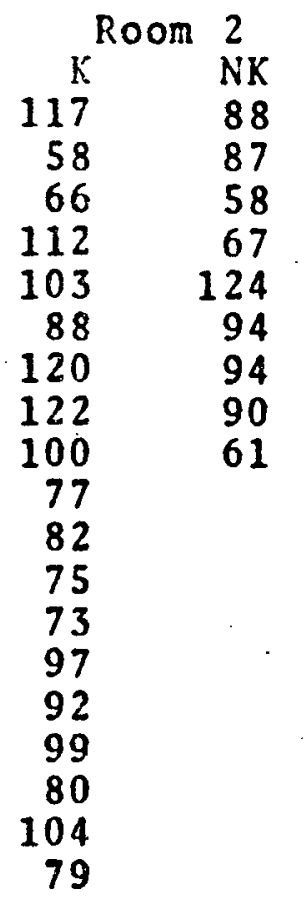

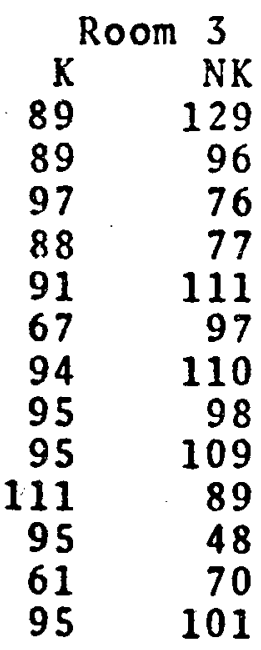


APPENDIX G

SRA ACHIEVEMENT TEST SCORES 
SRA ACHIEVEMENT TEST SCORES

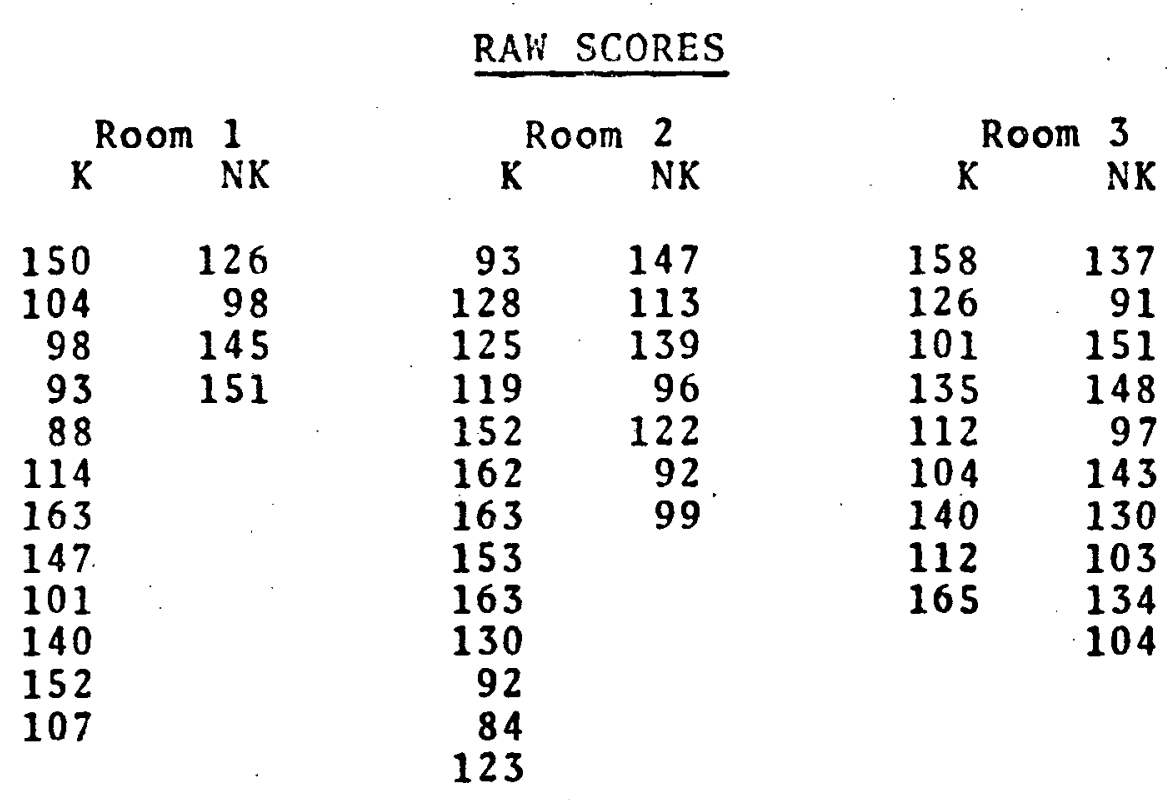

*Test taken by fourth graders during their second semester of third grade. 
APPENDIX $\mathrm{H}$

QUESTIONNAIRE 


\section{QUESTIONNAIRE}

\section{Dear Parents:}

I would like to invite you to participate in a research study on the effect of kindergarten experience upon academic achievement and social adjustment in later school experiences.

Because Penn-Harris-Madison School Corporation has not been able to offer public kindergarten for all children, only a portion of the children entering first grade in our school system have had kindergarten experience. It is the purpose of this study to discover what relationships exist between kindergarten experience and subsequent academic achievement and social adjustment in later school experiences.

Hould you be so kind as to complete the questionnaire below and return it to school with your child? The accuracy of the interpretation of the study results will depend, to a large degree, upon your cooperation.

you.

Thank-you: We will share the study results with

$$
\text { Mrs. Janice Trevan }
$$

\section{QUEST IONNAIRE}

Name of child

Please circle one response to the following:

The child has had kindergarten experience. Yes No

The child has had no kindergarten experience because:

a) the high cost of tuition prohibited our being able to afford sending the child to kindergarten

b) the child did not need the experience provided by kindergarten to be sufficiently prepared for first grade

The annual family income most nearly falls within one of the two following brackets:
a) $1,000-10,000$
b) $10,000-20,000$ 
B I B L I O G R A P H Y 


\section{BIBLIOGRAPHY}

Almy, Millie, "New Views on Intellectual Development in Early Childhood Education," Intellectual Development: Another Look. Washington, D.C.: ASCD, 1964, P. 24.

Ames, Louise Bates. Is Your Child in the Wrong Grade? New York: Harper and Row, 1967.

Bergamini, Yolanda and Walter Swanson. "Does Kindergarten Make a Difference?" School Executive, 41. (December, 1954), 54-55.

Bloom, Benjamin S. Stability and Change in Human Characteristics. New York: John Wiley \& Sons, Inc., 1964.

Buck, Carol, Rose Gregg, Mary Harper and Sandra Snider, "The Effect of Kindergarten Experience Upon I.Q. Test Performance." Psychology in the Schools. (Brandon, Va.) Clinical Psychology Pub. Co., Inc., 8, 1971, 62-64.

Deutsch, Martin. "Facilitating Development in the Pre-school Child: Social and Psychological Perspectives," in Encyclopedia of Educational Research, 4 th Edition, a product of the American Educational Research Assn. London: MacMillan Ltd., 1969.

"Early Childhood Education Today," ASCD. Washington: NEA, 1968, 1-39.

Encyclopedia of Educational Research. The American Educational Research Assn., New York: MacMillan Co., 1950.

Encyclopedia of Educational Research. The American Educational Research Assn., London: Wackilian Co. Collier-MacMillan Limited, 1969.

Fast, Irene. "Kindergarten Teaching and Grade One Reading," Journal of Educational Psychology, 48, 1957, 52-57.

Frank, Lawrence. "A Good Beginning Has No End," Childhood Education, 36, (Sept-mber, 1959), 2-3.

Frazier, Alexander. "Early Childhood Education Today," Washington: ASCD - NEA, 1968, 1-6.

Frost, Joe L., and Hawkes, Glenn R. The Disadvantaged Child. Boston: Houghton-Mifflin Co., 1966. 
Fuller, Elizabeth Nechem. About the Kindergarten. Washington, D.C.: NEA Pub., 1961.

Gesel1, Arnold. The Mental Growth of the Preschool Child. New York: The MacMilian Co., 1925.

Gotts, Edward Earl and Pierce-Jones, John. "Evaluating Head Start Inputs and Outcomes," in Early Childhood Education Rediscovered. Edited by Joe L. Frost. New York: Holt, Rinehart and Winston, Inc., 1968.

Hammond, Ruth Arthur and Harriet Forsythe. "Should Any Child Skip Kindergarten?" Instructor, 78 (May 1968), 60.

Headley, Neith. The Kindergarten: Its Place in the Program of Education. New York: The Center for Applied Research in Ed., Inc., 1965 .

Hefferman, Helen. "Early Childhood Education - Influence on the Elementary School." Today's Education (NEA) 59, 1971, 41-42.

- "Significance of Kindergarten Education," Childhood Education, 36, (March, 1960), 313=19.

Hunt, J. McVicker. "The Psychological Basis for Using Pre-school Enrichment as an Antidote for Cultural Deprivation." in Encyclopedia of Educational Research, 4th Edition, London: MacMillan Limited, 1969.

Hymes, James L., Jr., "Public Kindergartens," NEA Elementary Instructional Service, University of Maryland, 1969, 1-6.

Irwin, 0. C. "Infant Speech: Effect of Systematic Reading of Stories," Journal of Speech and Hearing Research, 3 (June, 1960), 187-190.

Keliher, Alica V., "Effective Learning and Pupil Teacher Ratio." Childhood Education, 43, 1966, 1 .

Knoblock, Hilda and B. Pasamanick, "Environmental Factors Affecting Human Development Before and After Birth," Pediatrics, Aug., 1960.

Lambert, Hazel M. Early Childhood Education. Boston: Allyn and Bacon, Inc., 1960 .

Leeper, Sarah Hammond, Dales, Ruth J., Skipper, Dora Sikes and Witherspoon, Ralph L. Good Schools for Young Children. New York: The MacMilian Co., 1968.

Lindquist, E. F., Design and Analysis of Experiments in Psychology and Education. Boston: Houghton-Mifflin Co., 1953. 
Marsh, L. A. "Kindergarten versus Nonkindergarten Children with Respect to Certain Traits of Character." Elementary School Journa1, 15, 1915, 543-50.

Milner, Esther. "A Study of the Relationship Between Reading Readiness in Grade 1 School Children and Patterns of ParentChild Interaction," Child Development, 22 (June, 1951), 95-112.

Mindness, Mary, and Alice V. Keliher. "Review of Literature related to the Advantages of Kindergarten," Childhood Education, $43,1967,505-12$.

Moore, Elenora Hegele. Fives at School. New York: G. P. Putnam's Sons, 1959.

Morrison, Ida E. and Ida F. Perry. Kindergarten-Primary Education. New York: The Ronald Press, 1961.

Peters, W. J. "The Progress of Kindergarten Pupils in Elementary Grades." Joumal of Educational Research, 7, 1923, 117-26.

Reisser, Faye, and Elder, H. E. "The Relation Between Kindergarten Training and Success in Elementary School." Elementary School Journal, 28, 1927, 286-89.

Rudolph, Marguerita and Dorothy H. Cohen. Kindergarten: A Year of Learning. New York: Appleton-Century-Crofts, 1964.

Sabath, Mildred R. Toward Better Kindergartens. Washington, D.C.: ACEI, 1965-67.

Shaftel, Fannie. "Let's Look at the Kindergarten." in Encyclopedia of Educational Research, 4th Edition, London: MacMillan Limited, 1969.

Spodek, Bernard. "Poverty, Education and the Young Child." in Frost, Joe L. and Hawkes, Glenn R. (Eds.) The Disadvantaged Child. Boston: Houghton-Mifflin Co., 1966.

Standard Education Almanac. "Enrollment of 3, 4 and 5 year old Children in Pre Primary Programs." U. S. Dept. of Health, Education and Welfare, Office of Education, Los Angeles: Academic Media, 1971.

Todd, Vivian Emiston and Helen Hefferman. The Years Before School. New York: The MacMillan Co., 1964. 
Wattenberg, William W., and Clifford Clare. "Relationship of the Self-Concept to Eeginning Achievement in Reading," in the Encyclopedia of Educational Research, 4 th Edition, London: Macililan Limited, 1969.

Widmer, E. L. "Why Kindergarten?" Peabody Journal of Education, $44: 210-15,1967$. 